University of Louisville

ThinkIR: The University of Louisville's Institutional Repository

Electronic Theses and Dissertations

$12-2019$

\title{
Understanding object motion encoding in the mammalian retina.
}

Victor Julian DePiero

University of Louisville

Follow this and additional works at: https://ir.library.louisville.edu/etd

Part of the Biology Commons, Computational Neuroscience Commons, Molecular and Cellular Neuroscience Commons, and the Systems Neuroscience Commons

\section{Recommended Citation}

DePiero, Victor Julian, "Understanding object motion encoding in the mammalian retina." (2019).

Electronic Theses and Dissertations. Paper 3323.

https://doi.org/10.18297/etd/3323

This Doctoral Dissertation is brought to you for free and open access by ThinkIR: The University of Louisville's Institutional Repository. It has been accepted for inclusion in Electronic Theses and Dissertations by an authorized administrator of ThinkIR: The University of Louisville's Institutional Repository. This title appears here courtesy of the author, who has retained all other copyrights. For more information, please contact thinkir@louisville.edu. 


\title{
UNDERSTANDING OBJECT MOTION ENCODING IN THE MAMMALIAN RETINA
}

\author{
By \\ Victor Julian DePiero \\ B.S Clemson University, 2013 \\ A Dissertation \\ Submitted to the Faculty of the \\ School of Medicine of the University of Louisville \\ in Partial Fulfillment of the Requirements \\ for the Degree of \\ Doctor of Philosophy \\ in Anatomical Sciences and Neurobiology \\ Department of Anatomical Sciences and Neurobiology \\ University of Louisville \\ Louisville, KY
}

August 2019 
Copyright 2019 by Victor Julian DePiero

All rights reserved. 



\title{
UNDERSTANDING OBJECT MOTION ENCODING
}

IN THE MAMMALIAN RETINA

\author{
By \\ Victor Julian DePiero \\ B.S Clemson University, 2013 \\ A Dissertation Approved on \\ August $15^{\text {th }}, 2019$ \\ by the following Dissertation Committee
}

Bart Borghuis, Ph.D.

Martha Bickford, Ph.D.

William Guido, Ph.D.

Anthony Leonardo, Ph.D.

Maureen McCall, Ph.D. 


\section{ACKNOWLEDGEMENTS}

I have to start by thanking my mom for letting me live with her during my graduate school tenure, cooking the majority of my dinners and supporting me. I also need to thank Emily Duderstadt for buying me coffee when I needed it and helping me out when times were tough. There have been many animals around during my tenure in graduate school. Though they didn't help me do experiments or write for me, they did provide comfort when I needed it. I want to thank two dogs, Ruby for coming around for scratches while I was writing and editing and Lena for not barking too much when I was trying to relax. There are also a few cats that need mentioning, Ode, Jack, Socrates, and Buc for not distracting me too much. Lastly, I need to thank my mentor and friend Bart for teaching me everything I know. 


\section{ABSTRACT \\ UNDERSTANDING OBJECT MOTION ENCODING \\ IN THE MAMMALIAN RETINA \\ Victor J. DePiero}

August 15, 2019

Vision is not real-time. Phototransduction, transmission of visual information down the optic nerve, and signal processing at subsequent neural stages incurs delays on the order of $50-100 \mathrm{~ms}$. This implies that the neuronal representation of a moving object should lag behind the object's actual position. However, studies have demonstrated that the visual system compensates for neuronal delays using a predictive mechanism called phase advancing, which shifts the population response toward the leading edge of a moving object's retinal image. Models responsible for phase advancing include cellintrinsic contrast-gain control and inhibitory feed-forward circuit interactions, but the neural underpinnings remain incompletely understood. To understand how this compensation is achieved in the retina, I investigated cellular and synaptic mechanisms that may drive phase advancing.

I used three approaches, each testing phase advancing at a different organizational level within the mouse retina. First, I studied phase advancing at the level of ganglion cell populations, using two-photon imaging of visually evoked calcium responses. Second, I measured synaptic current responses of individual ganglion cells with patch-clamp electrophysiology, and I used a computational model to compare the observed responses to simulated responses based on the ganglion cell's spatio- 
temporal receptive fields. Third, I tested whether phase advancing originates presynaptic to ganglion cells, by assessing phase advancing at the level of bipolar cell glutamate release using two-photon imaging of the glutamate biosensor iGluSnFR expressed in the inner plexiform layer.

Using calcium responses, I found populations of phase advancing OFF-type, ONtype, ON-OFF type, and horizontally tuned directionally selective ganglion cells. My electrophysiological recordings and glutamate imaging found phase advancing in ON and OFF-layers of the inner plexiform layer, indicating that phase advancing starts presynaptic to ganglion cells. Model simulations show that phase advancing at the ganglion cell and bipolar cell level is largely consistent with the spatial interaction between the cells' linear receptive field and the moving stimulus. Based on the results of my experiments, I conclude that bipolar and ganglion cell receptive field structure generates phase advanced responses and acts to compensate for neuronal delays within the retina. 


\section{TABLE OF CONTENTS}

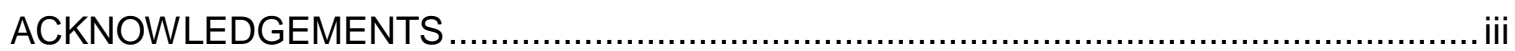

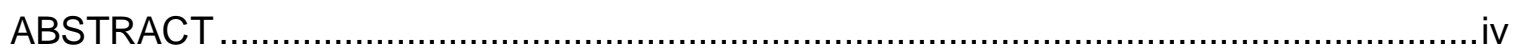

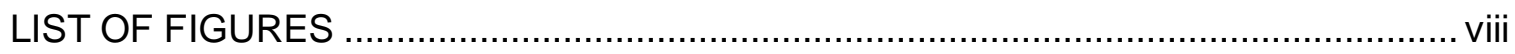

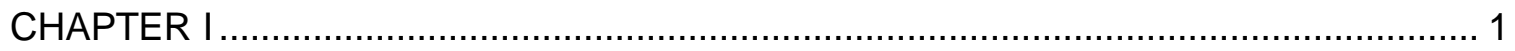

INTRODUCTION AND BACKGROUND …........................................................ 1

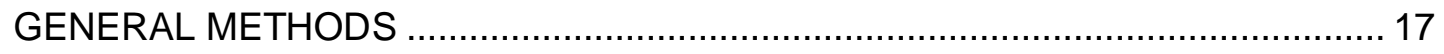

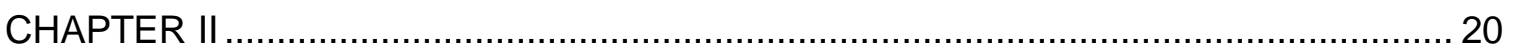

POPULATION STUDY OF MOTION ENCODING GANGLION CELLS USING

FLUORESCENCE CALCIUM IMAGING

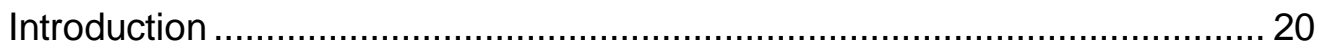

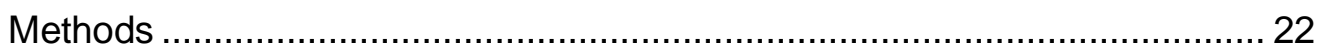

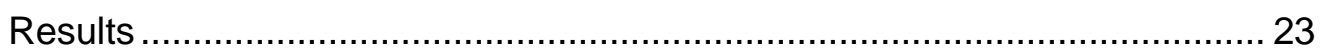

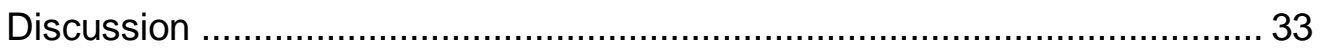

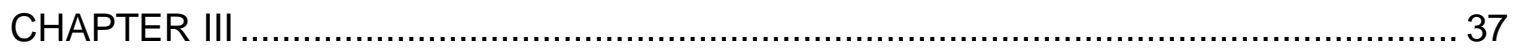

MOTION COMPENSATION IN SYNAPTIC INPUTS TO ALPHA-TYPE GANGLION

CELLS IN THE MOUSE RETINA

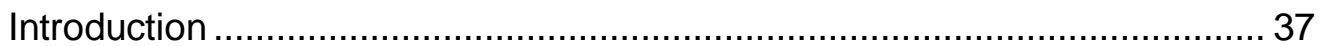

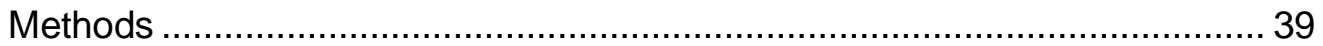

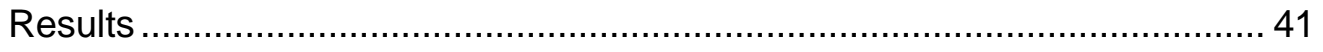


Discussion

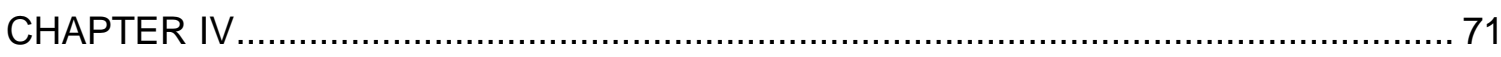

PHASE ADVANCING IN THE INNER PLEXIFORM LAYER, PRIOR TO GANGLION CELL INTEGRATION

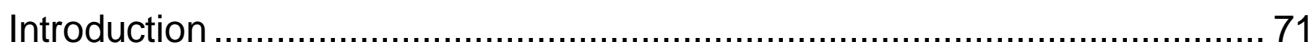

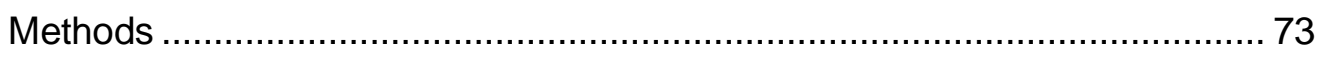

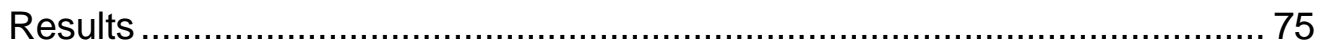

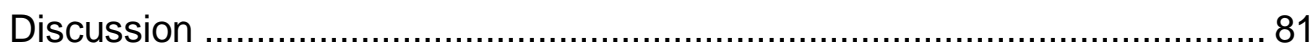

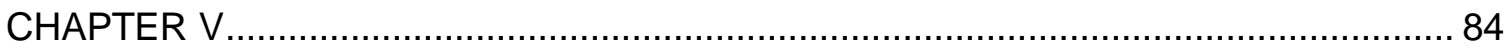

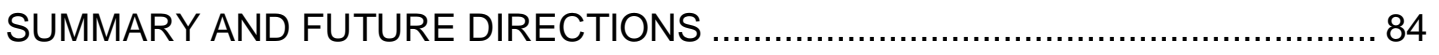

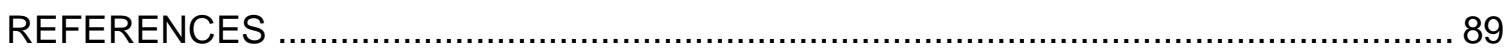

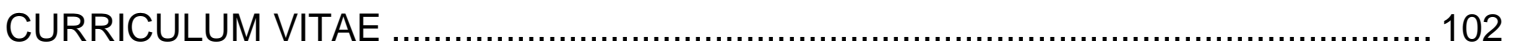




\section{LIST OF FIGURES}

Figure 1. Schematic diagram of a motion compensation mechanism........................... 2

Figure 2. Layers of the Retina. ................................................................................ 3

Figure 3. Directionally Selective Retinal Ganglion Cells............................................. 9

Figure 4. Rotating snake illusion from .................................................................. 11

Figure 5. Multielectrode array recording show phase advancing in salamander and rabbit

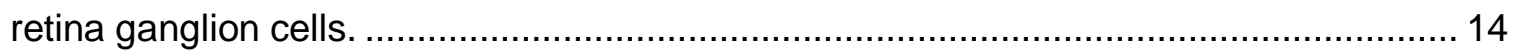

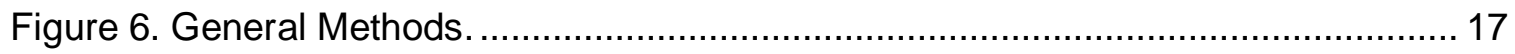

Figure 7. GCaMP6f labeled ganglion cells............................................................ 24

Figure 8. Spiking and GCaMP6f fluorescence in retinal ganglion cells ......................... 26

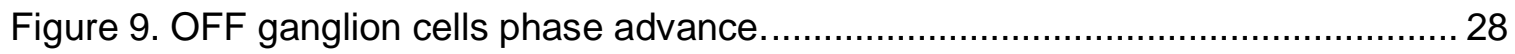

Figure 10. ON ganglion cells phase advance. …………….................................... 30

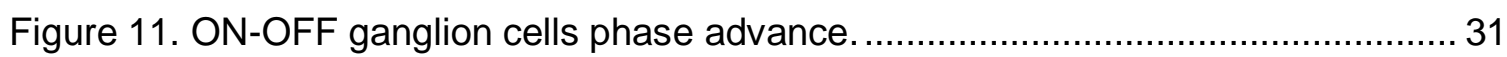

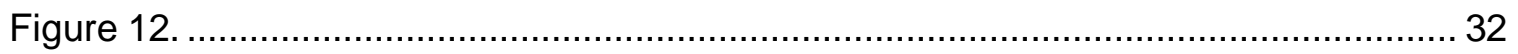

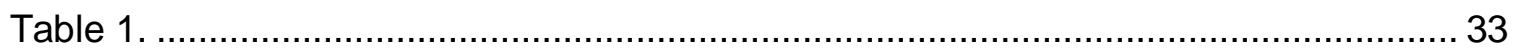

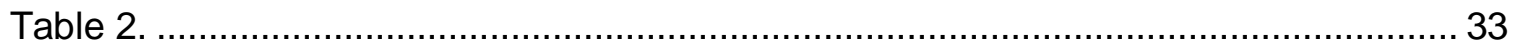

Figure 13. Example of phase advancing OFF-alpha ganglion cell electrophysiological

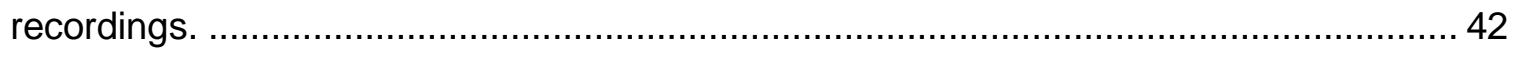

Figure 14. Population plots of phase advancing values from OFF-alpha ganglion cells. 43 Figure 15. Example of phase advancing $\mathrm{ON}$-alpha ganglion cell electrophysiological

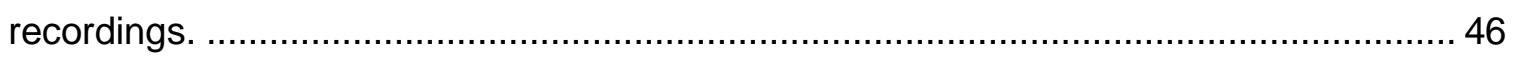

Figure 16. Population plots of phase advancing values from $\mathrm{ON}$-alpha ganglion cells. . 47 
Figure 17. Magnitude of phase advancing depends on speed of visual stimuli in OFFalpha ganglion cells.

Figure 18. Magnitude of phase advancing depends on speed of visual stimuli in ON-

alpha ganglion cells. 50

Figure 19. GABAA receptor blockage in OFF-alpha ganglion cells.............................. 51

Figure 20. GABAc receptor blockage in OFF-alpha ganglion cells. .............................53

Figure 21. Glycine receptor blockage in OFF-alpha ganglion cells. ............................ 55

Figure 22. $\mathrm{GABA}_{\mathrm{A}}$ receptor blockage in $\mathrm{ON}$-alpha ganglion cells. .............................. 57

Figure 23. GABAc receptor blockage in $\mathrm{ON}$-alpha ganglion cells................................ 59

Figure 24. Glycine receptor blockage in $\mathrm{ON}$-alpha ganglion cells............................... 60

Figure 25. Linear-nonlinear cascade model............................................................ 62

Figure 26. Spatiotemporal filter collected from OFF-alpha ganglion cells....................... 63

Figure 27. Modeled responses of OFF-alpha GCs to the sweep stimulus...................... 64

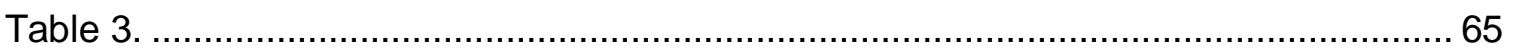

Figure 28. Spatiotemporal filter collected from ON-alpha ganglion cells.........................65

Figure 29. Modeled responses of ON-alpha GCs to the sweep stimulus........................ 66

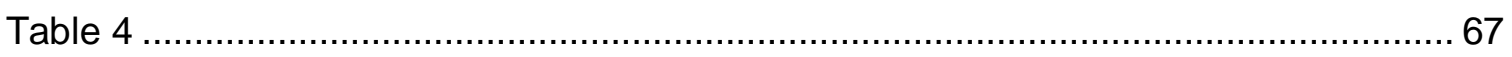

Figure 30. iGluSnFR phase advancing responses in the OFF layer of the IPL. ............ 74

Figure 31. iGluSnFR phase advancing responses recorded in the ON layer of the IPL. 75 Figure 32. Phase advancing values from iGluSnFR recordings during stimulation with different sized moving and flashed spots. ................................................................. 77

Figure 33. Phase advancing responses to sweep stimulus during strychnine application

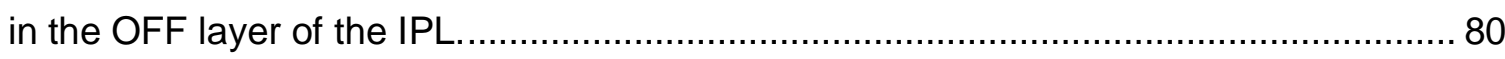

Figure 34. Phase advancing responses to sweep stimulus during strychnine application in the ON layer of the IPL. 


\section{CHAPTER I}

\section{INTRODUCTION AND BACKGROUND}

Most animals, including humans, rely on their visual system for navigating the environment, identifying danger, finding food and mates, and communicating with conspecifics. The importance of vision for survival has given rise to many specializations across species including adaptations for night vision, color vision, and - relevant for the research described in this thesis - the processing of visual object motion.

Our perception of the world is highly dynamic. Whether we interact with stationary objects or watch objects moving through the air we need an accurate evaluation of our environment. Our visual system keeps up with the speed of everyday life. However, in games such as ice hockey and baseball, professional athletes outperform the average person to a degree that suggests a significant ability of the visual system to predict motion, and to train this ability. For example, professional baseball players can accurately track and hit a ball moving around $100 \mathrm{mph}$, while fans watching from the stands can hardly see the ball crossing the plate.

Motion processing also plays a crucial role in the survival of lower animals. Some salamander and chameleon species have the ability to track moving prey and precisely propel their tongue, over a distance up to $80 \%$ of their body length, to catch it (Borghuis \& Leonardo, 2015; Deban, O'Reilly, Dicke, \& van Leeuwen, 2007). Humans similarly need to react quickly to moving objects whether they are a professional athlete or navigating a busy sidewalk. Fortunately, neural circuitry has evolved to process motion 
accurately, and our interactions with moving objects in daily life rarely fail. My thesis research aimed to further our understanding of what it is that makes our interactions with the dynamic outside world so robust.

Visual transduction begins when light enters the eye. The optics of the anterior eye focus a visual image of the exterior world onto the retina, a thin ( $250 \mu \mathrm{m})$ sheet of neuronal tissue that lines the posterior inner wall of the eye. The retina is tasked with converting the incoming light signal into an output from which downstream pathways in the brain can generate a representation of the visual environment. Dependent on light level, phototransduction in human and macaque cone photoreceptors requires $50-100$ ms (Baylor, Nunn, \& Schnapf, 1987; Schnapf, Kraft, \& Baylor, 1987). Because subsequent circuitry incurs additional delays on the order of 100 ms or more (Maunsell \& Gibson, 1992) the neuronal representation in central target areas is not real-time. The perceptual lag that is an inevitable consequence of these delays challenges behavioral interactions with moving objects in the external environment.
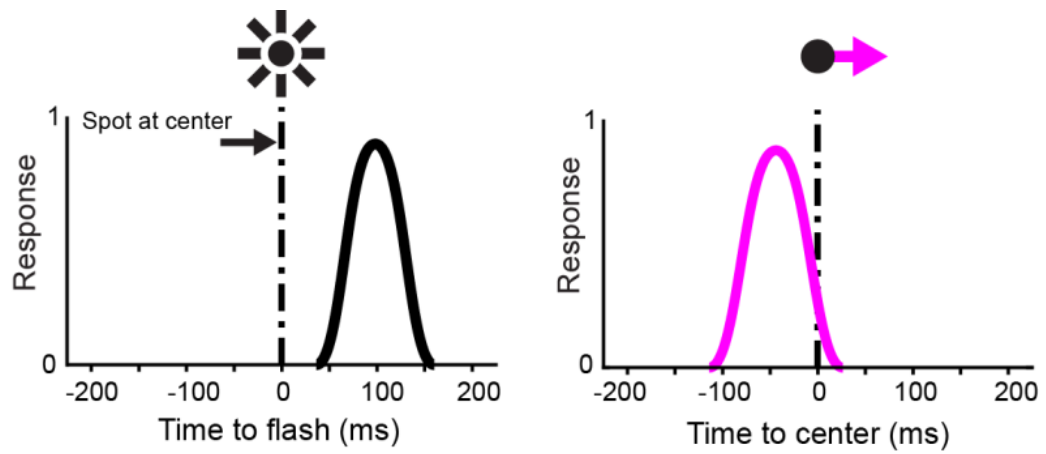

Figure 1. Schematic diagram of a motion compensation mechanism. Left, black trace, a retinal ganglion cell stimulated with a brief ( $80 \mathrm{~ms})$ stationary flashed spot at the center if that cells receptive field. The expected peak response would occur 50-100 ms after flash presentation. Right, magenta trace, the response of a retinal ganglion cell to a spot moving across the retina. As the spot enters the receptive field the response onset is roughly at $\mathrm{t}=-100 \mathrm{~ms}$. The peak response is roughly at $\mathrm{t}=-50 \mathrm{~ms}$ after the flash is presented.

Given that we can interact successfully with objects in motion, effective mechanisms for encoding visual object motion must be in place, but what they are at a 
mechanistic level, and at what stage of visual signaling they originate, remains incompletely understood. The broad goal of my research was to study the neural encoding of visual object motion and to identify mechanisms that help compensate for temporal delays within first functional module of the early visual system, the retina (Figure 1).

\section{Retinal Structure and Circuitry}

The retina includes five cell classes, with of a total of $~ 120$ unique cell types distributed in three nuclear layers separated by two synaptic layers (Sanes \& Masland, 2015) (Figure 2). The retinal photoreceptors, (rods and cones) transduce light into graded electrical potentials, which via two synaptic stages and diverse neuronal circuit interactions culminate at the level of the ganglion cell axonal output in trains of action potentials that represent various aspects of the visual input.

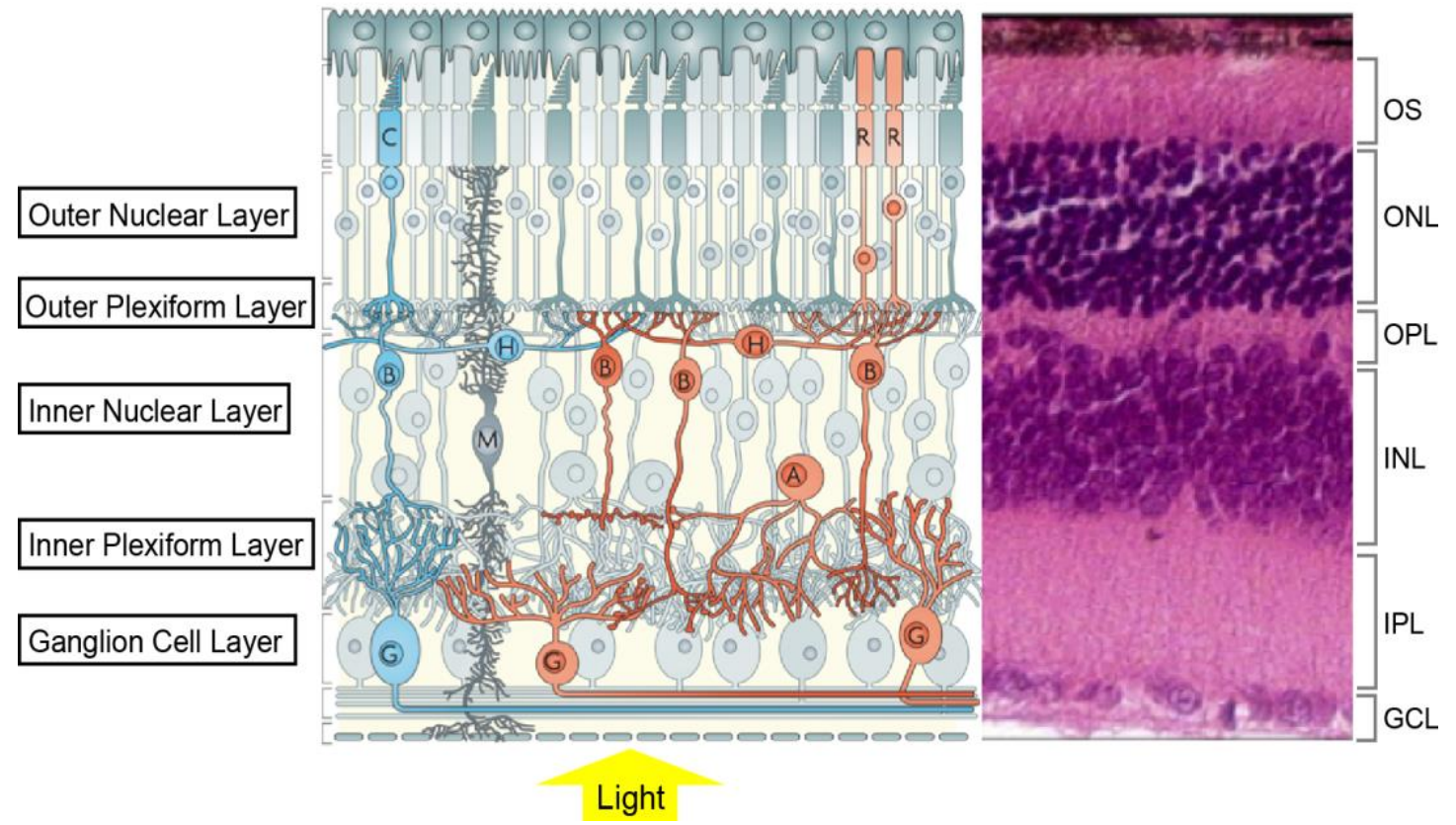

Figure 2. Layers of the Retina. Adapted from Swaroop et al. 2010. Layers of the retina shown in a drawn schematic (middle) and micrograph (right). The yellow arrow (bottom) shows the direction which light travels through the eye. 
Rods are more sensitive to light than cones and mediate visual responses in lower light (scotopic and mesopic) conditions. Cones operate in brighter light (photopic) and through differences in spectral sensitivity the expressed photopigment between cones enable the detection of color. Within the photoreceptor outer segment, the light signal is converted to an electrical signal through the visual phototransduction cascade. Since this molecular cascade introduces a significant delay in visual signaling, it is important to consider this process in detail and identify its rate-limiting steps.

Phototransduction starts with the photoactivation of opsin, a protein expressed in the outer segments of the rod and cone photoreceptors that is made light-sensitive through an associated chromophore called retinal. When the opsin absorbs an incoming photon, the 11-cis retinal isomerizes to all-trans retinal, which causes the opsin to change its conformational state to $R^{*}$. By exchanging GDP for GTP, $R^{*}$ causes the rapid activation of the G protein transducin. The GTP bound transducin dissociates from $\mathrm{R}^{*}$ and binds to the cGMP phosphodiesterase, PDE6, activating it. Activated PDE6 reduces cytoplasmic cyclic guanosine monophosphate (cGMP) and causes the closure of membrane bound cGMP-gated channels. Experimental and theoretical evidence show activation of PDE6 and subsequent close of cGMP-gated channels as the rate limiting step of visual phototransduction (Hestrin \& Korenbrot, 1990; Lamb, 1996; Lamb, Heck, \& Kraft, 2018; Rotov, Astakhova, Firsov, \& Govardovskii, 2017). This, in turn, reduces the movement of the cations $\mathrm{Na}^{+}$and $\mathrm{Ca}^{2+}$ into the photoreceptor outer segment, resulting in hyperpolarization of the photoreceptor. The end result of light increment on a photoreceptor is a decrease in glutamate release from the photoreceptor terminal (Arshavsky, Lamb, \& Edward N. Pugh, 2002). In dark conditions photoreceptors remain depolarized, causing it to tonically release glutamate from its axon terminal onto the dendrites of bipolar cells. The response latency, from incident photon capture to depolarization depends on light level, and ranges from $150-250 \mathrm{~ms}$ in dim light 
(scotopic) conditions, to 50 - 100 ms in day light (photopic) (Baylor, Nunn, \& Schnapf, 1984; Schnapf et al., 1987).

Divergent signaling from photoreceptors onto the dendrites of multiple bipolar cell dendrites divides the light signal into two distinct parallel signaling pathways, $O N$ (activated following a light increment) and OFF (activated following a light decrement).

Bipolar cells that are part of the ON pathway (ON bipolar cells) depolarize in response to the decrease in glutamate release from photoreceptors due to a light increment. OFF bipolar cells depolarize during glutamate release from photoreceptors due to a light decrement. When depolarized, both the ON and OFF bipolar cells release glutamate in a graded fashion onto ganglion cell dendrites. Depending on the sampled bipolar cell population, the response polarity in the ganglion cells results in ON, OFF, or ON/OFFtype. Next, the ganglion cells encode the glutamate signal, modulated by inhibitory synaptic inputs from amacrine cells, into action potentials that travel to an estimated 60 brain areas (Ito \& Feldheim, 2018; Martersteck et al., 2017; Morin \& Studholme, 2014). The large majority of these projections target the superior colliculus (85\%) and visual thalamus (20\%) (Ellis, Gauvain, Sivyer, \& Murphy, 2016).

\section{Understanding the ganglion cell receptive field}

A central concept for understanding visual encoding at the level of the retinal ganglion cell is the receptive field (Hartline, 1938, 1940). The receptive field encompasses the region in visual space that impacts the cell's response. It represents the culmination of converging feedforward excitatory inputs from photoreceptors and presynaptic bipolar cells as well as the inhibitory horizontal and amacrine cell input that acts on the feedforward signal. The receptive field extends both in space and in time and can be viewed as a filter that determines which aspects of the visual stimulus are communicated downstream. Differences in receptive fields, determined by bipolar cell and amacrine cell 
input, indicate differences in response properties and response polarity (light increment, ON cells; light decrement, OFF cells; light increment and decrement, ON-OFF cells).

The ganglion cell receptive field does not encode its visual input uniformly. When a ganglion cell is stimulated with a small spot of light $(100 \mu \mathrm{m})$, near the cell's position on the retina, the spike rate increases (Kuffler, 1953). Remarkably, when the spot's location on the retina was moved away from the cell's center, action potential firing decreased. Furthermore, when a peripheral location was stimulated with a spot of opposite contrast relative to the preferred stimulus for the center, the cell firing rate increased (Kuffler, 1953). This response profile is called the center-surround receptive field. It was later shown that the receptive field center response is generated primarily by excitatory inputs from bipolar cells, whereas, the surround is generated from horizontal cell lateral feedback inhibition to the photoreceptor terminal. Additional amacrine cell inhibition input onto bipolar cell terminals or directly onto ganglion cell dendrites further modulates the retinal output (Buldyrev \& Taylor, 2013).

A few years after Kuffler probed the organization of the center-surround receptive field, Lettvin et al. (1959) demonstrated that receptive fields in frog retina had diverse, feature detector-like responses. Lettvin proposed that each ganglion cell type encoded and transmitted a different aspect of the visual scene to downstream brain areas. The study by Lettvin et al. (1959) concluded that four unique signals output from the retina to the brain: sustained contrast detectors, net convexity detectors, moving edge detectors, and net dimming detectors (Lettvin, Maturana, McCulloch, \& Pitts, 1959). This work was fundamental for its recognition of specialized ganglion cell types, with diverse visual encoding properties. Increasingly detailed measurements in mammalian ganglion cells shows that the full complement of response types far exceeds the four types found in the cat retina that gave rise to the concept of functional diversity at the ganglion cell level. 
Over a half century later we now have identified as many as 39 ganglion cell types in the mouse retina based on functional, morphological, and genetic experiments (Baden et al., 2016; Bae et al., 2018; Sumbul et al, 2014). A number of groups have used calcium imaging, electrophysiological recordings, and electron microscopy in an attempt to classify all the ganglion cell types functionally and morphologically (Baden et al., 2016; Bae et al., 2018). A major goal toward understanding the encoding and decoding of the visual scene during natural vision is to know how specific features (contrast, orientation, etc.) are selectively extracted and transmitted to the brain. All types together are the foundation for visual drive in reflexive behaviors and voluntary behaviors that rely on imaging forming vision. A central question remains, how are responses organized and coordinated in time when encountering visual motion?

\section{Motion encoding in the retina}

An important aspect of visual encoding in the retina in the context of my research is how the receptive field responds to a moving object versus a stationary object. In the following section I will review a subset of ganglion cell types and their specific response features with respect to motion.

Alpha-type ganglion cells are among the most studied ganglion cells types in the mouse retina. They are easily recognized by large soma size $(>20 \mu \mathrm{m})$ and monostratified dendritic arbors with diameters between $250-300 \mu \mathrm{m}$ in mouse. Alpha ganglion cells were first identified morphologically in the cat, and also referred to as $\mathrm{Y}$ cells on the basis of their visual function in that species, alpha-type ganglion cells have high firing rates, short response latency, and transmit to both superior colliculus and visual thalamus (Sanes \& Masland, 2015). Based on the ganglion cell's preferred contrast polarity (ON or OFF) and response duration, four types of alpha ganglion cells have been identified: ON-sustained, ON-transient, OFF-sustained, and OFF-transient 
(Krieger, Qiao, Rousso, Sanes, \& Meister, 2017; Pang, Gao, \& Wu, 2003; Van Wyk, Wässle, \& Taylor, 2009).

Recently, Kuo et al. (2016) investigated a property of the ON-sustained ganglion cell's receptive field that endows these cells with increased sensitivity to moving objects compared to OFF alpha ganglion cells (Demb \& Singer, 2016; Kuo, Schwartz, \& Rieke, 2016). In their experiments, Kuo et al. (2016) presented two narrow positive contrast bars $(18 \mu \mathrm{m})$ presented first separately and then paired, while recording excitatory synaptic inputs from ON-sustained ganglion cells to test how the ganglion cells integrate spatially correlated visual stimuli. The two bars presented together evoked a greater response than the summation of the responses from the two bars presented separately, a phenomenon called nonlinear summation.

While nonlinear summation of inputs has been previously demonstrated in ONsustained ganglion cells (Demb, Zaghloul, Haarsma, \& Sterling, 2001) this observation offered new insight into the contribution of bipolar cells. Next, Kuo et al. (2016) showed a similar nonlinear amplification during the presentation of a moving bar compared to random presentations of a flashed bar over the same visual space. The increased response to the moving stimulus was credited to the network of gap junction coupling of ON bipolar cells that synapse with ON-sustained ganglion cells. These electrical synapses allow bidirectional passage of ions between cells to generate excitation, effectively increasing the size of the receptive field beyond that of the dendrites (Kuo et al., 2016). These results show that bipolar cell receptive field expansion through gap junctions serves as a mechanism to increase motion sensitivity in $\mathrm{ON}$ alpha ganglion cells. 
The second type of ganglion cells I will describe are the direction selective ganglion cells (DSGCs). DSGCs were first described in the rabbit retina (Barlow and Hill, 1963). DSGCs are characterized by the increased response to visual motion in one direction (preferred) and suppressed response during motion in other (null) directions (Figure 3) (Barlow \& Levick, 1965). In mouse, DSGCs which are selectively responsive to motion along the body axes (Sabbah et al., 2017). DSGCs are sensitive to both object motion (local motion) and moving textures (global motion) (Cafaro, Zylberberg, \& Field, 2019).

A

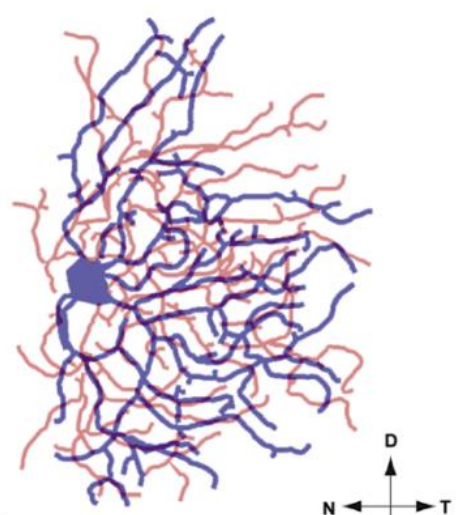

B

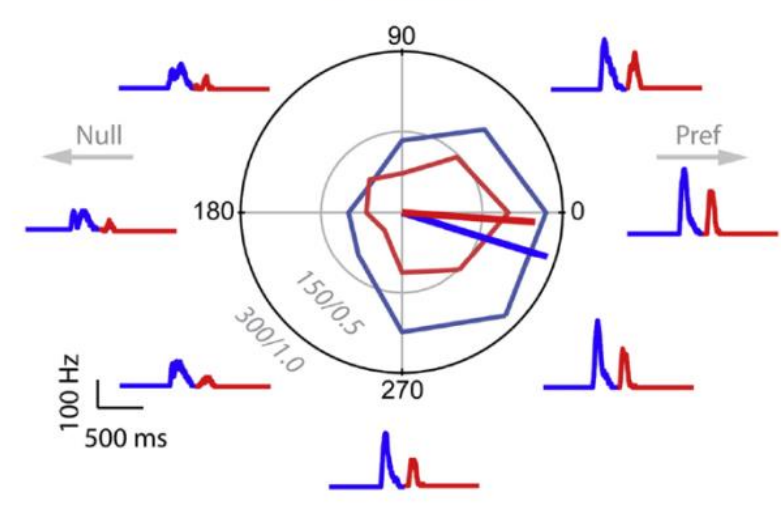

Figure 3. Directionally Selective Retinal Ganglion Cells. Adapted from Trenholm et al. 2011. A, the reconstruction of an ON-OFF DSGC with ON dendrites as blue and OFF dendrites as red. B, Polar plot of a DSGC that prefers visual stimuli moving towards the right.

Following the discovery by Barlow and Hill (1963), the neural circuit that gives rise to direction selectivity has been widely studied first in rabbit and now predominantly in mouse. The circuit and cellular mechanisms that give rise to direction selectivity have complex computations and are difficult to decipher (Ding, Smith, Poleg-Polsky, Diamond, \& Briggman, 2016; Fransen \& Borghuis, 2017). The direction selective response comes from the asymmetrical synaptic connections between the DSGC and the starburst amacrine cell (SAC) (Fried, Münch, \& Werblin, 2002; Vaney, Sivyer, \& Taylor, 2012). SAC-DSGCs are wired so that a stimulus moving in the null direction causes the SAC to release GABA onto the dendrites of DSGC and inhibit any response, while motion in the 
preferred direction does not evoke GABA release from the SAC (Demb, 2007; Wei, Hamby, Zhou, \& Feller, 2011), thus allowing the ganglion cell to generate action potentials. The dendritic computations that occur in the SAC dendrites remain to be resolved.

Other feature-detecting ganglion cell types include types tuned to stimulus orientation (Nath \& Schwartz, 2016), contrast (Tien, Pearson, Heller, Demas, \& Kerschensteiner, 2015), and event detection of a looming spot (Munch et al., 2009; Zhang, Kim, Sanes, \& Meister, 2012). Further computational processing done in higher brain regions integrates these different outputs together to form the visual percept.

In sum, the known motion-specific responses of a few different ganglion cells discussed here, demonstrate that motion information can be extracted and encoded but is not exclusive to a single cell type.

An important question concerns the timing of these responses, with respect to the real-time state of objects or patterns in the external environment, and with respect to the relative timing of the motion-evoked responses across the ganglion cell population. The relevance of this question is made clear when we take a look at the following example: a visual illusion that demonstrates that relative timing matters - and that the brain not always gets it right.

\section{A visual illusion that gives information about a mechanism in visual object motion} processing

Fabricated images called visual illusions trick the visual system into misperceiving reality. Visual illusions often evoke a universal reaction from people by revealing a failure mode of the brain, which makes them a valuable tool for researchers (Conway et al., 2005; Eagleman, 2001; Nijhawan, 1994; Pérez-Schuster et al., 2016; Watanabe, Kitaoka, Sakamoto, Yasugi, \& Tanaka, 2018). In Figure 4, Conway et al. (2005) 
demonstrate how patterning differences in luminance and contrast in a static image forms the illusion of motion. Interestingly, even though there is no actual motion, these stimuli evoke direction-selective responses from macaque monkey cortical neurons (Conway et al., 2005).

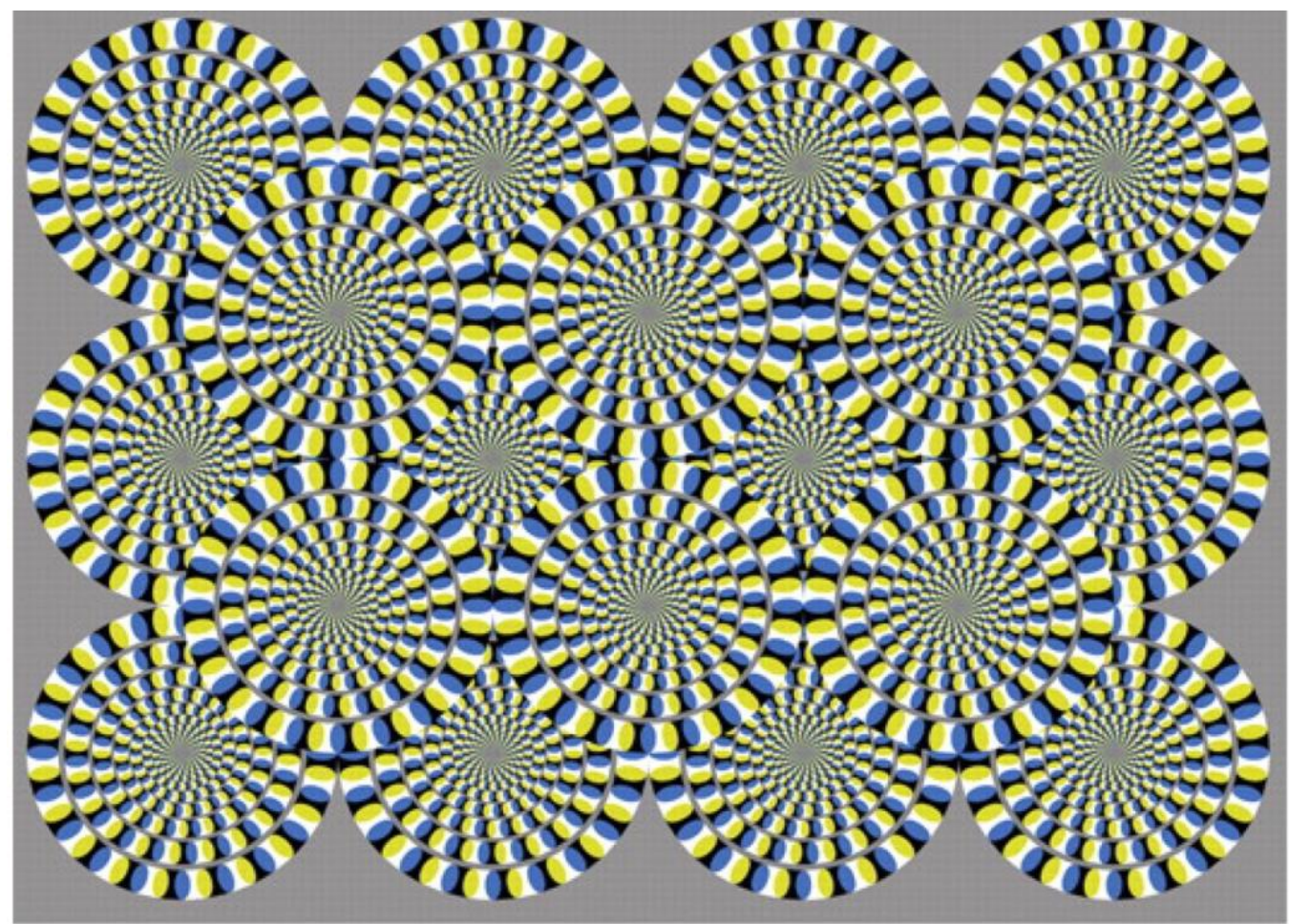

Figure 4. Rotating snake illusion from (Conway, Kitaoka, Yazdanbakhsh, Pack, \& Livingstone, 2005). Static image that results in the viewer perceiving motion.

A second example, the Flash-Lag Effect (FLE), is a visual illusion that causes the viewer to see the leading edge of a moving object spatially ahead of a stationary flashed object, when in reality the objects are aligned. This perceptual illusion is highly relevant for my thesis research because it identifies a difference in the timing of visual processing in response to moving vs. stationary objects. Psychophysical studies in humans have presented three theories explaining the FLE: motion extrapolation (Nijhawan, 1994), differential latency, and motion integration/postdiction (Eagleman \& Sejnowski, 2000). Each theory has supporting evidence to explain for the flash-lag effect, but ultimately none have been definite (Nijhawan, 2002). 
Mackay (1958) was the first to remark on a possible compensation mechanism when perceiving motion (Mackay, 1958). Nearly 30 years later, Nijhawan further investigated the disconnect between the transduction latency in the visual system and perception of moving objects (Nijhawan, 1994, 1997). Nijhawan hypothesized that the visual system extrapolated the position of the moving object based on the predicted trajectory of the moving object.

Unsatisfied with the motion extrapolation theory, proponents of the differential latency theory proposed that the visual system processes moving objects more efficiently than stationary flashed stimuli (Whitney \& Murakami, 1998). Whitney and Murakami's presented a visual stimulus that differed from the traditional flash-lag paradigm by reversing the direction of the moving bar at the time of the presentation of the flashed bar. Thereby, disrupting the constant trajectory of the moving bar. Observers did not perceive the moving bar ahead of the flashed bar and the authors concluded that motion extrapolation was not responsible for the flash-lag effect.

In response to the differential latency theory, Eagleman et al. (2000) presented motion integration/postdiction as the third theory to explain the flash-lag effect (Eagleman \& Sejnowski, 2000). Postdiction states that the flash resets motion integration and approximately one visual latency later ( $80 \mathrm{~ms})$ motion integration resumes. When perception resumes, the observer sees the moving bar ahead of the flashed bar. Eagleman's visual stimulus at frame zero was a blank screen, then at frame one both the moving bar and flashed bar were presented aligned on screen. At frame two, the flashed bar was removed, and the moving bar began moving. Observers still perceived the flash-lag illusion without the prior trajectory of a moving bar. The study overall demonstrated that the trajectory prior to the flash did not dictate perception of the flash-lag illusion. This proves that not all is extrapolation or differential latency. At the perceptual level there is postdiction during processing of visual motion. 
Two theories presented, differential latency and postdiction, sought to disprove that motion extrapolation is solely responsible for the flash-lag effect in humans and the evidence supports that perception of visual illusions require more complex neural computations (Eagleman \& Sejnowski, 2000). Motion extrapolation and differential latency remain important theories of neural transmission in the visual and perceptual system. Next, I will discuss efforts to that aimed to test these theories using electrophysiological recordings.

Population recordings of neurons in the visual cortex of anaesthetized cats support delay compensation during object motion (Jancke, Erlhagen, Schöner, \& Dinse, 2004). Multiunit recordings showed a 'propagating peak of activity' to moving bars when responses are pooled from populations up to 200 neurons. Time-to-peak responses to a stationary flashed bar significantly lag behind the peak responses to a moving bar, supporting the psychophysical evidence collected in humans (Eagleman \& Sejnowski, 2000; Nijhawan, 1994). This study by Jancke et al. (2004) presented evidence of a neural representation of the flash lag effect in visual cortex.

Combining electrophysiological recordings and behavioral tasks in non-human primates has further explored motion compensation mechanisms in downstream brain areas. Trained macaque monkeys perceive the flash lag effect with a significantly smaller lag than compared to humans (Subramaniyan, Ecker, Berens, \& Tolias, 2013). Following up the demonstration of macaque monkeys perceiving the flash-lag effect (Subramaniyan et al., 2013), there is now evidence supporting the differential latency theory that moving stimuli are processed faster than flashed stimuli (Subramaniyan et al., 2018). Using multiunit recording arrays placed in visual cortex of awake macaque monkeys to record action potentials, flashed and moving bars of different luminance and velocities were presented to the head fixed macaques. Subramaniyan et al. (2018) measured the latency differences of neural activity in response to the flashed and 
moving bars in awake behaving animals. Jancke et al. (2004) and Subramaniyan et al. (2013 and 2018) showed evidence of motion compensation mechanisms in downstream cortical areas but it remains unclear whether similar mechanisms act at early stages of vision.
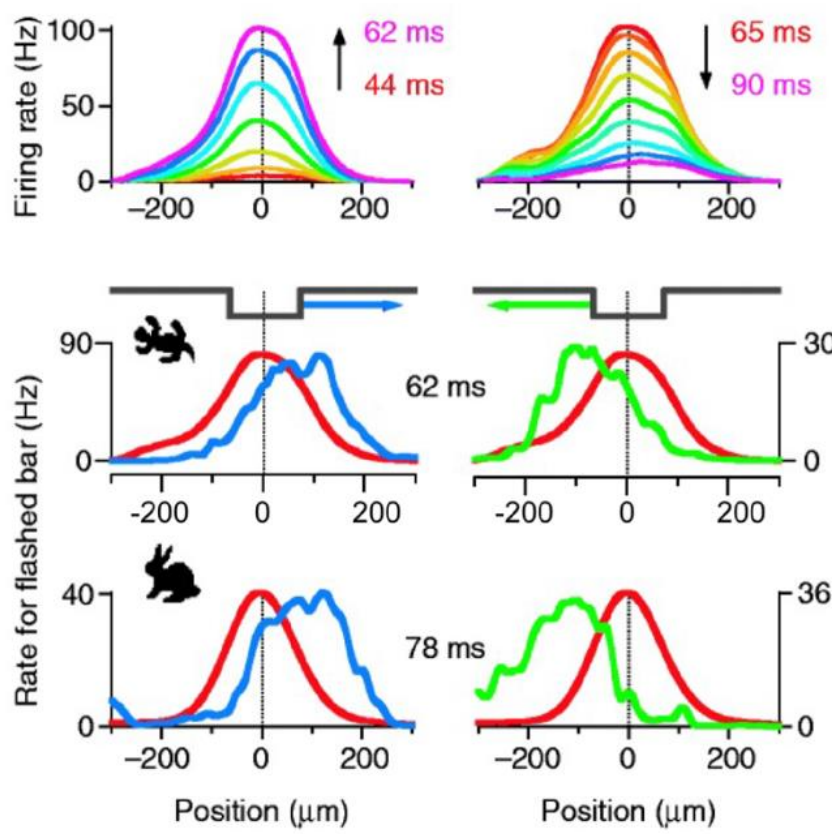

Figure 5. Multielectrode array recording show phase advancing in salamander and rabbit retina ganglion cells. Adapted from Berry et al. (1999). Top, action potential recordings of salamander OFF brisk transient ganglion cells when stimulated with flashed bar. Each color represents a time point during the rising phase (top, left, 44-62 ms) and falling phase (top, right, 65-90 ms) with a peak response at $\sim 65 \mathrm{~ms}$. Middle, salamander ganglion cell responses to a moving bar (blue and green) overlain the response to the flashed bar at $62 \mathrm{~ms}$ after bar presentation (red). The responses plotted with respect to position of the bar stimulus (x-axis) and shown to be ahead of the leading edge of the moving stimulus. Bottom, same as in the middle but for rabbit retinal ganglion cells.

\section{Motion Anticipation in the Retina}

In 1999, a landmark study published in Nature by Berry et al. discovered a retinal mechanism called motion anticipation that they hypothesized could compensate for the delay introduced by phototransduction in the retina (Berry, Brivanlou, Jordan, \& Meister, 1999). Using a multielectrode array (MEA) to measure firing rates of action potentials in salamander and rabbit OFF-type ganglion cells. The visual stimulus was either a stationary dark bar presented for $15 \mathrm{~ms}$ or a dark bar moving at a constant rate across the retina. Berry et al. (1999) discovered that the peak firing rate of the stimulated neuronal ensemble occurred ahead of the leading edge of the dark moving bareffectively compensating for visual signaling delays. In contrast, the response of the same cells to a stationary flashed spot lagged the stimulus by $50-100 \mathrm{~ms}$ (Figure 5). 
This study of OFF-type ganglion cells led to a quantitative model of motion anticipation (Berry et al., 1999). The proposed mechanism for motion anticipation was a contrast gain-control feedback loop, an intrinsic property of ganglion cells that increases sensitivity of stimulation at the periphery of the receptive field (Shapley \& Victor, 1978). During presentation of a moving stimulus, once the ganglion cell's response exceeds stimulation threshold, the response is quickly decreased. This rapid decline shifts the peak response forward in time, toward and, in some cases ahead of the neural image of the moving bar (Berry et al., 1999). Removal of the contrast gain-control feedback loop in the model results in the cell's response lagging behind the moving bar. An additional test varied the velocity of the moving bar, and showed that velocities greater than 1 $\mathrm{mm}^{*} \mathrm{~s}^{-1}$ eliminated the motion anticipation both empirically and in the model. The interpretation is that higher velocities did not allow the ganglion cell enough time to initiate contrast gain-control.

Leonardo and Meister (2013) followed up with a study on how the trajectory of a moving spot and model components support motion anticipation in salamander ganglion cells. Similarly, to Berry et al. (1999), Leonardo and Meister (2013) observed the population response of OFF-type ganglion cells ahead of the moving spot. By introducing an abrupt 90 degree turn in the trajectory of the moving spot, the population response overshot the turn and recovered $\sim 80$ ms later (Leonardo \& Meister, 2013). Furthermore, behavioral studies in different salamander species confirmed that some salamanders extrapolate prey motion to compensate for neuronal delays during visuallyguided tongue-projections (Borghuis \& Leonardo, 2015). The computational power of the retina in part eliminates phototransduction delays and does not leave it to higher brain regions to play 'catch-up'. This early work on motion compensation in the retina did not test mechanisms extrinsic to the gasnglion cells (Berry et al., 1999; Leonardo \& Meister, 2013) and assumed that this compensation was an intrinsic ganglion cell mechanism. 
The possibility of motion anticipation originate at the level of the input to ganglion cells from bipolar cells was not considered. The focus on OFF-type ganglion cells leaves open the issue of whether ON-type ganglion cells also show motion compenation.

A special case of motion compensation mechanisms was studied in the direction selective circuit of upward preferring ON-OFF DSGCs in the mammalian retina (Trenholm, McLaughlin, Schwab, \& Awatramani, 2013; Trenholm, Schwab, Balasubramanian, \& Awatramani, 2013). These bistratified ganglion cells, fluorescently labeled in the Hb9-eGFP transgenic line, respond to both light increment and light decrement moving stimuli. When recording from gap-junctional coupled DSGCs, motion in the preferred direction elicited an initial action potential response before the moving bar was in the receptive field. Uncoupled DSGCs did not show an advanced response onset to moving stimuli (Trenholm, Schwab, et al., 2013). Though this work showed that a network of gap junction coupled DSGCs permit an advanced response onset it does not fully describe a compensation mechanism in the retina.

In a recent study, Johnston and Lagnado (2015) used whole-cell patch clamp electrophysiology of goldfish retinal ganglion cells to explore inhibitory and excitatory inputs during presentation of moving stimuli. Recording from a subset of ganglion cell types (brisk transient, brisk sustained, and orientation selective cells) Johnston and Lagnado (2015) found motion anticipation did not depend on the excitatory inputs from bipolar cells but on a feedforward inhibitory circuit from amacrine cells. Patching ganglion cells with an intracellular solution high in $\mathrm{Cl}^{-}$disrupted inhibition and resulted in the response to the moving stimulus lagging behind the response to the stationary flashed bar. This study directly showed motion anticipation depends on inhibitory synaptic contacts (Johnston \& Lagnado, 2015).

In the subsequent chapters I tested the following questions related to phase advancing in the mammalian retina: 1) How general is phase advancing across parallel 
ganglion cell signaling pathways, 2) is phase advancing an intrinsic property of ganglion cells or does it originate from their inputs, and 3) what are the mechanisms that drive phase advancing?

\section{GENERAL METHODS}

\section{Tissue Preparation}

All animal procedures were approved by the Institutional Animal Care and Use Committee at the University of Louisville and were in compliance with National Institutes of Health guidelines. Adult mice (aged 2-6 months) of either sex were dark adapted for 30 minutes. Under dim red light I anesthetized the mouse with isoflurane before killing by cervical dislocation. Eyes were enucleated and hemisected in a bath of oxygenated Ames medium $\left(95 \% \mathrm{O}_{2}-5 \% \mathrm{CO}_{2}\right.$; Sigma-Aldrich) using infrared night vision scopes adapted for microscope use (OWL Night Vision Scopes, third generation; B. E. Meyers). I used the choroid structures on the posterior eye to maintain orientation along the dorsal ventral axis (Stabio et al., 2018).
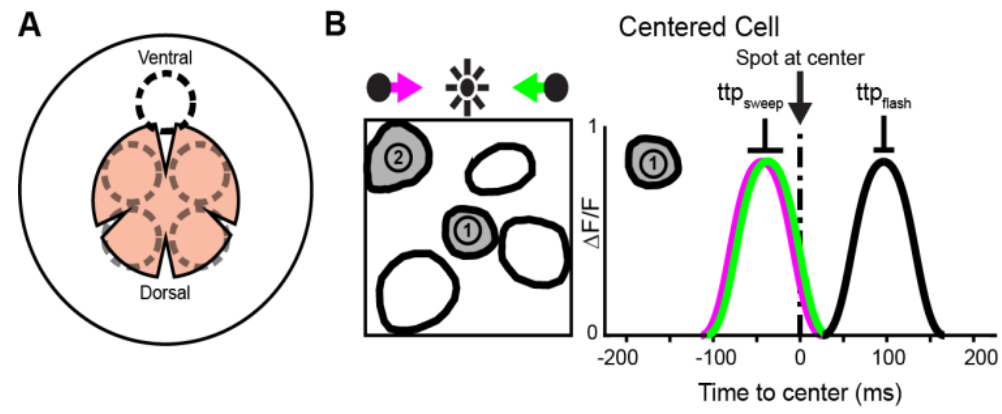

Offset Cell

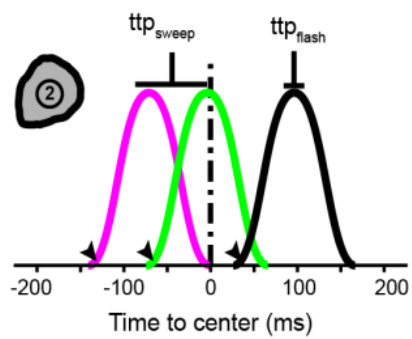

Figure 6. General Methods. A, Schematic of the retina preparation. Dotted lines represent the holes punched in the filter paper where we record from. B, Left, schematic of the imaging window with ganglion cells labeled 1 and 2. Middle, representative GCaMP6f fluorescence responses from Cell 1. Right, GCaMP6f fluorescence responses from Cell 2. My calculations of phase advancing are based on timing of the responses to the moving stimuli with respect to the timing of the response to the flashed spot (Eq. 1).

The retina was then isolated from the eye cup to allow for flat mounting with the ganglion cell side facing up onto a perforated nitrocellulose filter paper (Millipore) (Figure 6A). The retina was then placed in a 3D-printed recording chamber and held in place 
with a custom-made harp. Finally, the chamber and retina apparatus were placed into a custom two-photon microscope (Olympus BX-51) and continuously perfused with warmed $\left(\sim 6 \mathrm{ml} / \mathrm{min} ; 33-35^{\circ} \mathrm{C}\right)$ oxygenated Ames medium for the extent of the experiment (approximately three hours per retina).

\section{Visual Stimulation and Data Analysis}

Visual stimuli were generated in Matlab (Mathworks, Natick, MA) using the Psychophysics toolbox (Brainard, 1997) version 3.0.14 for Mac OSX. The 'sweep' stimulus consisted of a leftward moving, rightward moving and stationary flashed spots of either +100 (light increment) or -100 (light decrement) contrasts pseudo randomly presented on a gray background to stimulate both the ON and OFF pathway of the retina, respectively.

Mouse retinas are $\sim 4 \mathrm{~mm}$ in diameter. Mouse cones have a diameter of $1.2 \mu \mathrm{m}$ resulting in an angular resolution of $.034 \mu \mathrm{m} /{ }^{\circ}$ (Carter-Dawson \& LaVail, 1979; Daniele et al., 2005). The angular velocity of the spot was calculated in rads/s as $\omega=v / r$ with $v$ being the speed of the moving spot in $\mu \mathrm{m} / \mathrm{s}$ and $r$ the radius of the retina. Multiplying the value by $180 / \pi$ gives us the angular velocity in degrees/s. The standard spot size of the stimulus was $\sim 220 \mu \mathrm{m}$ diameter or $6^{\circ}$.

Unless otherwise stated the moving spot was recorded at two speeds, $670 \mu \mathrm{m} / \mathrm{s}$ $\left(17^{\circ} / \mathrm{s}\right)$ and $1340 \mu \mathrm{m} / \mathrm{s}\left(32^{\circ} / \mathrm{s}\right)$. Stimuli were focused and projected onto the photoreceptor layer using a DLP video projector (HP AX325AA; Hewlett-Packard) with a peak wavelength at $395 \mathrm{~nm}$. I restricted the two-photon fluorescence imaging and electrophysiological recordings to the ventral retina. There I could isolate the input to the short-wavelength cones (S-opsin cones) that are the most numerous and most sensitive to ultraviolet light (360 nm) in the ventral retina (Wang, Weick, \& Demb, 2011). 
Custom Matlab programs were used to identify regions of interest (ROIs) and calculate response time-to-peak, and response-onset for each $\mathrm{ROI}$. Because the moving stimulus reaches each ganglion cell within an imaged population at slightly different time points, I had to compensate for the relative position of the stimulus to each cell body (Figure 6B). The box on the left shows a schematic of ganglion cells that labeled with GCaMP6f. Cell 1 in the center of the imaging window has nearly overlapping responses to the leftward and rightward moving spot. Cell 2. on the other hand. is not centered in the imaging window, as a result its responses to the leftward and rightward moving spots are not aligned in time. Because the resulting offset is symmetrical in time, equal but of opposite sign for left versus rightward condition, I can fully correct for it by averaging the response times to the moving spots $\left(t r_{\text {sweep }}\right)$ and calculate the phase advancing $(P A)$ value by subtracting from the time of the response to the flashed spot ( rr $\left._{\text {flash }}\right)$ :

$$
P A=t r_{\text {flash }}-\overline{t r_{\text {sweep }}}
$$

I calculated phase advancing for the response-onset time (osPA) and response time-topeak (ttpPA). Response-onset time was calculated when the response was three standard deviations from the baseline (500 ms of response to gray background).

Statistical analysis was performed in either Matlab, Microsoft Excel or GraphPad Prism (La Jolla, CA). In general, results are presented as mean \pm SEM. Significance was determined using paired or unpaired $t$-test for comparison between two groups. For multigroup comparison, one-way ANOVA and Tukeys post hoc test were performed to determine significance. A $p$ value $<0.05$ was considered statistically significant. Additional methods are described in each chapter. 


\section{CHAPTER II}

\section{POPULATION STUDY OF MOTION ENCODING GANGLION CELLS USING FLUORESCENCE CALCIUM IMAGING}

\section{Introduction}

Previous work established that some compensation for neuronal delays takes place already at the level of the retina. Multi-electrode array (MEA) recordings of amphibian and mammalian retinae showed that specific ganglion cell populations compensate for the phototransduction delay, either partially or completely depending on stimulus conditions, using a predictive mechanism called phase advancing (Berry et al., 1999; Leonardo \& Meister, 2013).

In phase-advancing ganglion cells, continuous motion stimuli evoke a response that may match or precede the leading edge of the moving spot or bar. This helps compensate for visual signaling delays, while the response of the same cells to a stationary, flashed spot lagged the stimulus by approximately $50-100 \mathrm{~ms}$. Phase advancing as an encoding strategy was first demonstrated in tiger salamander retina, and rabbit OFF-type ganglion cells (Berry et al., 1999).

Two important developments have provided neuroscientists with innovative ways of measuring activity in populations of neurons. First, two-photon microscopy has delivered the ability to live-image fluorescently labeled cells (Denk, Strickler, \& Webb, 1990). A femtosecond pulsed infrared (IR) laser excites fluorophores with negligible 
photoreceptor activation compared with single photon fluorescence microscopy, and minimal tissue damage (Svoboda \& Yasuda, 2006). Additionally, dyes and fluorescent biosensors have been developed to detect changes in neuronal calcium (Chen et al., 2012; Tian et al., 2009), changes in membrane voltage (Peterka, Takahashi, \& Yuste, 2011), and glutamate release (Marvin et al., 2013). These two innovative techniques enable monitoring many cells simultaneously, making it possible to efficiently address unanswered, object motion-related questions.

Recently, researchers have used two-photon fluorescence calcium imaging to collect responses from large populations of ganglion cells (Baden et al., 2016). When neurons generate action potentials, ion channels open and extracellular calcium moves into the cell. The incoming calcium ions bind to the calcium sensor, causing a change in fluorescence. The fluorescent signal is indicative of neuronal activation and using compuatational methods to infer spike rate from fluorescence changes has expanded how these signals may be analyzed (Theis et al., 2016). Imaging offers two specific advantages over MEA recordings. First, calcium imaging can be used to detect responses of non-spiking cell types such as amacrine cells but distinguishing between ganglion cells and amacrine cells is challenging. Second, its spatial sampling resolution is not constrained by electrode density.

The current assortment of available fluorescent calcium sensors falls into two broad groups: small molecule indicator dyes and genetically encoded protein biosensors. The family of small molecule indicators includes Oregon Green BAPTA (OGB), and genetically encoded calcium indicators (GECI) include the GCaMP family of biosensors (Chen et al., 2013). OGB requires entry into the soma by physical means, such as electroporation or chemical means with AM-ester variants (Baden et al., 2016; Borghuis et al., 2011). GCaMP can be introduced either through viral transduction or creation of transgenic mouse lines to label specific cell types. OGB lacks cell specificity 
but has a lower baseline of fluorescence, faster response kinetics, and is more resistant to photobleaching than the current $\mathrm{GECl}$ variants.

GCaMP is an engineered protein comprising a circularly permuted green fluorescent protein (GFP) bound to calmodulin and the calmodulin interacting protein M13. As calcium flows into a cell following activation, it binds to the calmodulin group. This binding causes a conformational change that leads to an increase in the fluorescence emission (Chen et al., 2013). Intravitreal injections of plasmid DNA with the synapsin1 gene promoter and encoded GCaMP gene sequence packaged in adenoassociated virus (AAV) 2/1 labels ganglion cells with minimal tissue disruption. This combination of serotype and promoter does not label displaced amacrine cells in the ganglion cell layer (Mandell, Czernik, De Camilli, Greengard, \& Townes-Anderson, 1992). This approach requires $18-21$ days incubation and has been a useful direction for calcium imaging in retinal ganglion cells (Borghuis et al., 2011).

In salamander, phase advancing was proposed to be exclusive to the OFF pathway, signifying the OFF pathway as a bug detector (Leonardo \& Meister, 2013; Lettvin et al., 1959). Single cell recordings from goldfish retina, on the other hand, implied inhibitory circuitry as a mechanism, which connect to many ganglion cell types broadly. This observation led to the hypothesis that, in principle, many cell types could phase advance (Johnston \& Lagnado, 2015). I tested this hypothesis in mouse ganglion cell populations. In this chapter I describe my results using two-photon fluorescence calcium imaging and to establish that phase advancing is a property that is common to many ganglion cell types in the mouse retina.

\section{Methods}

All animal procedures were approved by the Institutional Animal Care and Use Committee at the University of Louisville and were in compliance with National Institutes 
of Health guidelines. I recorded visually evoked calcium responses in whole-mount retina from two lines of Thy1-GCaMP6f-WPRE transgenic mice: GP5.11 (Jackson Laboratory \#025393) and GP5.17 (Jackson Laboratory \#024339). I used PCR genotyping to confirm expression in offspring from breeding pairs of GP5.11 x C57/BI6 and GP5.17 x C57/B|6. Retinal preparation is described in the General Methods. Fluorescence imaging was performed with a modified Olympus microscope controlled with Scanlmage 3.8 software and an Olympus 60x, 1.0NA, LUMPlanFL/IR objective. The scan laser (Chameleon Ultra II; Coherent) was tuned to 910nm for GCaMP6f fluorescence excitation in retinal areas up to $150 \times 150 \mu \mathrm{m}$ recorded at 16 frames per second. Visual stimuli are described in the General Methods.

In the imaging analysis window, I drew ROIs around each ganglion cell's soma (Figure 9). I extracted the fluorescence responses for OFF-type ganglion cells and calculated the amount of phase advancing using Eq. 1 in the General Methods. I measured phase advancing using two metrics; the time-to-peak phase advancing (ttpPA) value and the onset response (osPA) (Figure 9 middle, black arrows and arrowheads, respectively).

To compare the relative timing of the fluorescence and spike response I simultaneously recorded spiking in loose-patch configuration and changes in fluorescence in ganglion cells of the Thy1-GCaMP6f-WPRE transgenic mice. For this, glass-recording microelectrodes were filled with Ames solution (Sigma-Aldrich) and a red fluorescent dye (Sulforhodamine 101) to see where my pipette is in relation to the cell of interest. In current clamp mode $(I=0 \mathrm{pA})$ I formed a loose seal $(\mathrm{RM}<150 \mathrm{M} \Omega)$ on the cell soma. I then used the standard sweep stimulus while recording GCaMP6f fluorescence responses and somatic action potentials.

\section{Results}




\section{GCaMP6f expression in mammalian retina}

I used transgenic mouse lines that expressed a recently developed member of the GCaMP family, GCaMP6f, which offered improved sensitivity and faster return to baseline compared with previous versions (Chen et al., 2013). Of three GCaMP6 variants (slow, medium, and fast), GCaMP6f had the fastest response onset and time-topeak, which was important for measurements of phase advancing in ganglion cells. GCaMP6f was used to generate a transgenic mouse line with stable expression of GCaMP6f in the brain. This mouse line had important advantages over the use of viral transduction because transgenic expression reduced animal-to-animal variability and obviated the need for intraocular injection followed by incubation (Dana et al., 2014). The Thy1 promoter stochastically drives expression in projection neurons often with variable expression across lines. Dana et al. screened for GCaMP6f expression in select brain regions including $\mathrm{V} 1$, thalamus, hypothalamus, and hippocampus, but did not assess GCaMP6f expression in the retina. A few of the founders $(5.1,5.9,5.11,5.12,5.17)$ showed strong expression of GCaMP6f in visual cortex and thalamus. Therefore, my first goal was to determine which of the GCaMP6f founder lines had robust fluorescence expression in the retina.
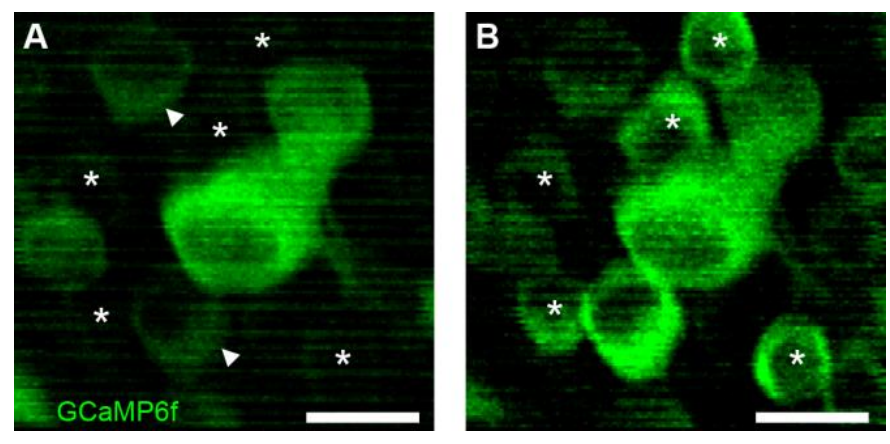

Figure 7. GCaMP6f labeled ganglion cells. A, Imaging window of the ganglion cells under black background (no visual stimulation). B, Same panel from A but at peak fluorescence response after stimulation with a dark spot ( 220 $\mu \mathrm{m}$ diameter) on a gray background. Arrowheads show outer edge of labeled cell membrane. Asterisks show light responsive cells with increased fluorescence in panel B. Scale bar, 10 $\mu \mathrm{m}$.

I screened three lines of Thy1-GCaMP6f transgenic mice based on the results published by Dana et al. (2014): GP5.5, GP5.11, GP5.17. Screening was accomplished by looking for robust GCaMP6f expression under experimental conditions in whole 
mounted retina (General Methods). GP5.5 did not show robust GCaMP expression in the retina (data not shown). On the other hand, stable, robust expression of GCaMP6f in ganglion cells was observed in both the GP5.11 and GP5.17 lines. Because the expression patterns were similar, both lines were used interchangeably, data obtained from the two lines was combined, and from this point forward in describing results I will not distinguish between GP5.11 and GP5.17.

Baseline fluorescent expression was concentrated to the cytosol with nuclear exclusion (Figure 7A arrowheads and asterisks). Some cells have high fluorescence baseline, whereas others had scarcely visible fluorescence in the absence of visual stimulation (asterisk). Upon presentation of the visual stimulus, intensity of the fluorescent signal increases until the response peaks (Figure 7B). I found that in the ventral retina, labeled ganglion cells are clustered in groups of $4-8$ cells, whereas in the dorsal retina labeling is more uniform. As discussed in the General Methods I restricted my recordings to the ventral retina for optimal stimulation of UV cone photoreceptors.

The time course of the GCaMP6f fluorescence rise and decay back to baseline is crucial to our understanding of phase advancing. My next step was to test whether the time course of ganglion cell GCaMP6f fluorescence responses to the time course of action potential responses is sufficiently accurate for my study of phase advancing.

GCaMP6f reliably reports neuronal activity in retinal ganglion cells

Fluorescence calcium responses do not directly translate into spike rate. This is due, in part, to differences in baseline calcium and calcium response dynamics across neuron types and species (Theis et al., 2016). To gain a better understanding of my measurement of phase advancing in the Thy1-GCaMP6f labeled ganglion cells I performed loose patch recording of extracellular action potentials. For loose seal 
patching I targeted cells with robust fluorescence responses $(\Delta \mathrm{F} / \mathrm{F})$ to a flashing spot. After establishing a loose seal $(\mathrm{R} \sim 150 \mathrm{M} \Omega)$, I observed spiking and fluorescence changes, simultaneously when presenting the sweep stimulus (Figure 8C).

\section{A ON-OFF DSGC}

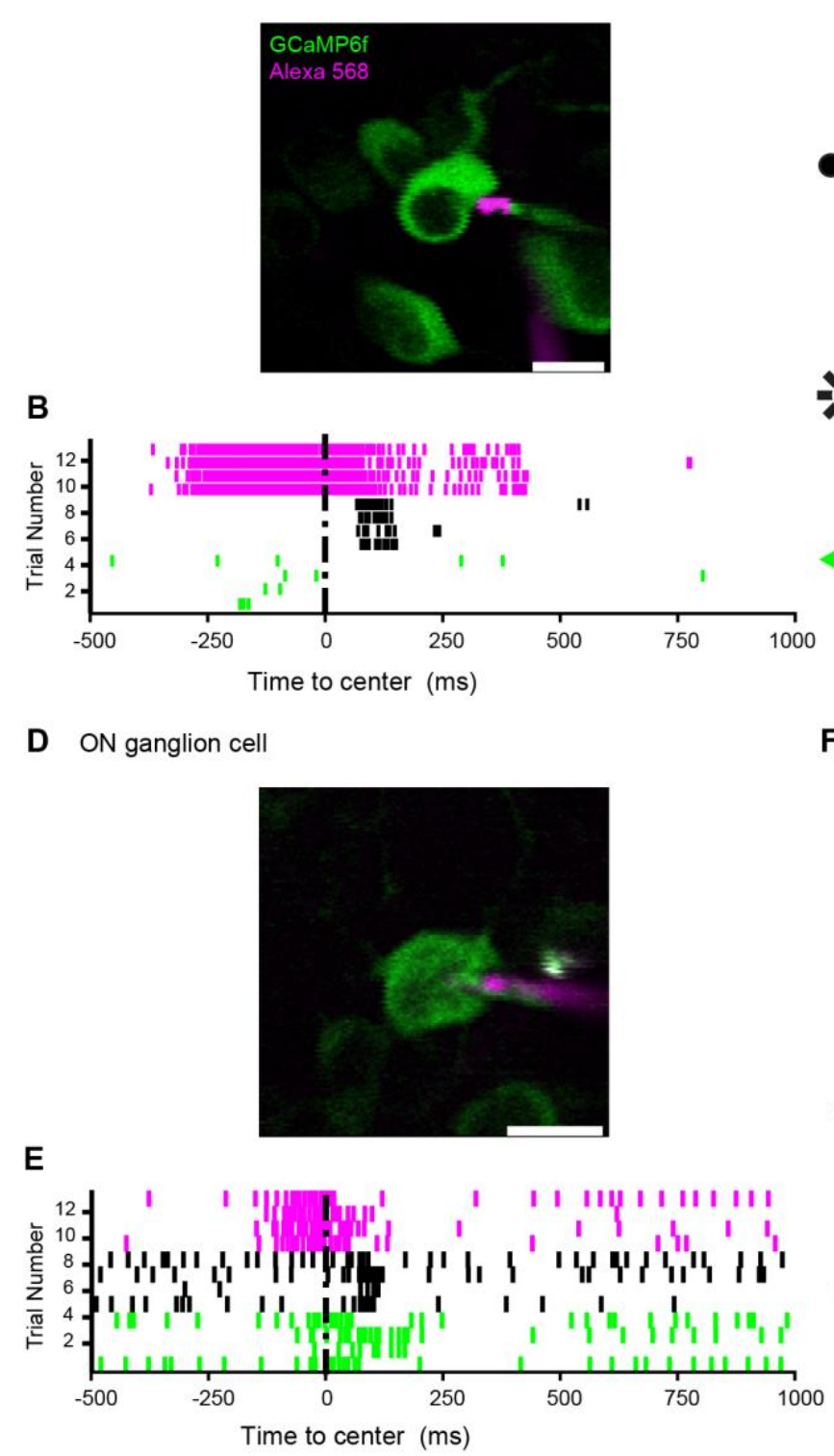

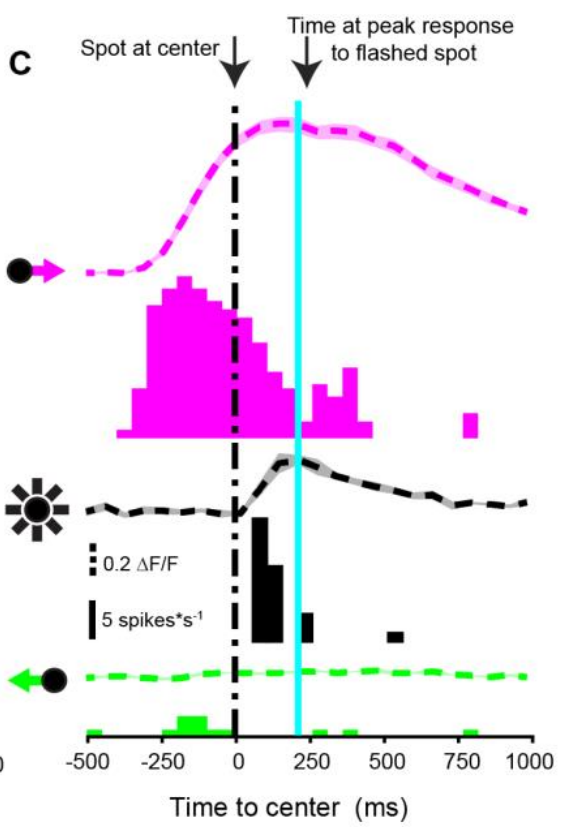

$\mathbf{F}$

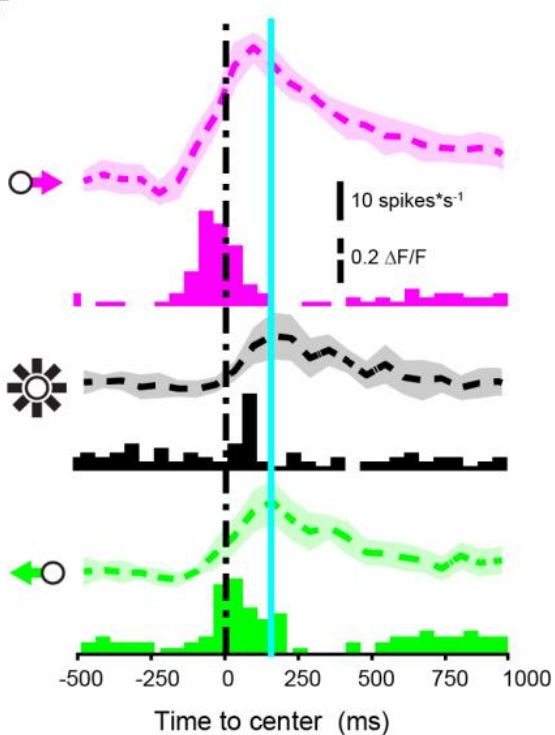

Figure 8. Spiking and GCaMP6f fluorescence in retinal ganglion cells. A, ON-OFF DSGC under loose patch configuration. B, Raster plot from the ON-OFF DSGC when stimulated with light increment sweep stimulus. C, GCAMP6f fluorescence responses (dashed line) and PSTHs. D, Two-photon images of loose patched ON GC. E, Raster plot of the above ON GC when stimulated with the sweep stimulus. F, GCaMP6f fluorescence traces and corresponding PSTHs. Vertical black line shows when the spot is in the center of the imaging window $(\mathrm{t}=0)$. Vertical cyan line shows the time at the peak response to the flashed spot. Shaded area on fluorescence traces $C$ and $F$ show $\pm S E M$. Scale bar, 10 $\mu \mathrm{m}$. 
As discussed in Chapter I, OFF ganglion cells respond to light decrements and ON ganglion cells respond preferentially to light increments. Additionally, there are ganglion cells responsive to both light increments and light decrements. ON-OFF ganglion cells have bistratified dendrites within the inner plexiform layer (IPL).

The ON-OFF DSGC example in Figure $8 \mathrm{~A}$ is tuned to rightward motion. The raster plots, where each action potential is represented by a dot and responses to repeated stimulus presentations are offset vertically, show a large increase in spike output to the rightward moving spot (Fig. 8B, magenta) while the leftward moving spot elicits almost no action potentials (green). The response to the flashed spot (black) shows a burst of action potentials sometime after the presentation of the spot. That pattern of firing activity is also shown in the peristimulus time histogram (PSTH) and fluorescence responses (Figure 8C).

An additional example of an ON-type ganglion cell is shown in Figure 8D. When stimulated with a stationary flashed spot (light increment), the cell shows a burst of action potentials (black raster and black PSTH) and a corresponding increase in fluorescence (black trace). There is a similar response to the moving spots, as shown in the magenta and green traces, the peaks of the fluorescence traces centered around $t=0$ (Figure 8E, F). Next, I tested for phase advancing responses recorded from population recordings of ganglion cells.

\section{OFF-type ganglion cells phase advance}

Post-recording analysis sorted and classified ganglion cell responses from the 40 retinas of 23 mice. I quantified the distribution of phase advancing from a stochastically labeled population of ganglion cells. Shown previously, in the salamander and rabbit retina phase advancing was common to fast-OFF type ganglion cells (Berry et al., 1999; Leonardo \& Meister, 2013). Of note, the visual stimuli of previous studies (Berry et al., 
1999; Leonardo \& Meister, 2013) consisted of only light decrement visual stimuli, moving bars/spots and flashed bars/spots. The sweep stimulus included light decrement moving and flashed spots of $\sim 220 \mu \mathrm{m}$, i.e., roughly the size of an alpha ganglion cells excitatory receptive field (Krieger et al., 2017). Spots moved at a constant velocity of $1340 \mu \mathrm{m}^{*} \mathrm{~s}^{-1}$. The stationary flashed spot was presented for 5 video frames ( $80 \mathrm{~ms})$ centered in the imaging window.

A Phase advancing OFF GC
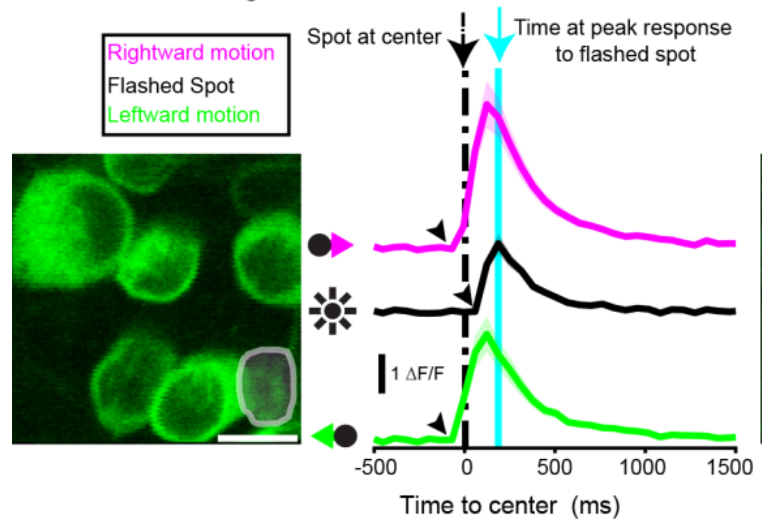

B Non-phase advancing OFF GC

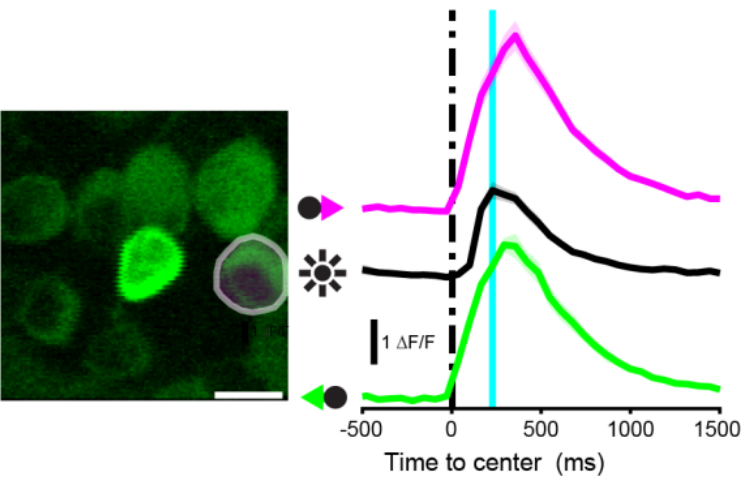

C
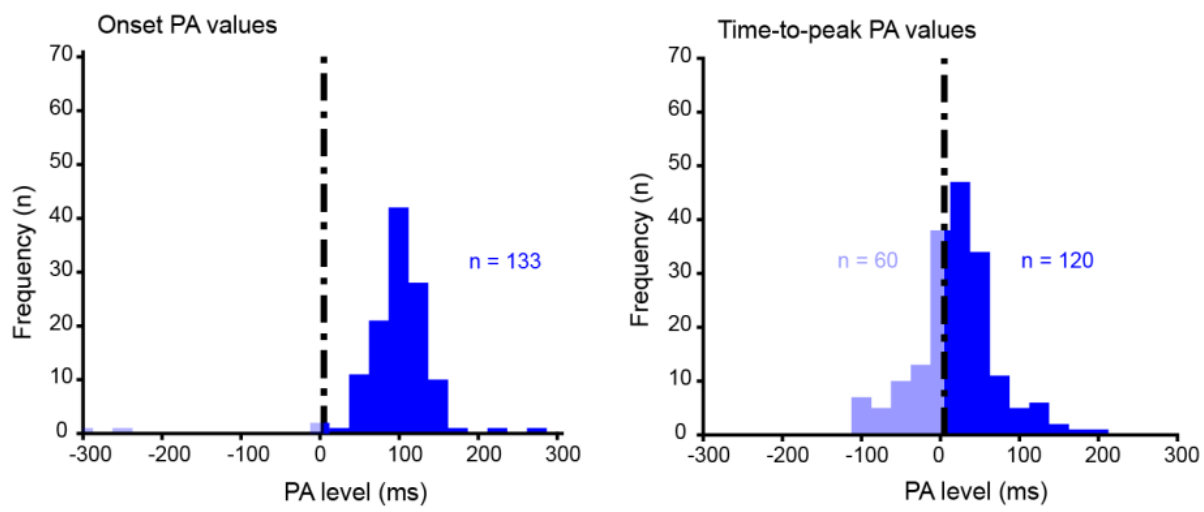

Figure 9. OFF ganglion cells phase advance. A, Calcium responses (right) of a phase advancing OFF ganglion cell selected from the micrograph (left, ttpPA=56 ms; osPA=119 ms). $B$, Example of a non-phase advancing OFF ganglion cell (ttpPA=-104 ms; osPA=100 ms). Vertical dashed black line shows when the spot is in the center of the imaging window $(t=0)$. Vertical cyan line shows the time at the peak response to the flashed spot. Shaded area represents \pm SEM, scale bar, $10 \mu \mathrm{m}$. C, Population histograms of OFF ganglion cell phase advancing responses (left, onset phase advancing; right, timeto-peak phase advancing).

I recorded fluorescence responses from 180 OFF-type ganglion cells. The traces

in Figure 9A show the visually evoked fluorescence response from a phase advancing OFF type ganglion cell shown in the image frame (left). The vertical black dashed line 
shows the time at which the spot is in the center of the imaging window. This example cell has a time-to-peak (ttpPA) value of $56 \mathrm{~ms}$ and a response onset (osPA) value of 119 ms. I also found OFF-type ganglion cells that did not phase advance with respect to its ttpPA but had an osPA value of $100 \mathrm{~ms}$ (Figure 9B). Of the 180 responsive OFF cells, $120(67 \%)$ had a ttpPA that showed phase advancing with a mean of $46.7 \mathrm{~ms} \pm 3.8 \mathrm{~ms}$. $133(97 \%)$ of the 137 responsive OFF ganglion cells had an mean osPA value of $103.2 \pm$ $2.9 \mathrm{~ms}$. Time-to-peak response of the remaining 60 cells lagged behind the response to the flashed spot mean ttpPA of $-32.5 \pm 4.3 \mathrm{~ms}$.

I used the center of the spot as the reference point for the light-evoked responses (see General Methods), because in one view this is the relevant biological variable: where is the center of the spot when a cell first reports it. To estimate instead the time of the fluorescence response relative to the position of the leading edge of the moving spot requires subtracting the temporal difference between the moving edge and the center. Given the size and speed of the stimulus spot $\left(220 \mu \mathrm{m}, 1340 \mu \mathrm{m}^{\star} \mathrm{s}^{-1}\right)$ this amounts to $83.3 \mathrm{~ms}$. Using this metric, response onset still showed phase advancing of $34 \mathrm{~ms}$ in $69 \%$ of cells and time to peak of $44 \mathrm{~ms}$ in $8 \%$ of OFF cells.

\section{ON-type ganglion cells phase advance}

Novel to my experiments was a probe for ON-type ganglion cells, which respond to light increments and are suppressed by light decrements. To stimulate ON-type ganglion cells, the sweep stimulus included a light incremented flashed spot of fixed intensity and horizontally moving light incremented spots, all on a gray background. I recorded responses, then measured time-to-peak phase advancing responses from 171 ON-type ganglion cells. Similar to OFF-type ganglion cells, the peak response of ON-type ganglion cells to the moving spots (magenta and green traces) occurred before the peak response to the flashed spot (black trace) (Figure 10A). 
The example phase advancing cell shown in Figure 10A had a ttpPA value of 80 ms and an osPA value of $92 \mathrm{~ms}$. Of the 171 responsive ON cells, $137(80 \%)$ had a mean ttpPA of $51 \mathrm{~ms} \pm 4.7 \mathrm{~ms}$. The remaining 34 cells lagged behind the response to the flashed spot (Figure 10C). 127 (88\%) of the 145 responsive ON cells had an mean osPA value of $111.6 \pm 4.3 \mathrm{~ms}$. Correcting for the leading edge using the edge estimation factor gives an osPA of $50 \mathrm{~ms}$ in $61 \%$ of cells and a ttpPA of $47 \mathrm{~ms}$ in $11 \%$ of ON ganglion cells. I have demonstrated that ON ganglion cells like OFF ganglion cells phase advance in the mammalian retina.

A Phase advancing ON GC
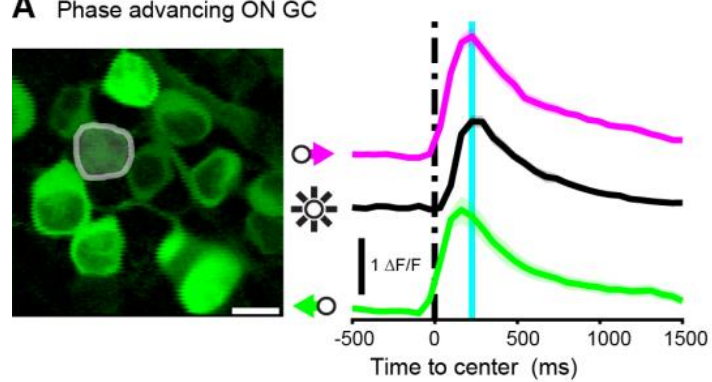

B Non-phase advancing ON GC

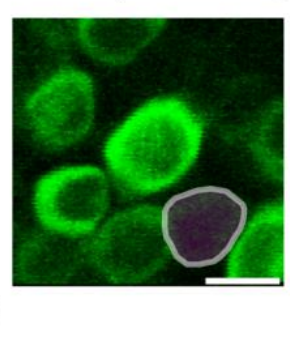

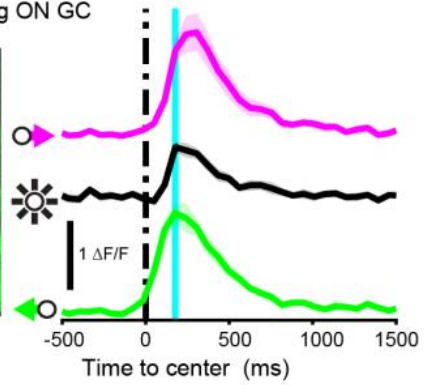

C
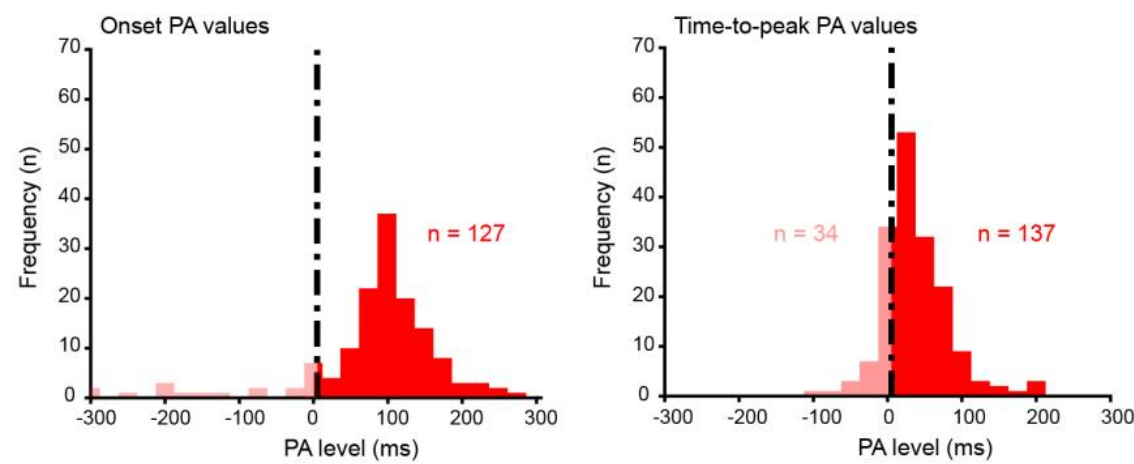

Figure 10. ON ganglion cells phase advance. A, Calcium responses (right) of a phase advancing ON ganglion cell selected from the micrograph (left, ttpPA=80 ms; osPA=92 ms) $B$, Example of a nonphase advancing $\mathrm{ON}$ ganglion cell (ttpPA=-38 ms; osPA=96 ms). Vertical black line shows when the spot is in the center of the imaging window $(\mathrm{t}=0)$. Vertical cyan line shows the time at the peak response to the flashed spot. Shaded area represents \pm SEM, scale bar, $10 \mu \mathrm{m}$. C, Population histograms of OFF ganglion cell phase advancing responses (left, onset phase advancing; right, time-to-peak phase advancing).

\section{Additional phase advancing ganglion cells}

The diversity of retinal ganglion cell types provides a unique input signal to downstream brain regions. From my collection of ganglion cell fluorescence responses, I sorted out 
the two other classes of ganglion cells: ON-OFF non-DS and DSGCs. The ON-OFF nonDS ganglion cells may include vertically tuned ON-OFF DSGCs. Phase advancing based on first-spike responses to a moving bar has already been shown in a population of upward-encoding ON-OFF DSGCs (Trenholm, Schwab, et al., 2013).

A Phase advancing ON-OFF GC

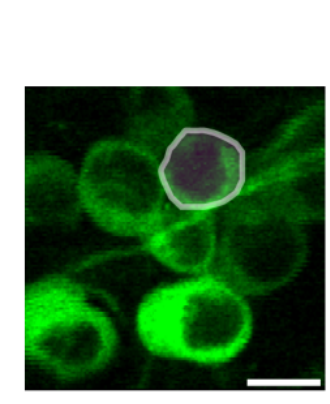

B

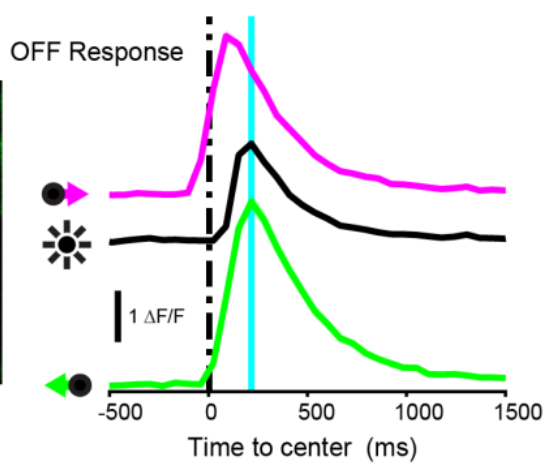

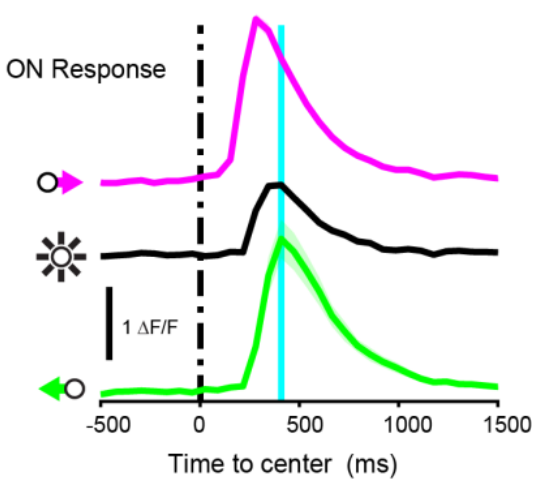

Time to center (ms)
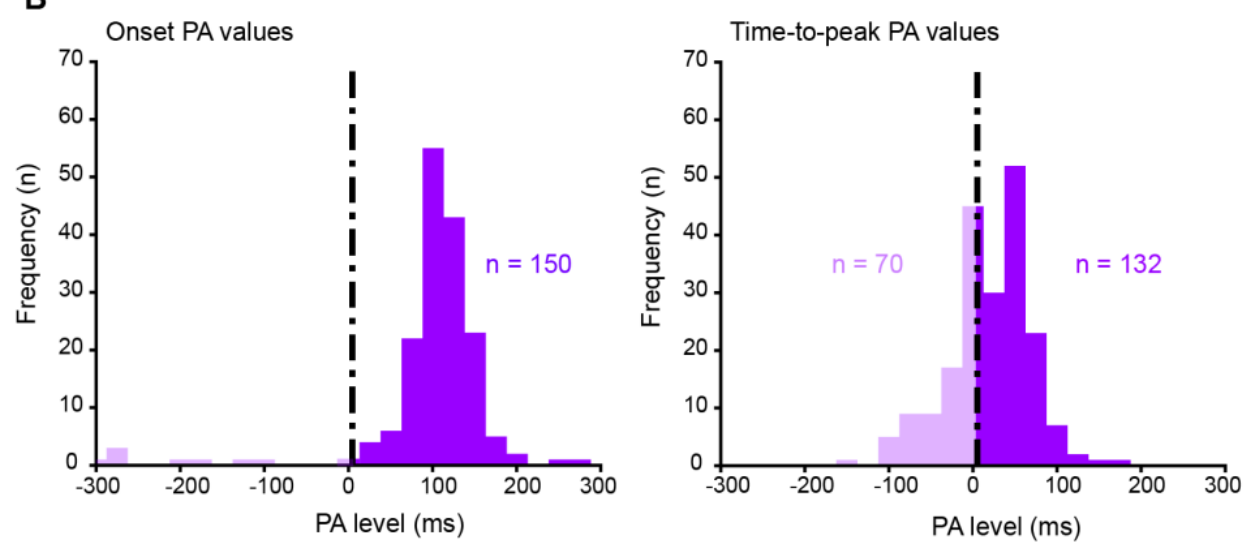

Figure 11. ON-OFF ganglion cells phase advance. A, Calcium responses (middle and right) of a phase advancing OFF ganglion cell selected from the micrograph (left, ttpPA=30 ms; osPA=112 ms) $(\operatorname{ttpPA}=24 \mathrm{~ms}$; osPA=101 ms). Vertical black line shows when the spot is in the center of the imaging window $(\mathrm{t}=0)$. Vertical cyan line shows the time at the peak response to the flashed spot. Shaded area represents \pm SEM, scale bar, $10 \mu \mathrm{m}$. B, Population histograms of OFF ganglion cell phase advancing responses (left, Onset phase advancing; right, time-to-peak phase advancing).

Shown in Figure 11 are the responses recorded from ON-OFF ganglion cells.

The example ON-OFF ganglion cell shown in Figure 11A and $\mathrm{B}$ was visually responsive to both the light increment and light decrement visual stimulus. The ttpPA value for the OFF response was $30 \mathrm{~ms}$ and the osPA value was $112 \mathrm{~ms}$. The ON response ttpPA was $24 \mathrm{~ms}$ and the osPA of $101 \mathrm{~ms} .150$ (96\%) of the 157 responsive ON-OFF ganglion cells 
had a mean osPA value of $116.5 \pm 3.1 \mathrm{~ms}$. Of the 202 ON-OFF ganglion cells I

recorded, $132(65 \%)$ had phase advancing responses with an mean ttpPA value of 47.9 $\mathrm{ms} \pm 3.9 \mathrm{~ms}$. Correcting for the leading edge of the moving spot using the edge estimation factor gives an osPA of $44 \mathrm{~ms}$ in $78 \%$ of cells and a ttpPA of $34 \mathrm{~ms}$ in $4 \%$ of ON-OFF ganglion cells.

A Phase advancing DSGC
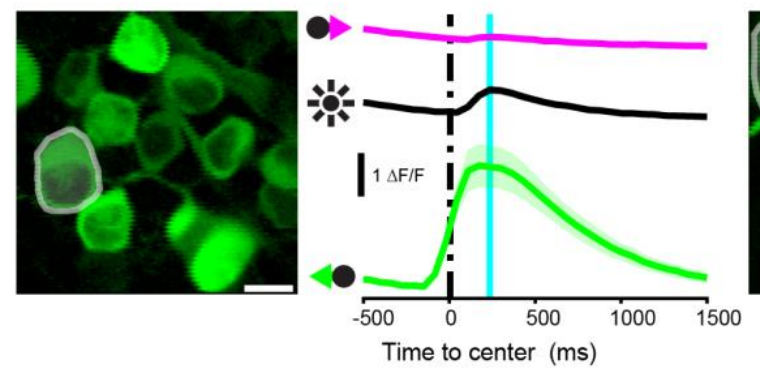

B Non-phase advancing DSGC

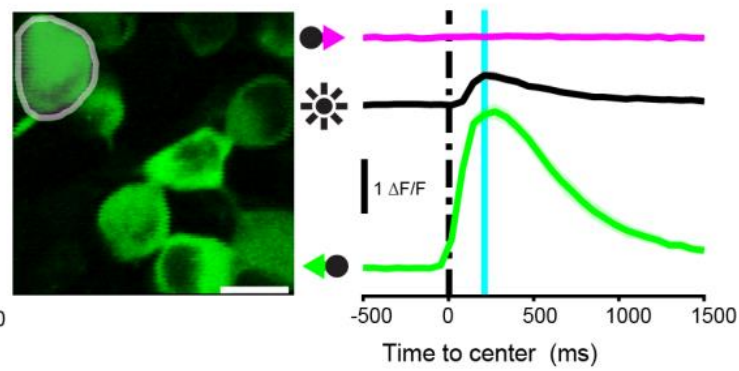

C
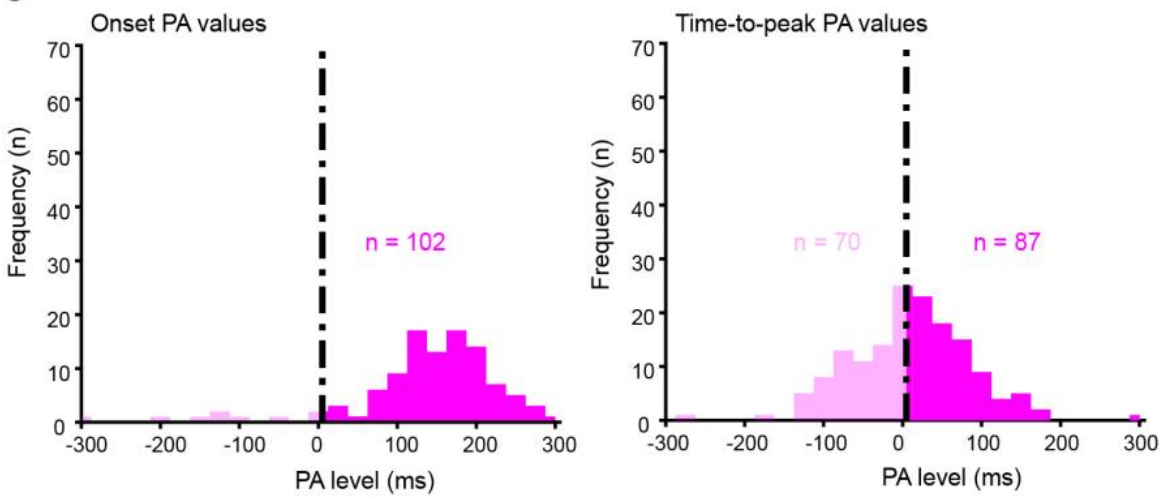

Figure 12. DSGCs phase advance. A, Calcium responses (right) of a phase advancing DSGC ganglion cell selected from the micrograph (left, ttpPA=77 ms; osPA=234 ms). B, Example of a non-phase advancing DSGC (ttpPA=-8 ms; osPA=107 ms). Vertical black line shows when the spot is in the center of the imaging window $(\mathrm{t}=0)$. Vertical cyan line shows the time at the peak response to the flashed spot. Shaded area represents \pm SEM, scale bar, $10 \mu \mathrm{m}$. C, Population histograms of OFF ganglion cell phase advancing responses (left, Onset phase advancing; right, time-to-peak phase advancing).

Also included in the ganglion cell population are direction selective ganglion cells (DSGCs). The population of DSGCs comprises two types, ON and ON-OFF, with individual cells tuned to selectively respond to visual motion aligned with movements along the body axes (Sabbah et al., 2017). The moving spots only moved horizontally across the retina and not vertically, so that only horizontally-, and not vertically-tuned DSGCs were detected in my experiments. I calculated the direction selectivity index 
(DSI) using the amplitudes of the fluorescence response: DSI = (Preferred - Null) /

(Preferred + Null). The example phase advancing DSGC shown in Figure 12A had an osPA value of $234 \mathrm{~ms}$ and a ttpPA value $77 \mathrm{~ms} .102$ (92\%) of the 111 responsive DSGCs had a mean osPA value of $172.4 \pm 7.4 \mathrm{~ms}$. Of 157 DSGCs I recorded, 87 (55\%) phase advancing DSGCs with a mean ttpPA value of $70.9 \pm 7.2$ (Figure 12C). Correcting for the leading edge using the edge estimation factor gives an an osPA of $101 \mathrm{~ms}$ in $83 \%$ of cells and a ttpPA of $48 \mathrm{~ms}$ in $7 \%$ of DSGCs.

Table 1. Values for onset phase advancing and non-phase advancing cells collected from GCaMP6f imaging data.

\begin{tabular}{|c|c|c|c|c|c|c|}
\hline Cell type & $\begin{array}{l}\text { Total } \\
\text { cells }\end{array}$ & $\begin{array}{l}\text { Non-PA } \\
\text { cells }\end{array}$ & $\begin{array}{l}\text { PA } \\
\text { cells }\end{array}$ & $\begin{array}{l}\text { Mean PA value } \\
\text { (ms) }\end{array}$ & \pm SEM & $\begin{array}{c}\text { Percentage of PA } \\
\text { cells }(\%)\end{array}$ \\
\hline OFF cells & 137 & 4 & 133 & 103.2 & 2.9 & 97 \\
\hline ON cells & 145 & 18 & 127 & 111.6 & 4.3 & 88 \\
\hline DS cells & 111 & 9 & 102 & 172.4 & 7.4 & 92 \\
\hline $\begin{array}{l}\text { ON-OFF } \\
\text { cells }\end{array}$ & 157 & 7 & 150 & 116.5 & 3.1 & 96 \\
\hline Total cells & 550 & 38 & 512 & & & \\
\hline
\end{tabular}

Table 2. Values for time-to-peak phase advancing and non-phase advancing cells collected from GCaMP6f imaging data.

Time-to-peak phase advancing

\begin{tabular}{|c|c|c|c|c|c|c|}
\hline Cell type & $\begin{array}{l}\text { Total } \\
\text { cells }\end{array}$ & $\begin{array}{l}\text { Non-PA } \\
\text { cells }\end{array}$ & $\begin{array}{l}\text { PA } \\
\text { cells }\end{array}$ & $\begin{array}{c}\text { Mean PA value } \\
(\mathrm{ms})\end{array}$ & \pm SEM & $\begin{array}{c}\text { Percentage of PA } \\
\text { cells (\%) }\end{array}$ \\
\hline OFF cells & 180 & 60 & 120 & 46.7 & 3.8 & 67 \\
\hline ON cells & 171 & 34 & 137 & 51 & 4.7 & 80 \\
\hline DS cells & 157 & 70 & 87 & 70.9 & 7.2 & 55 \\
\hline $\begin{array}{l}\text { ON-OFF } \\
\text { cells }\end{array}$ & 202 & 70 & 132 & 47.9 & 3.9 & 65 \\
\hline Total cells & 710 & 234 & 476 & & & \\
\hline
\end{tabular}

\section{Discussion}

In my probe of GCaMP6f labled and visually responsive ganglion cells, I found that 512 (93\%) of 550 ganglion cells were phase advancing based on response onset (Table 1) 
and $476(67 \%)$ of 710 cells had phase advancing time-to-peak values (Table 2 ) in the fluorescence response. I showed that phase advancing in the mammalian retina was not limited to the OFF retinal pathway, but instead was prevalent in four major groups of retinal ganglion cell types (ON, OFF, ON-OFF, and DSGC). If phase advancing were limited to a single retinal pathway, the mechanism responsible may be comparatively easier to discover, by comparing the cellular and circuit-level properties of non-PA versus PA cell types. Since phase advancing appears to be a common feature of many retinal ganglion cells, it could be a cell intrinsic property as originally proposed (Berry et al., 1999; Leonardo \& Meister, 2013). Alternatively, phase advancing may result from an extrinsic circuit mechanism acting on ganglion cells (Johnston \& Lagnado, 2015).

Previous work showed peak action potential firing ahead of the leading edge of a moving bar (Berry et al., 1999; Johnston \& Lagnado, 2015). In my experiments, I recorded and calculated the fluorescent response time relative to the center of the spot, so that I could more directly come the response timing to a stationary flashed spot center on the receptive field. I considered time to center zero $(t=0)$ as when the spot is centered in the imaging window. A positive phase advancing value shows how many milliseconds ahead in time the fluorescent response to moving spots is compared with the flashed spot. To more directly compare my findings to published data, I recalculated my results to compute the leading edge of the stimulus and the phase advance. Even here I still see a majority of ganglion cells (ON, OFF, ON/OFF and DS) whose responses show phase advancing.

Ganglion cell receptive fields range from $\sim 100 \mu \mathrm{m}$ to $\sim 300 \mu \mathrm{m}$ (Krieger et al., 2017; Zhang et al., 2012). The stochastic label of GCaMP6f under the Thy1 promoter labels an unknown number of ganglion cell types with a ranges of receptive field sizes. The onset time-to-peak values give insight about initial detectable responses when the moving spot first enters the ganglion cell's receptive field. My experiment was designed 
to image calcium fluorescence at ganglion cell somas and not at the dendritic arbors. In the case of the Thy1-GCaMP6f transgenic lines I used, 5.11 and 5.17, the dendrites are not labeled for imaging visually evoked calcium signals. In contrast, previous studies have filled individual starburst amacrine cells with OGB and measured changes in fluorescent calcium signals at the dendrites (Euler, Detwiler, \& Denk, 2002; Hausselt, Euler, Detwiler, \& Denk, 2007). In general, these studies demonstrate that there are computational units of direction selectivity at the dendrites of starburst amacrine cells. It is possible that phase advancing mechanisms occur in the dendrites of ganglion cells but further experiments are needed to test that hypothesis. Perhaps in conjunction with a bipolar cell and amacrine cells, the ganglion cell receptive field has the ability to adjust its computational power depending on the visual stimulus, e.g. nonlinear subunits alter output.

A limitation of my approach is that the moving spot only moves horizontally. My experimental paradigm excluded the DSGCs that are tuned to vertical motion, which likely included in the labeled GC population. This means that I was able to distinguish only the DSGCs tuned to horizontal motion (Figure 12A possible next step to study phase advancing would be to compare horizontal versus vertical phase advancing values in DSGCs. In particular, because phase advancing has been previously shown in electrically-coupled ON-OFF DSGCs using a transgenic mouse line, Hb9-eGFP, which labels ON-OFF DSGCs tuned to upward motion. In that study, paired recordings of labeled DSGCs showed that gap junctions were necessary for phase advancing in these cells (Trenholm, Schwab, et al., 2013). Further studies could compare phase advancing in vertically tuned DSGCs versus horizontally tuned DSGCs, which lack identified gap junction expression.

An early proposed experimental design was to image visually evoked GCaMP6f fluorescent responses from a specific ganglion cell type, the alpha ganglion cells. The 
fluorescent responses could then be compared to the alpha ganglion cell electrophysiological recordings from Chapter III. First, I crossed the KCNG4-Cre $x$ Ai95(RCL-GCaMP6f)-D (Jax 028865) reporter line to label the four alpha type ganglion cells (Krieger et al., 2017) with the calcium indicator. Second, I intravitreally injected AAV2/1.Syn.Flex.GCaMP6f.WPRE.SV40 (Addgene) into KCNG4-Cre positive mice and harvest the retinas for recording (see Chapter IV for viral injection technique). In both cases, transgenic and viral transfection, ganglion cells were labeled with GFP but there was no visually evoked fluorescence change when stimulated with the sweep stimulus (data not shown). This could be due to the limited kinetics of the sensor in the $\mathrm{Ca}^{2+}$ concentration range of alpha ganglion cells (Badura, Sun, Giovannucci, Lynch, \& Wang, 2014). Newer GECls have shown to improve the signaling kinetics over GCaMP6f in mouse visual cortex (Dana et al., 2018). It would be interesting to determine if these GECls can resolve light-evoked signaling in alpha-type ganglion cells.

There are advantages to having a majority of retinal ganglion cells phase advance, because this means that many ganglion cells convey the phase advanced response to higher order visual areas, potentially facilitating synchronized visual processing across these areas. A strong signal conveying an advanced motion stimulus gives an organism more time to respond. In the case of evading danger, prey capture or even navigation, many neurons with concurrent timing of output signals would enhance the animal's response and increases survival. 


\section{CHAPTER III \\ MOTION COMPENSATION IN SYNAPTIC INPUTS TO ALPHA-TYPE \\ GANGLION CELLS IN THE MOUSE RETINA}

\section{Introduction}

The fluorescence imaging experiments of Chapter II established that phase advancing is a response property that is common to multiple ganglion cell types. For each of these cell types the measured, stimulus-evoked response was the culmination of interacting excitatory and inhibitory synaptic input. The goal of the experiments described in this chapter was to assess the potential contribution of excitatory and inhibitory mechanisms to the observed phase advancing. I measured for a subset of identified, phaseadvancing ganglion cell types the relative timing of excitation and inhibition, using the same stimulus paradigm as in the imaging experiments.

Each ganglion cell generates action potentials by integrating excitatory and inhibitory synaptic inputs from bipolar cells and amacrine cells across ganglion cell dendrites. While MEA recording can be used to measure action potentials from many ganglion cells, it cannot give information about the synaptic inputs that drove them (Meister, Pine, \& Baylor, 1994). Whole-cell voltage-clamp electrophysiology, on the other hand separates and measures the underlying excitatory and inhibitory synaptic inputs to an individual ganglion cell.

Integration of excitatory and inhibitory input is the basis for signal processing at the neuronal level and takes place in various forms in cell types throughout the retina. Early work showed that retinal ganglion cells may integrate spatial features of a stimulus 
predominantly linearly or nonlinearly (Enroth-Cugell \& Robson, 1966a; Gollisch, 2013; Schwartz et al., 2012). This distinction was first made in cat, where ganglion cells were functionally classified as linear (X-cells) or nonlinear (Y-cells) (Enroth-Cugell \& Robson, 1966b). Homologues to these cell types were soon found also among the ganglion cell populations in other species, including salamander (Smirnakis, Berry, Warland, Bialek, \& Meister, 1997), rabbit (Famiglietti, 2004), mouse (Kuo et al., 2016; Stone \& Pinto, 1993), and primate (Benardete \& Kaplan, 1997).

In the mouse retina, Y-type cells also are referred to as alpha type ganglion cells (alpha cells). Alpha cells have large dendritic fields $(250-300 \mu \mathrm{m})$ and thick axons that offer rapid signal transmission to downstream brain regions. The mouse retina contains four recognized alpha cell subtypes: OFF-sustained, OFF-transient, ON-sustained, and ON-transient (Krieger et al., 2017). ON-alpha type ganglion cells have been shown to be more nonlinear than OFF-alpha type ganglion cells (Borghuis, Marvin, Looger, \& Demb, 2013; Roska \& Werblin, 2001). With regards to motion stimuli and nonlinear integration, ON-sustained ganglion cells integrate a network of electrically coupled inputs to increase sensitivity to moving stimuli (Kuo et al., 2016). The model Kuo et al. (2016) presented supports the hypothesis that nonlinear responses of ON-sustained ganglion cells are due to nonlinear integration at the level of presynaptic bipolar cells.

Johnston and Lagnado (2015) used whole-cell voltage-clamp recordings in goldfish retina to rule out excitatory inputs as responsible for phase advancing and found inhibition dominates. The goal for the experiments described here was to directly test whether this also occurs in the mouse retina. To do this I measured the relative timing of excitatory and inhibitory synaptic inputs to alpha ganglion cells as well as to parse out the potential contributions of excitatory and inhibitory inputs to phase advancing. Using pharmacological blockers of inhibitory receptors, I can isolate the retinal excitatory pathways and by comparing to the intact response determine the role of inhibition in 
phase advancing. Previous studies have demonstrated that a nonlinear feedback loop contribute to phase advancing (Berry et al., 1999; Leonardo \& Meister, 2013), I ask how can a linear model account for the phase advanced response to a spot moving into a cell's receptive field?

\section{Methods}

\section{Tissue Preparation}

All animal procedures were approved by the Institutional Animal Care and Use Committee at the University of Louisville and were in compliance with National Institutes of Health guidelines. I recorded visually evoked calcium responses in whole-mount retina from two lines of Thy1-GCaMP6f-WPRE transgenic mice: GP5.17 (Jackson Laboratory \#025393) and GP5.11 (Jackson Laboratory \#024339). To specifically label the four alpha-type ganglion cells with the enhanced yellow fluorescent protein (EYFP) I crossed the KCNG4-cre (Krieger et al., 2017) and Ai3-EYFP reporter strain.

Heterozygous adult mice (aged $2-6$ months) of either sex were dark adapted under dim red light for $\sim 30$ minutes. Retinas were harvested for recording as described in the General Methods section.

\section{Electrophysiology}

I targeted both ON and OFF alpha-type ganglion cells for whole-cell electrophysiological recordings. Due to the stochastic expression pattern of GCaMP6f in the Thy 1 animals, I recorded from cells based on soma size (>20 $\mu$ m diameter), not GCaMP6f expression. In the KCNG-cre $x$ Ai3-EYFP mice I used two-photon fluorescent imaging to target large soma ganglion cells that were labeled with EYFP and have been demonstrated to be the four alpha-type cells previously (Krieger et al., 2017). 
Borosilicate glass microelectrodes were filled with intracellular solution containing (in mM): 120 Cs-methanesulfonate, 5 TEA-Cl, 10 HEPES, 10 BAPTA, $3 \mathrm{NaCl}, 2 \mathrm{QX}$ 314-Cl, 4 ATP-Mg, 0.4 GTP-Na2, and 10 phosphocreatine-Tris2 (pH 7.3, 280 mOsm), and red fluorescent dye (Sulforhodamine 101). Voltage clamp recordings of ganglion cells were performed at the reversal potential for chloride and cations, respectively -67 $m V$ and $+15 \mathrm{mV}$. Recording in current clamp mode $(\mathrm{l}=0 \mathrm{nA})$ permits measurements of the membrane potential of the cell. Cs-based solution suppressed potassium channel activity, which helped optimize voltage clamp recordings. Cs likely also altered the resting potential and amplitude of the recorded membrane voltage response but, important for my study, was not expected to substantially alter the timing of the stimulus evoked response. The sweep stimulus as described in the General Methods was presented at the three recording configurations, $\mathrm{E}_{\mathrm{Cl}}, \mathrm{E}_{\mathrm{cat}}$, and $\mathrm{I}=0$. In all cases, post-hoc assessment of dendritic morphology of the recorded cell confirmed my initial alpha cell type classification.

I tested how inhibitory amacrine cell inputs contribute to phase advancing in ganglion cells by selectively blocking glycine receptors with $1 \mu \mathrm{M}$ strychnine (Tocris), GABA $_{A}$ receptors with $10 \mu \mathrm{M}$ gabazine (SR95531; Tocris). I also tested for a role of presynaptic inhibition by blocking $\mathrm{GABA}_{c}$ receptors with $50 \mu \mathrm{M}$ TPMPA (Tocris) and evaluated the impact on timing of excitatory responses to flashed and moving stimuli. $G A B A_{A}$ receptors are found on ganglion cell dendrites. $G A B A_{C}$ receptors have been found predominantly expressed on bipolar cell terminals (Eggers \& Lukasiewicz, 2006). Glycinergic receptors have been found on OFF bipolar cell terminals and ganglion cell dendrites, as well as amacrine cell dendrites (Nobles, Zhang, Müller, Betz, \& McCall, 2012).

Spatiotemporal filter and model simulations 
I used response-triggered averaging to calculate the spatial and temporal receptive fields for the recorded ganglion cells (Chichilnisky, 2001; Sakai, 1992). To collect ganglion cell spatiotemporal filters, a 700 x $700 \mu \mathrm{m}$ white noise checkerboard with randomly flickering $\sim 22 \times 22 \mu \mathrm{m}$ patches of either $+100 \%$ or $-100 \%$ contrasts were presented at each frame for 5000 video frames ( 3 minutes). For membrane voltage and voltage clamp recordings, reverse correlation analysis was performed using custom Matlab algorithms to acquire the ganglion cell's spatiotemporal filters.

To model changes in ganglion cell synaptic input and membrane voltage, I crossmultiplied the stimulus with a Gaussian fit of the measured ganglion cell's spatial receptive field. Then, I convolved this product with the ganglion cell's measured temporal filter. This product gives the linear prediction of the ganglion cell's response to the flashed or moving stimulus (Figure 25). I normalized the experimental and modeled responses using Equation 2.

$$
\frac{x-\bar{x}}{\sigma}
$$

Where $x$ is the response, $\bar{x}$ is the mean of the response and $\sigma$ is the standard deviation. Paired t-test results are presented as mean difference \pm SEM.

\section{Results}

Excitatory and inhibitory synaptic inputs to OFF-alpha ganglion cells phase advance My first objective was to assess phase advancing of synaptic currents in OFF-alpha ganglion cells using whole-cell voltage clamp recording. I recorded excitatory synaptic inputs to OFF-type ganglion cells while presenting light decrement spots $(\sim 220 \mu \mathrm{m}$ diameter). The flashed spot ( $80 \mathrm{~ms}$ presentation) evoked a large transient downward deflection (400-600 pA), as shown in Figure 13A, right. Referred to as inward current, this downward deflection represents stimulus-evoked excitatory current; its origin is 
synaptically released glutamate from the bipolar cells. The moving $\left(1340 \mu \mathrm{m}^{*} \mathrm{~s}^{-1}\right)$ light decrement spots similarly evoked inward current but this current was more sustained, likely because the spot was present over the ganglion cell's receptive field longer. The example OFF-alpha ganglion cell in Figure 13A had an osPA value of $228 \mathrm{~ms}$ and a ttpPA value of $36 \mathrm{~ms}$
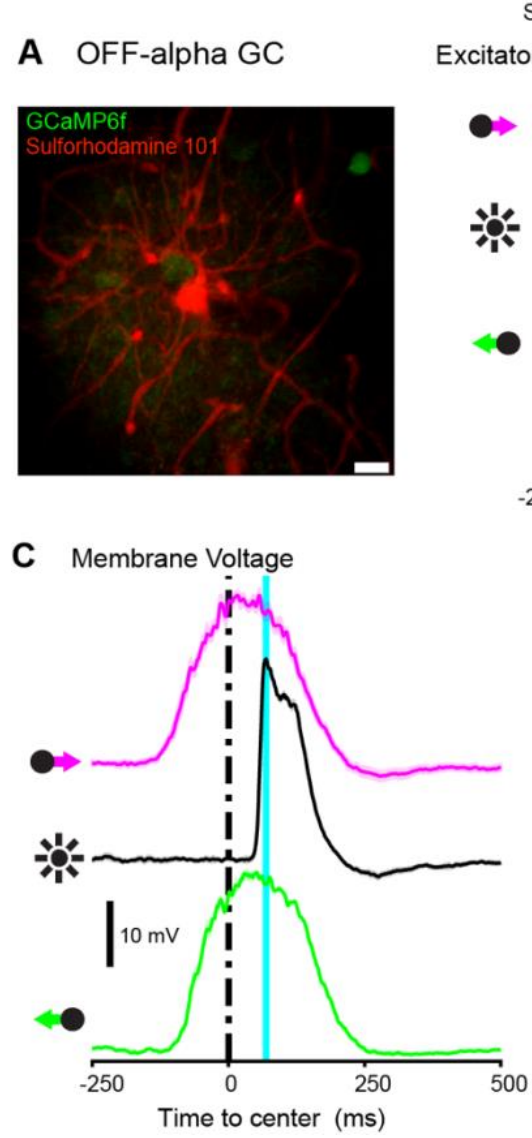
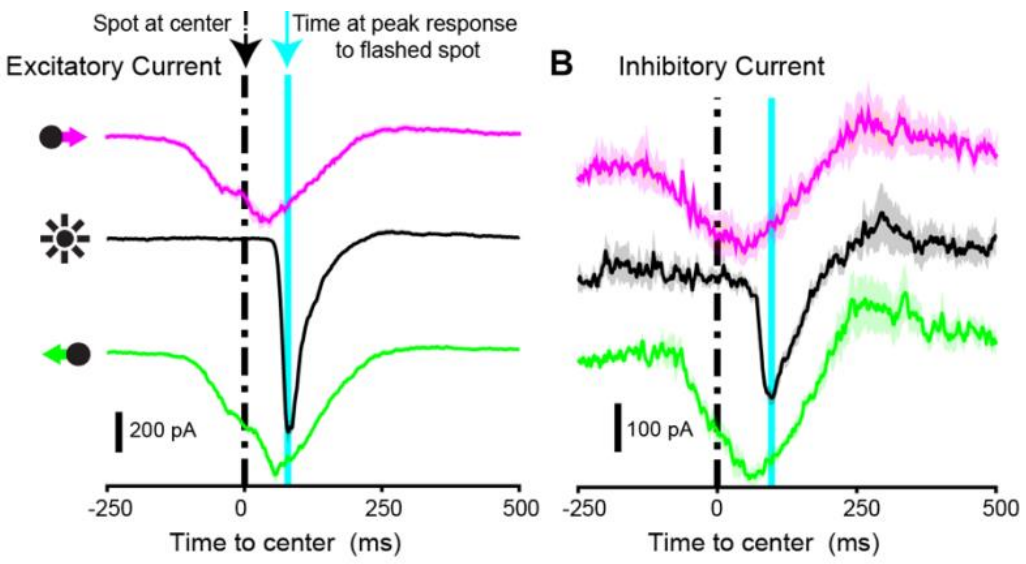

Figure 13. Example of phase advancing OFF-alpha ganglion cell electrophysiological recordings. A, two-photon micrograph of sulforhodamine 101 (red) filled ganglion cell, Scale bar, $20 \mu \mathrm{m}$. B, Light-evoked excitatory $\left(\mathrm{V}_{\text {hold }}=-67 \mathrm{mV}\right)$ responses to rightward (magenta line) and leftward (green line) moving spots and stationary flashed spot (black line). C, same as in $\mathrm{B}$ but for light-evoked inhibitory $\left(\mathrm{V}_{\text {hold }}=15 \mathrm{mV}\right)$ responses. D, Same as in B and C but for changes in membrane voltage $(\mathrm{l}=0 \mathrm{pA})$. Moving spot speed $=1340 \mu \mathrm{m}^{*} \mathrm{~s}^{-1}$; Shaded area represents \pm SEM.

The population of recorded OFF-alpha ganglion cells had a mean osPA value of $187 \pm 7.9 \mathrm{~ms}$ ( $\mathrm{n}=45$ cells) and a ttpPA value of $42 \pm 2.4 \mathrm{~ms}$ ( $\mathrm{n}=47$ cells) when stimulated with a faster moving spot $\left(1340 \mu \mathrm{m}^{*} \mathrm{~s}^{-1}\right.$; Figure $\left.14 \mathrm{~A}, \mathrm{~B}\right)$. From my population of recorded cells presented with slower moving spots $\left(670 \mu \mathrm{m}^{*} \mathrm{~s}^{-1}\right)$, OFF-alpha ganglion cells had mean ttpPA value of $78 \pm 4.4 \mathrm{~ms}$ ( $\mathrm{n}=71$ cells) and a mean osPA of $314 \pm 6.2 \mathrm{~ms}(\mathrm{n}=68$ cells). I observed a significant decrease in the excitatory osPA between the $670 \mu \mathrm{m}^{*} \mathrm{~s}^{-1}$ and $1340 \mu \mathrm{m}^{*} \mathrm{~s}^{-1}$ moving spots $(314 \pm 6.2 \mathrm{~ms}$ vs $187 \pm 7.9 \mathrm{~ms}, \mathrm{t}=12.77, \mathrm{p}<0.0001$; Figure 
14). The decreased speed of moving spots also significantly increased the ttpPA when

recording OFF-alpha excitatory synaptic inputs $78 \pm 4.4 \mathrm{~ms}$ vs $42 \pm 2.4 \mathrm{~ms}, \mathrm{t}=6.17$, $\mathrm{p}<0.0001$; Figure 14).

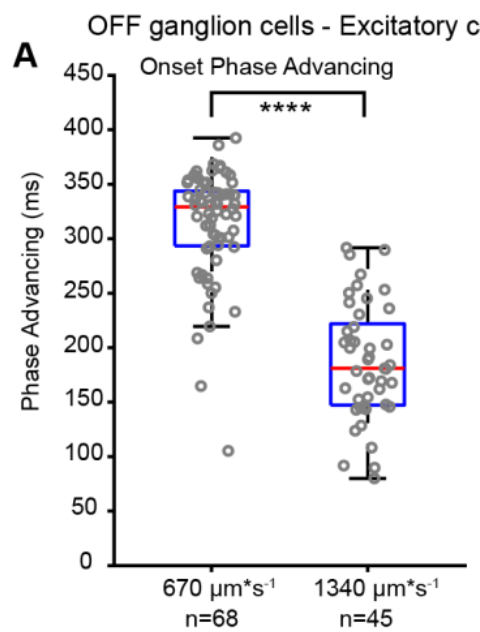

C Inhibitory currents

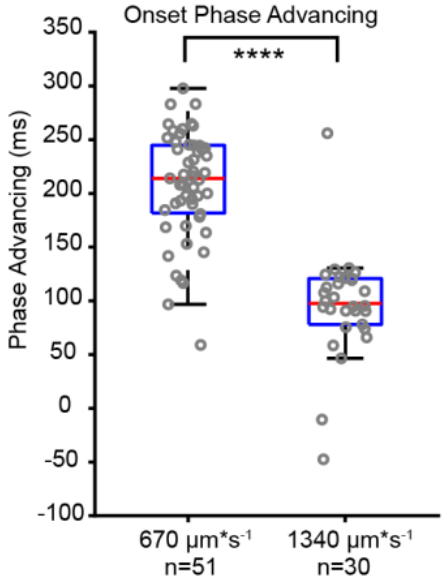

E Membrane voltage response

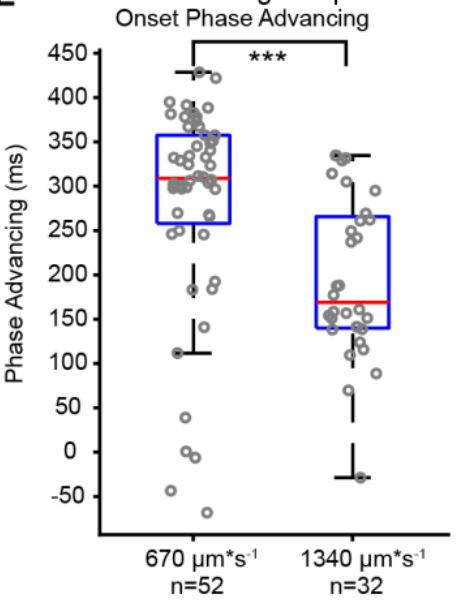

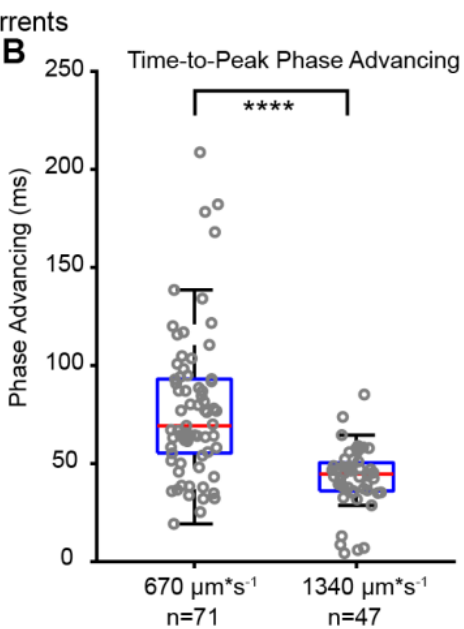

D
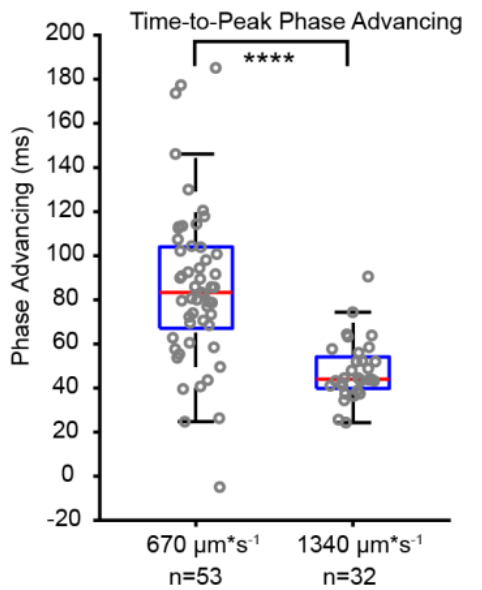

$\mathbf{F}$

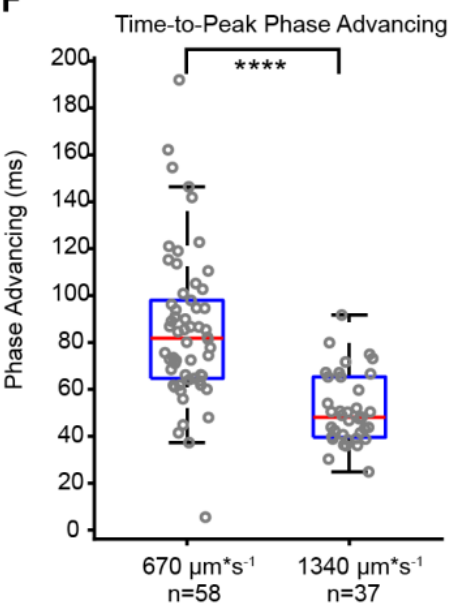

Figure 14. Population plots of phase advancing values from OFF-alpha ganglion cells. A, Onset phase advancing values for spots moving at two speeds $\left(670 \mu \mathrm{m}^{*} \mathrm{~s}^{-1} \mathrm{vs}\right.$ $\left.1340 \mu \mathrm{m}^{*} \mathrm{~s}^{-1}\right)$. Central red line is the median, the top and bottom edges of the box (blue) represent the 25th and 75th percentiles, respectively. B, Same as A but for time-to-peak phase advancing values. C, Same as $A$ but for onset phase advancing values from inhibitory current recordings. D, Same as $C$ but for time-to-peak phase advancing values. E, Same as A but for onset phase advancing values from membrane voltage recordings. $\mathbf{F}$, Same as $E$ but for time-to-peak phase advancing values. The gray circles are the individual datapoints. (Unpaired t-test, $\mathrm{p}<0.05$ ).

Next, I isolated

inhibitory synaptic inputs by voltage clamp of the ganglion cell at $+15 \mathrm{mV}$ and evaluated phase advancing. The inhibitory input to the OFFtype ganglion cells also show an inward current when stimulated with the light decrement spot (Figure 14C, 
D). Known as dis-inhibition, loss of inhibition during stimulation with the preferred stimulus (i.e., a dark spot) is characteristic of OFF-alpha ganglion cells as these cells receive tonic inhibition from amacrine cells. When stimulated with a light decrement, tonic inhibitory input to the ganglion cell is decreased and less chloride ions enter the cell (Manookin, Beaudoin, Ernst, Flagel, \& Demb, 2008; Van Wyk et al., 2009).

When the moving spot leaves the excitatory receptive field the gray background acts as a light increment and causes an increase of inhibitory input to the ganglion cell (Figure 13B). When recording inhibitory synaptic input, the example cell in Figure 13B had an osPA value of $130 \mathrm{~ms}$ and a ttpPA value of $45 \mathrm{~ms}$. When stimulated with faster moving spots the mean osPA of the OFF-alpha ganglion cells was $96 \pm 9 \mathrm{~ms}$ ( $\mathrm{n}=30$ cells) and the mean ttpPA was $48 \pm 2.4 \mathrm{~ms}$ ( $\mathrm{n}=32$ cells). The ganglion cells that I recorded inhibitory synaptic inputs from while stimulating with slower moving spots, had a mean osPA of $208 \pm 7.1 \mathrm{~ms}$ ( $\mathrm{n}=51$ cells) and mean ttpPA of $86 \pm 5 \mathrm{~ms}$ ( $\mathrm{n}=53$ cells). There was a significant decrease in the osPA when stimulating with faster moving spots compared to the slower moving stimuli (208 $\pm 7.1 \mathrm{~ms}$ vs $96 \pm 9 \mathrm{~ms}, \mathrm{t}=9.67, \mathrm{p}<0.0001$; Figure 14C). Likewise, I observed a significant decrease in the ttpPA when stimulating with the faster moving spot ( $86 \pm 5 \mathrm{~ms}$ vs $48 \pm 2.4 \mathrm{~ms}, \mathrm{t}=5.76, p<0.0001$; Figure 14D). This indicates that the magnitude of phase advancing does not scale with increased stimulus velocity similar to what Berry et al. (1999) found.

Next, to verify that the integration of synaptic inputs to the ganglion cell results in phase advancing, I recorded in current clamp mode $(\mathrm{I}=0 \mathrm{pA})$ to measure the changes in membrane voltage. The intracellular pipette solution contained sodium and potassium channel blockers (2 mM QX-314-Cl and 120 mM Cs-methanesulfonate, respectively), which eliminated action potentials and voltage gated potassium conductances. The example OFF-alpha ganglion cell (Figure 13C) had a ttpPA value of $15 \mathrm{~ms}$ and osPA of $155 \mathrm{~ms}$. The osPA recorded at the two speeds $\left(670 \mu \mathrm{m}^{*} \mathrm{~s}^{-1} \mathrm{vs} 1340 \mu \mathrm{m}^{*} \mathrm{~s}^{-1}\right)$ were 
significantly different ( $282 \pm 16.4 \mathrm{~ms}$ vs $197 \pm 15.9 \mathrm{~ms}, \mathrm{t}=3.49, \mathrm{p}=0.0008$; Figure 14E). The ttpPA values also significantly decreased when stimulated with faster moving spots compared to the slower moving spots $(86 \pm 4.2 \mathrm{~ms}$ vs $51 \pm 2.5 \mathrm{~ms}, \mathrm{t}=6.09, \mathrm{p}<0.0001$; Figure 14F).

The experimental data obtained from mouse alpha-type ganglion cells is consistent with what was shown previously in salamander fast OFF ganglion cells. Phase advancing is common to large soma light decrement preferring cells (Berry et al., 1999; Leonardo \& Meister, 2013). Next, I tested whether phase advancing synaptic currents were common also to $\mathrm{ON}$-alpha ganglion cells.

\section{Excitatory and inhibitory synaptic inputs to $\mathrm{ON}$-alpha ganglion cells phase advance}

In the ganglion cell layer, ON and OFF-type alpha ganglion cells can be distinguished based on soma shape. ON-alpha cells generally have a more angular shaped soma compared with OFF-alpha cells. This is explained by the stratification depth of the $\mathrm{ON}$-alpha ganglion cell dendrites, which is more proximal to the ganglion cell layer in sublamina $b$ of the IPL. This shallower stratification depth causes the ONalpha cell dendrites to extend from the soma outward. OFF-alpha ganglion cells, in the other hand, stratify deeper into sublamina $a$, which results in a more circular soma at the level of the ganglion cell layer.

ON-alpha ganglion cells have been shown to have stronger nonlinear inputs to the receptive field than OFF-alpha ganglion cells (Schwartz et al., 2012). These inputs or subunits summate contrast changes and rectify the the light inputs giving ganglion cells increase contrast sensitivity to fine spatial features (Jonathan B. Demb, Loren Haarsma, Michael A. Freed, \& Peter Sterling, 1999; Turner, Schwartz, \& Rieke, 2018). Since it is not known if and/or how increased nonlinear interactions in $\mathrm{ON}$-alpha ganglion cells contribute to phase advancing output, I tested this question. Recording excitatory 
synaptic input in voltage clamp mode, a light increment spot evoked a large depolarization of around $150-250$ pA (Figure 15A, right). The example ganglion cell shown in Figure 15A is representative for the recorded population and had a ttPA value of $30 \mathrm{~ms}$ and an osPA value of $98 \mathrm{~ms}$.

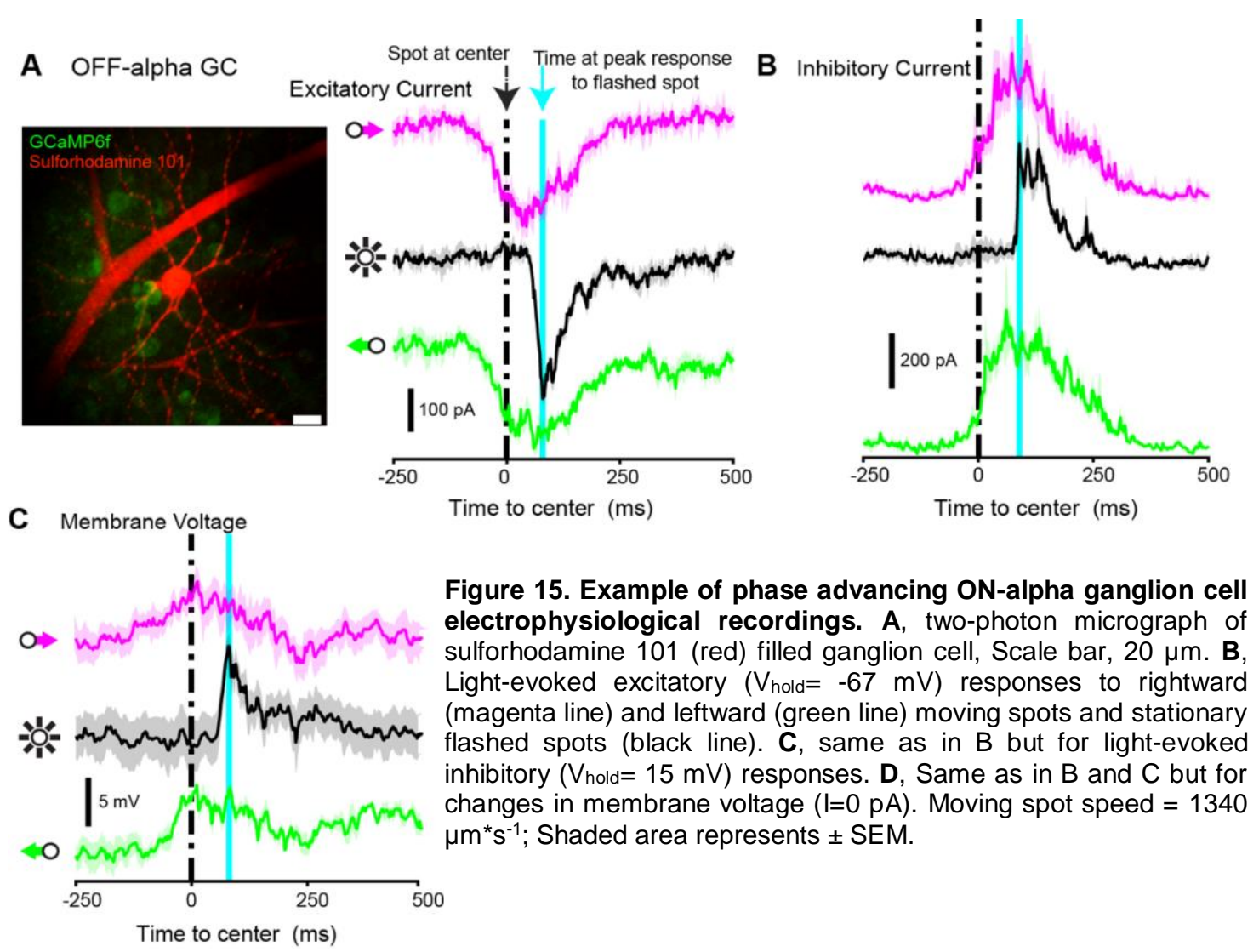

At spot velocity of $1340 \mu \mathrm{m}^{*} \mathrm{~s}^{-1}$ the sweep stimulus elicited a mean osPA of $105 \pm$ $10.7 \mathrm{~ms}$ ( $\mathrm{n}=40$ cells) and a mean ttpPA of $49 \pm 5 \mathrm{~ms}$ from ( $\mathrm{n}=41$ cells) ON-alpha ganglion cells, respectively (Figure 16A, B). Under the slower moving spot conditions $\left(670 \mu \mathrm{m}^{*} \mathrm{~s}^{-1}\right)$, I recorded phase advancing response $\mathrm{ON}$-alpha ganglion cells with a mean ttpPA of $99 \pm 4.8 \mathrm{~ms}$ ( $\mathrm{n}=58$ cells) and a mean osPA of $249 \pm 11 \mathrm{~ms}$ ( $\mathrm{n}=56$ cells). Similar to what was observed in OFF-alpha cells, there was a significant decrease in excitatory current osPAs and ttpPAs when stimulated with the faster moving spots compared to the slower moving spots (osPA: $249 \pm 11$ vs $105 \pm 10.7 \mathrm{~ms}, \mathrm{t}=9.07$, $p<0.0001$; ttpPA: $99 \pm 4.8$ vs $49 \pm 5$ ms, t=7.01, p<0.0001; Figure 16A, B). 

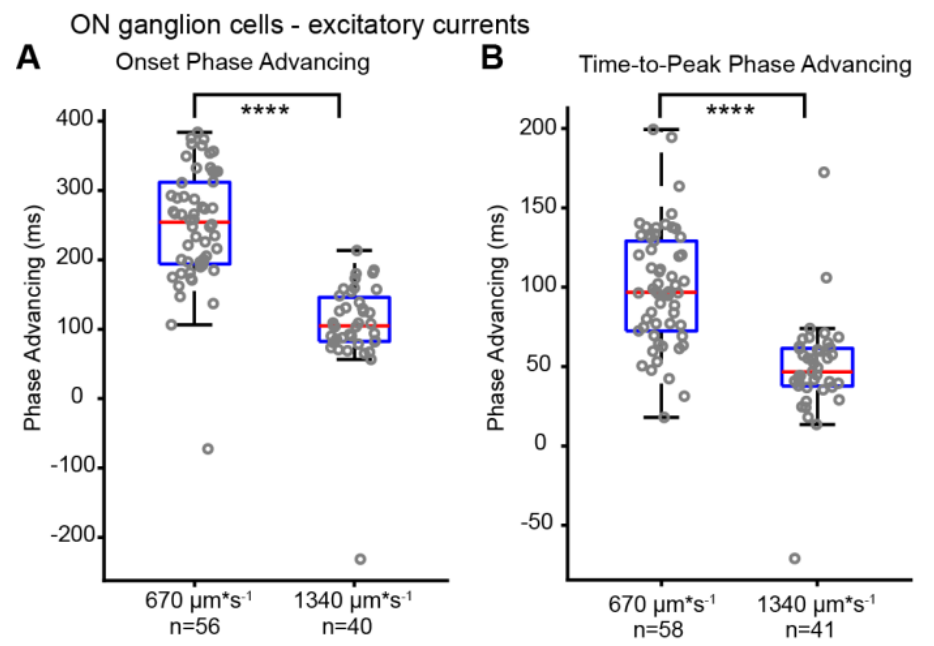

Figure 16. Population plots of phase advancing values from $\mathrm{ON}$ alpha ganglion cells. A, Onset phase advancing values for spots moving at two speeds $\left(670 \mu \mathrm{m}^{*} \mathrm{~s}^{-1}\right.$ vs $1340 \mu \mathrm{m}^{*} \mathrm{~s}^{-}$ $\left.{ }^{1}\right)$. Central red line is the median, the top and bottom edges of the box (blue) represent the 25th and 75th percentiles, respectively. B, Same as $A$ but for time-to-peak phase advancing values. C, Same as $\mathrm{A}$ but for onset phase advancing values from inhibitory current recordings. D, Same as $\mathrm{C}$ but for time-to-peak phase advancing values. E, Same as A but for onset phase advancing values from membrane voltage recordings. $\mathbf{F}$, Same as E but for time-to-peak phase

C Inhibitory currents

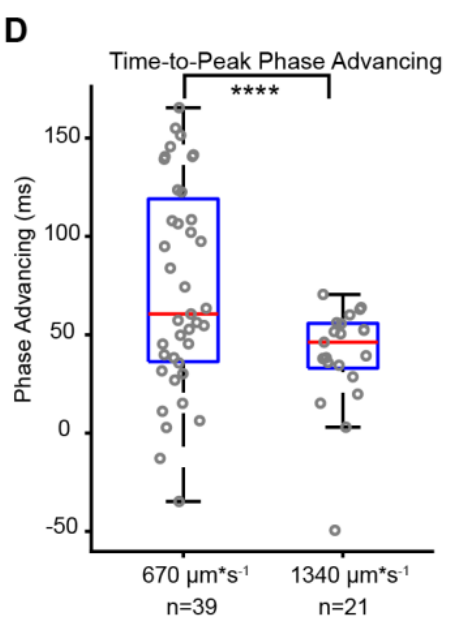
advancing values. The gray circles are the individual datapoints. (Unpaired t-

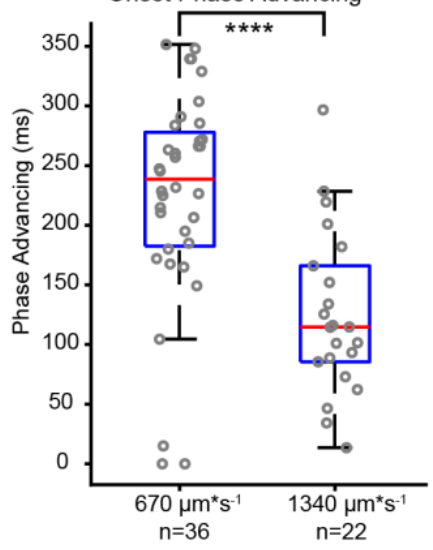

test, ${ }^{*} p<0.05$; ${ }^{* *} p<0.01$; ${ }^{* * *} p<0.001$; $* * * * p<0.0001)$.

E Membrane voltage response

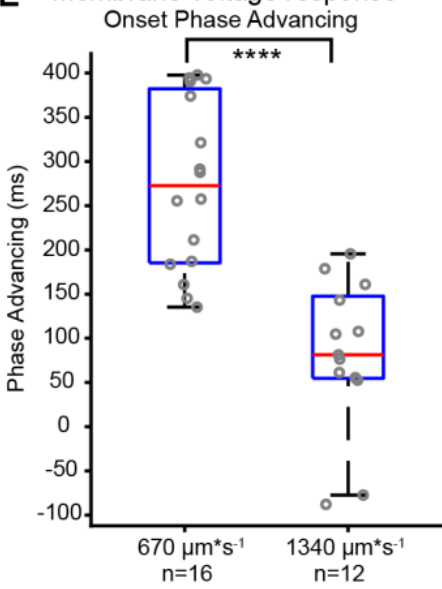

$\mathbf{F}$

Next, I investigated the

phase advancing response

during recording of inhibitory

synaptic inputs. The inhibitory

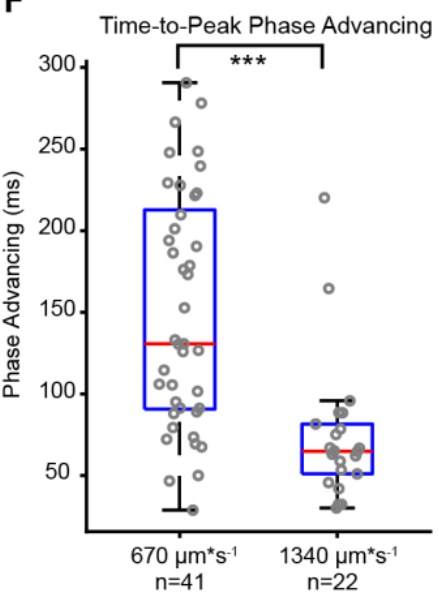

synaptic inputs to $\mathrm{ON}$-alpha

ganglion cells during light

increment stimulation show an

upward deflection (outward

current) as inhibitory chloride

ions move into the cell (Figure

15B). The stationary flashed

light increment spot evoked a large $(\sim 250 \mathrm{pA})$ transient increase of inhibitory current. As

the spot moved across the ganglion cell's receptive field there was a sustained increase of inhibition onto the cell figure 15B. 
I recorded inhibitory currents from ON-ganglion cells while stimulating with the faster moving spots $\left(1340 \mu \mathrm{m}^{*} \mathrm{~s}^{-1}\right)$. The example cell in Figure 17 had a ttPA value of 21 ms and an osPA value of $86 \mathrm{~ms}$. Figure 16C and D shows the population of recorded ON-alpha ganglion cells had a mean osPA of $125 \pm 17 \mathrm{~ms}$ ( $n=22$ cells) and mean ttpPA of $40 \pm 10.6 \mathrm{~ms}$ ( $\mathrm{n}=21$ cells). The inhibitory synaptic inputs to $\mathrm{ON}$-alpha ganglion cells had a mean ttpPA of $74 \pm 8.5 \mathrm{~ms}$ ( $\mathrm{n}=39$ cells) and a mean osPA of $225 \pm 14.9 \mathrm{~ms}(\mathrm{n}=36$ cells) when stimulating with the slower moving spots (Figure 16). There was a statistically significant decrease in inhibitory current osPAs and ttpPAs when stimulated with the faster moving spots compared to the slower moving spots (osPA: $225 \pm 14.9$ vs $125 \pm 14.8 \mathrm{~ms}, \mathrm{t}=9.07, \mathrm{p}<0.0001 ; \mathrm{ttpPA}: 74 \pm 8.5$ vs $39 \pm 5.8 \mathrm{~ms}, \mathrm{t}=4.49, \mathrm{p}<0.0001$ Figure 16).

Membrane voltage recordings in $\mathrm{ON}$-alpha ganglion cells also demonstrated phase advancing as shown in the example cell in Figure 15C (osPA: 119 ms; ttpPA: 68). There was a significant difference between the phase advancing values when stimulating with the faster compared with slower moving spots (osPA: $274 \pm 24.1$ vs $76 \pm$ $25.4 \mathrm{~ms}, \mathrm{t}=5.59, \mathrm{p}<0.0001 ; \operatorname{ttpPA}: 150 \pm 11.2$ vs $82 \pm 9.24 \mathrm{~ms}, \mathrm{t}=3.83, \mathrm{p}=0.0003$; Figure $16 \mathrm{E}, \mathrm{F})$.

To summarize the data obtained with targeted whole-cell recordings from alphatype ganglion cells, I have demonstrated phase advancing in both excitatory and inhibitory synaptic inputs, in both ON and OFF-alpha ganglion cells. Having established a baseline in phase advancing values among these specific cell types, I proceeded to probe the underlying mechanisms using additional experimental approaches.

\section{Increased speed of visual stimuli decreases phase advancing}

Berry et al. (1999) showed that phase advancing in salamander and rabbit retinal ganglion cells depended on speed of the moving bar. Leonardo and Meister (2013) 
followed up with experiments in salamander which corroborated the decline in phase advancing with increased speed of moving visual stimuli. With the following experiments I set out to test whether there is a match between the stimulus-dependence of phase advancing in ON-alpha and OFF-alpha ganglion cells in my electrophysiological recordings and those reported in the published literature.

A OFF-alpha ganglion cell
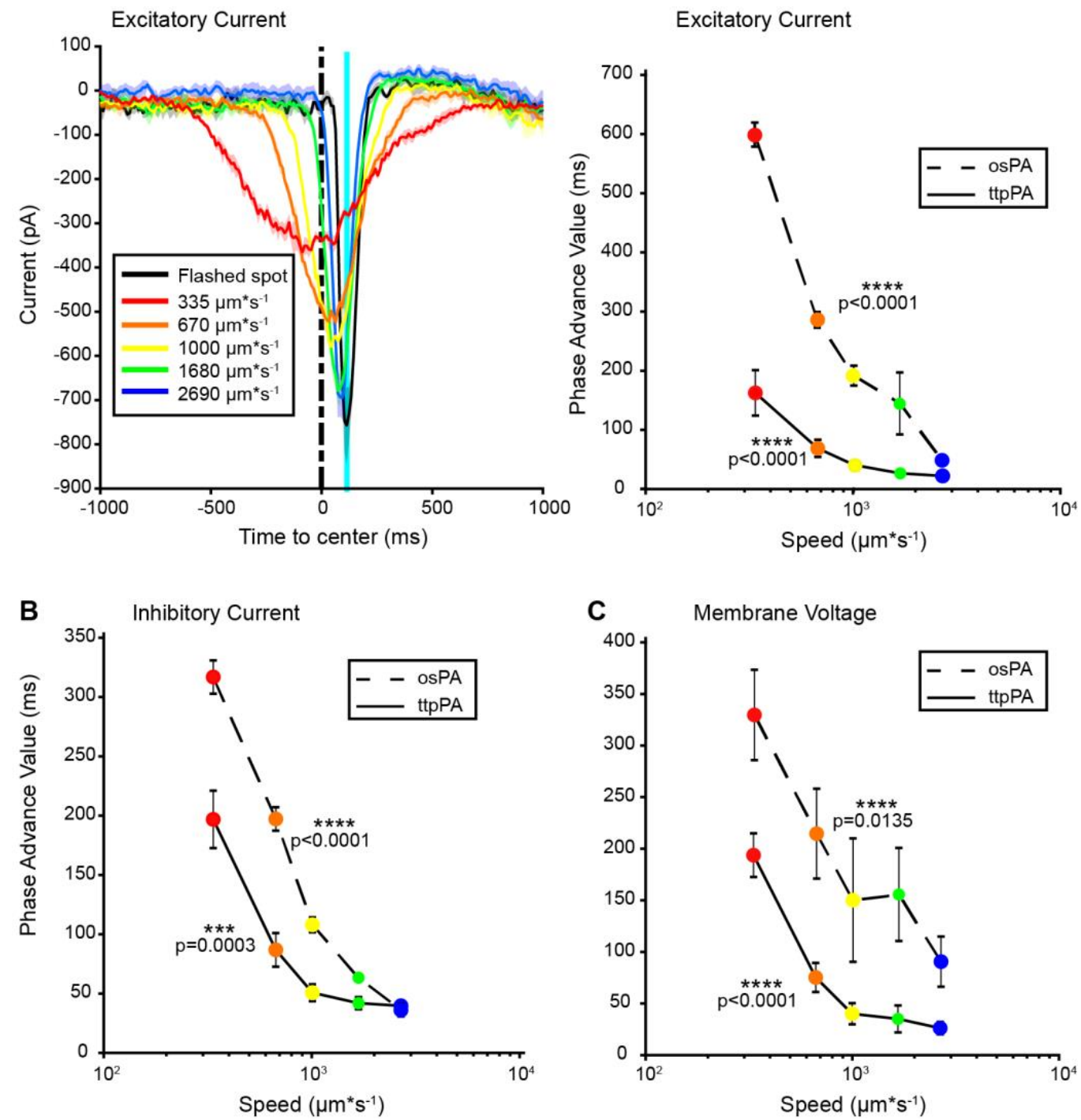

Figure 17. Magnitude of phase advancing depends on speed of visual stimuli in OFF-alpha ganglion cells. A, left, Example of light evoked responses from an OFF-alpha ganglion cell to spots moving at different speeds. Plotted are the averages of the left and right moving spots, shaded areas show $\pm S E M$. Black dashed line is when the spot was in the center of the frame and the cyan line is at the peak response to the flashed spot. Right, mean osPA (dashed line) and mean ttpPA (solid line) for light-evoked excitatory responses to spots moving at different speeds. B, same as in A but for lightevoked inhibitory responses. C, Same as in A and B but for light-evoked changes in membrane voltages. ns, not significant; ${ }^{*} p<0.05 ;{ }^{* *} p<0.01 ;{ }^{* \star *} p<0.001 ;{ }^{* \star * *} p<0.0001$. 
A ON-alpha ganglion cell
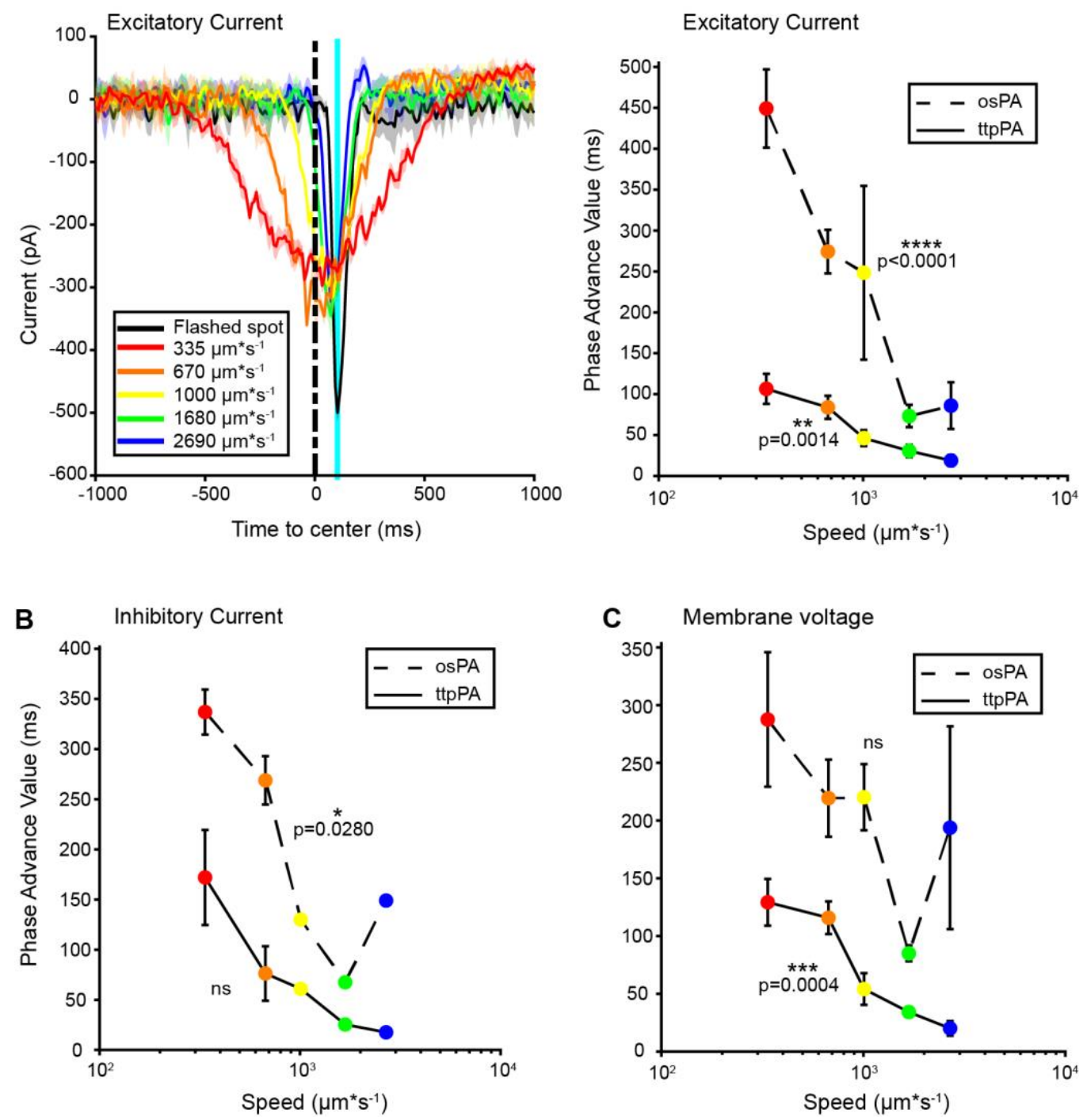

Figure 18. Magnitude of phase advancing depends on speed of visual stimuli in ON-alpha ganglion cells. A, left, Example of light evoked responses from an ON-alpha ganglion cell to spots moving at different speeds. Plotted are the averages of the left and right moving spots, shaded areas show \pm SEM. Black dashed line is when the spot was in the center of the frame and the cyan line is at the peak response to the flashed spot. Right, osPA (dashed line) and ttpPA (solid line) for light-evoked excitatory responses. B, same as in A but for inhibitory responses. C, Same as in A and B but for lightevoked changes in membrane voltages. ns, not significant; ${ }^{\star} p<0.05 ;{ }^{\star \star} p<0.01 ;{ }^{\star \star \star} p<0.001 ;{ }^{* \star \star}$ $\mathrm{p}<0.0001$.

Previous studies on phase advancing showed a dependence on stimulus

properties when measuring rate of action potentials (Berry et al., 1999; Johnston \&

Lagnado, 2015; Leonardo \& Meister, 2013). My goal was to test whether the

dependence of phase advancing on spot velocity is present at the level of the synaptic 
input. To test this, I presented linearly moving spots of fixed size at a range of velocities $\left(335,670,1000,1680\right.$, and $\left.2690 \mu \mathrm{m}^{*} \mathrm{~s}^{-1}\right)$.

A OFF ganglion cells - Gabazine application

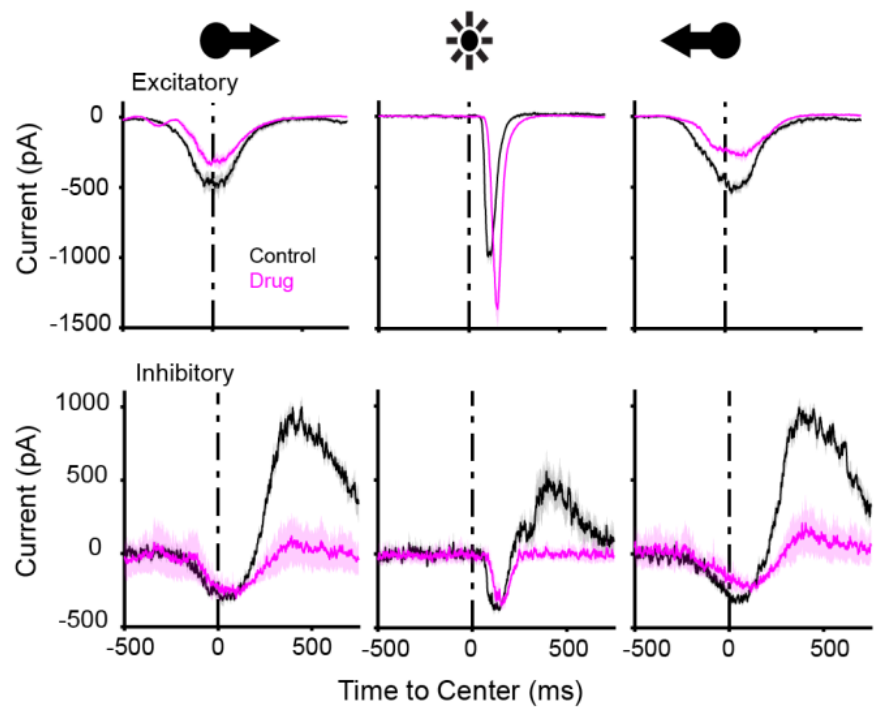

B Onset Phase Advancing
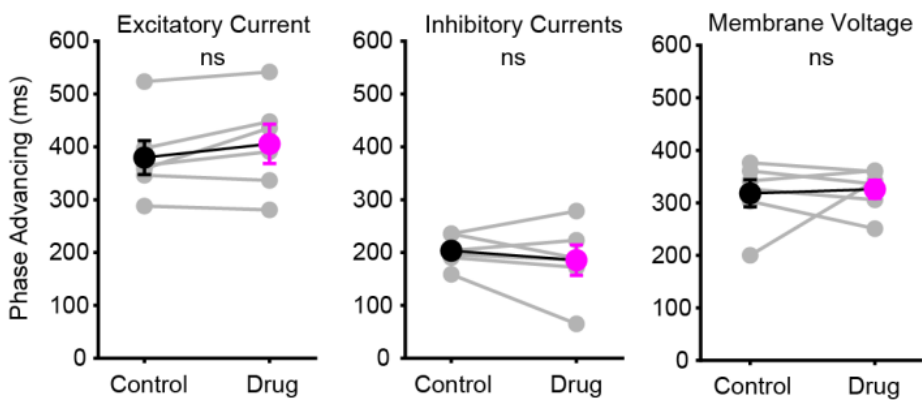

C Time-to-Peak Phase Advancing
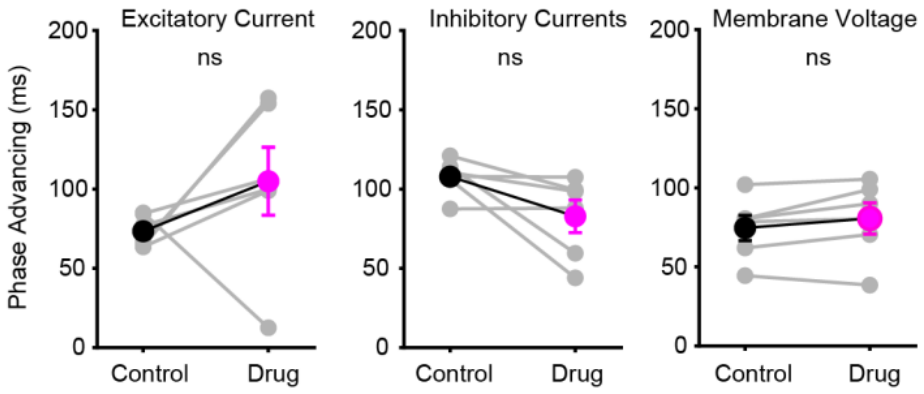

Figure 19. GABA receptor blockage in OFF-alpha ganglion cells. A, Top, Changes in excitatory synaptic inputs under control conditions (black) and during Gabazine $(10 \mu \mathrm{M})$ application (magenta). Bottom, Same as the top but for light-evoked inhibitory current recordings. Shaded area represents \pm SEM. B, left, onset phase advancing values in control and drug conditions during OFF ganglion cell excitatory current recordings $(n=6)$. Middle, osPA values for visually evoked inhibitory recordings in control and drug conditions $(n=5)$. Right, osPA values from recording changes in membrane voltages $(n=6)$. C, Same as B but for time-topeak phase advancing values (excitatory current, $n=5$; inhibitory current, $n=6$; membrane voltages, $\mathrm{n}=6$ ). Gray lines show individual cells, black and magenta points/error bars show summary mean \pm SEM, ns, not significant.

Figure 17 shows the changes in excitatory input to OFF-alpha ganglion cell to

various speeds of moving spots. Example excitatory synaptic inputs recorded from an OFF-alpha ganglion cell are shown in Figure 17A. At higher velocities phase advancing was not completely eliminated. One-way ANOVA analysis showed a significant decrease 
of osPA and ttpPA values for spots moving at higher speeds (Figure 17, $\mathrm{A} ; \mathrm{E}_{\mathrm{Cl}}$ : osPA, $\mathrm{F}$ $(4,29)=105, p<0.0001,\left(335 \mu m^{*} s^{-1}, n=8 ; 670 \mu m^{*} s^{-1}, n=8 ; 1000 \mu m^{*} s^{-1}, n=5 ; 1680 \mu m^{*} s^{-}\right.$ $\left.{ }^{1}, \mathrm{n}=5 ; 2690 \mu \mathrm{m}^{*} \mathrm{~s}^{-1}, \mathrm{n}=8\right) ; \operatorname{ttpPA}, \mathrm{F}(4,29)=7.6, \mathrm{p}=0.0003,\left(335 \mu \mathrm{m}^{*} \mathrm{~s}^{-1}, \mathrm{n}=8 ; 670 \mu \mathrm{m}^{*} \mathrm{~s}^{-1}\right.$, $\left.\mathrm{n}=8 ; 1000 \mu \mathrm{m}^{*} \mathrm{~s}^{-1}, \mathrm{n}=5 ; 1680 \mu \mathrm{m}^{*} \mathrm{~s}^{-1}, \mathrm{n}=5 ; 2690 \mu \mathrm{m}^{*} \mathrm{~s}^{-1}, \mathrm{n}=8\right) ; B, \mathrm{E}_{\text {cat }}:$ osPA, $\mathrm{F}$ $(4,11)=132, p<0.0001 ; \operatorname{ttpPA}, F(4,24)=19.5, p<0.0001,\left(335 \mu m^{*} s^{-1}, n=4 ; 670 \mu m^{*} s^{-1}\right.$, $\left.\mathrm{n}=4 ; 1000 \mu \mathrm{m}^{*} \mathrm{~s}^{-1}, \mathrm{n}=2 ; 1680 \mu \mathrm{m}^{*} \mathrm{~s}^{-1}, \mathrm{n}=2 ; 2690 \mu \mathrm{m}^{*} \mathrm{~s}^{-1}, \mathrm{n}=4\right) ; \mathrm{C}, \mathrm{l}=0$ : osPA, $\mathrm{F}(4,19)=4.2$, $\mathrm{p}=0.0135,\left(335 \mu \mathrm{m}^{*} \mathrm{~s}^{-1}, \mathrm{n}=47670 \mu \mathrm{m}^{*} \mathrm{~s}^{-1}, \mathrm{n}=7 ; 1000 \mu \mathrm{m}^{*} \mathrm{~s}^{-1}, \mathrm{n}=3 ; 1680 \mu \mathrm{m}^{*} \mathrm{~s}^{-1}, \mathrm{n}=3 ; 2690\right.$ $\left.\mu \mathrm{m}^{*} \mathrm{~s}^{-1}, \mathrm{n}=4\right)$; ttpPA, F $(4,23)=24.2, \mathrm{p}<0.0001,\left(335 \mu \mathrm{m}^{*} \mathrm{~s}^{-1}, \mathrm{n}=6 ; 670 \mu \mathrm{m}^{*} \mathrm{~s}^{-1}, \mathrm{n}=7 ; 1000\right.$ $\left.\left.\mu m^{*} s^{-1}, n=4 ; 1680 \mu m^{*} s^{-1}, n=4 ; 2690 \mu m^{*} s^{-1}, n=7\right)\right)$. Increased speeds showed a decrease in both the osPA and ttpPA during recording of changes in synaptic input to OFF-alpha ganglion cells.

I found a similar trend in the phase advancing values dependence on the speed of moving stimuli for ON-alpha ganglion cell (Figure 18). As the speed of the moving spots increased, the amount of phase advancing decreased for both the osPA and ttpPA. The results from the one-way ANOVA analysis are (Figure 18; $A, E_{C I}$ : osPA, $F$ $(4,26)=9.4, p<0.0001,\left(335 \mu m^{*} s^{-1}, n=10 ; 670 \mu m^{*} s^{-1}, n=6 ; 1000 \mu m^{*} s^{-1}, n=5 ; 1680 \mu m^{*} s\right.$ $\left.{ }^{1}, \mathrm{n}=5 ; 2690 \mu \mathrm{m}^{*} \mathrm{~s}^{-1}, \mathrm{n}=5\right) ; \operatorname{ttpPA}, \mathrm{F}(4,26)=6.0, \mathrm{p}=0.0014,\left(335 \mu \mathrm{m}^{*} \mathrm{~s}^{-1}, \mathrm{n}=4 ; 670 \mu \mathrm{m}^{*} \mathrm{~s}^{-1}\right.$, $\left.\mathrm{n}=4 ; 1000 \mu \mathrm{m}^{*} \mathrm{~s}^{-1}, \mathrm{n}=2 ; 1680 \mu \mathrm{m}^{*} \mathrm{~s}^{-1}, \mathrm{n}=2 ; 2690 \mu \mathrm{m}^{*} \mathrm{~s}^{-1}, \mathrm{n}=4\right) ; B, E_{\text {cat: }}$ osPA, $\mathrm{F}(4,4)=8.9$, $\mathrm{p}=0.0280,\left(335 \mu \mathrm{m}^{*} \mathrm{~s}^{-1}, \mathrm{n}=2 ; 670 \mu \mathrm{m}^{*} \mathrm{~s}^{-1}, \mathrm{n}=4 ; 1000 \mu \mathrm{m}^{*} \mathrm{~s}^{-1}, \mathrm{n}=1 ; 1680 \mu \mathrm{m}^{*} \mathrm{~s}^{-1}, \mathrm{n}=1 ; 2690\right.$ $\left.\mu m^{*} s^{-1}, n=1\right) ; \operatorname{ttpPA}, F(4,4)=1.8, p=0.290,\left(335 \mu m^{*} s^{-1}, n=2 ; 670 \mu m^{*} s^{-1}, n=4 ; 1000 \mu m^{*} s\right.$ $\left.{ }^{1}, \mathrm{n}=1 ; 1680 \mu \mathrm{m}^{*} \mathrm{~s}^{-1}, \mathrm{n}=1 ; 2690 \mu \mathrm{m}^{*} \mathrm{~s}^{-1}, \mathrm{n}=1\right) ; \mathrm{C}, \mathrm{l}=0$ : osPA, $\mathrm{F}(4,16)=1.5, \mathrm{p}=0.260,(335$ $\left.\mu m^{*} s^{-1}, n=8 ; 670 \mu m^{*} s^{-1}, n=4 ; 1000 \mu m^{*} s^{-1}, n=3 ; 1680 \mu m^{*} s^{-1}, n=3 ; 2690 \mu m^{*} s^{-1}, n=3\right)$; ttpPA, $F(4,19)=8.4, p=0.0004,\left(335 \mu m^{*} s^{-1}, n=8 ; 670 \mu m^{*} s^{-1}, n=4 ; 1000 \mu m^{*} s^{-1}, n=4\right.$; $\left.1680 \mu \mathrm{m}^{*} \mathrm{~s}^{-1}, \mathrm{n}=4 ; 2690 \mu \mathrm{m}^{*} \mathrm{~s}^{-1}, \mathrm{n}=4\right) ;$ ). I did observe an increase in the mean osPA value in response to the fastest moving spot $\left(2690 \mu \mathrm{m}^{*} \mathrm{~s}^{-1}\right)$ but I believe that to be an artifact due to the low number of responsive cells ( $\mathrm{n}=1$ cell). 
A OFF ganglion cells - TPMPA application
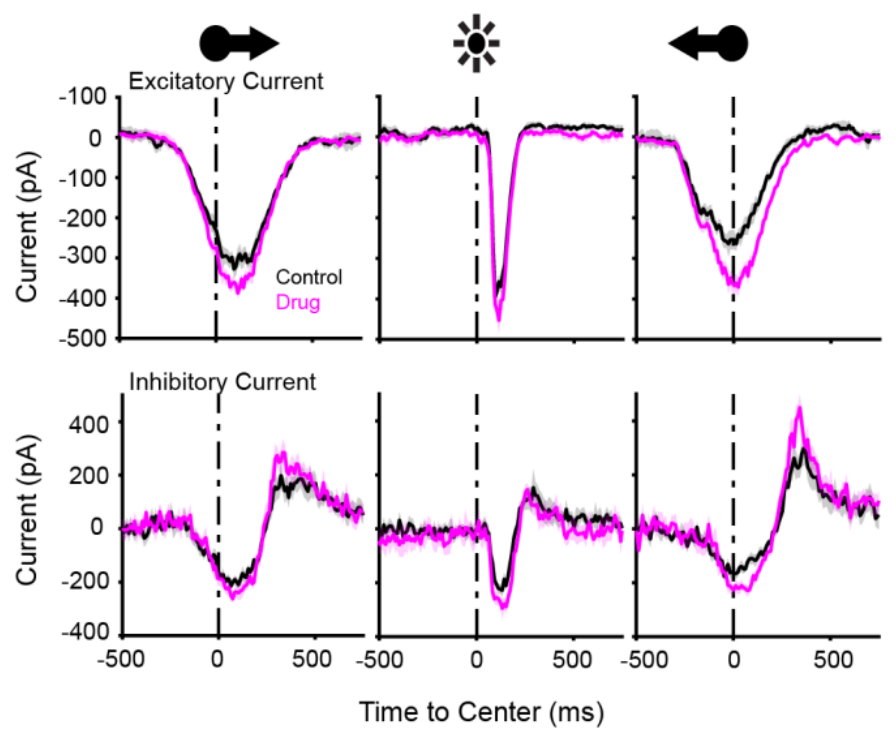

B Onset Phase Advancing
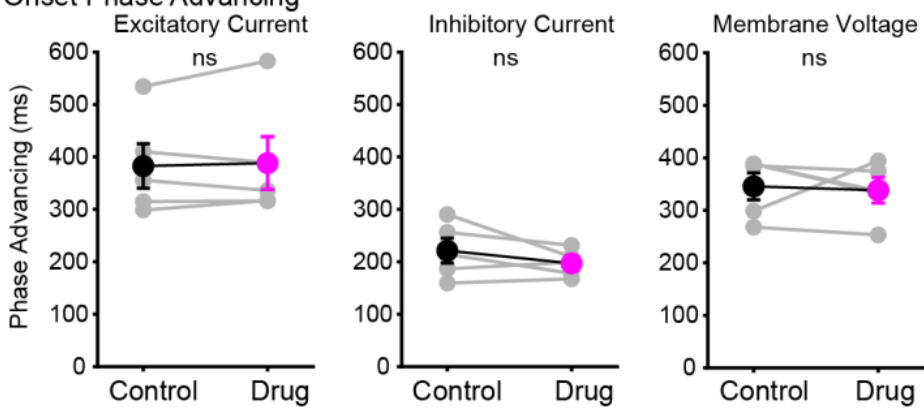

C Time-to-Peak Phase Advancing
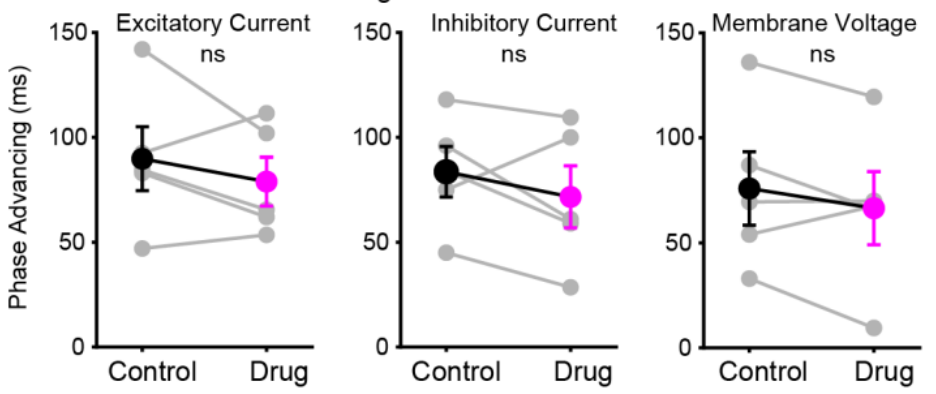

Figure 20. GABAc receptor blockage in OFF-alpha ganglion cells.A, Top, Changes in excitatory synaptic inputs under control conditions (black) and during TPMPA $(50 \quad \mu \mathrm{M})$ application (magenta). Bottom, Same as the top but for light-evoked inhibitory current recordings. Shaded area represents \pm SEM. B, left, onset phase advancing values in control and drug conditions during OFF ganglion cell excitatory current recordings $(n=5)$. Middle, osPA values for visually evoked inhibitory recordings in control and drug conditions $(n=5)$. Right, osPA values from recording changes in membrane voltages $(n=4)$. C, Same as B but for time-topeak phase advancing values (excitatory current, $\mathrm{n}=5$; inhibitory current, $n=5$; membrane voltages, $n=5)$. Gray lines show individual cells, black and magenta points/error bars show summary mean \pm SEM, ns, not significant.

Blocking inhibitory circuits in OFF-alpha ganglion cells

Inhibition plays a

fundamental role in shaping

the neuronal output of the

retina (Cook \& McReynolds, 1998; Demb \& Singer, 2015;

Werblin, 2010). As early as

the first synapse between photoreceptors and bipolar cells, horizontal cells create and modulate the ganglion cell's receptive field inhibitory surround (Drinnenberg et al., 2018; Mangel, 1991). Inhibitory amacrine cells distributed throughout the inner nuclear layer, IPL, and GCL synapse onto bipolar cells and ganglion cell dendrites. Particularly, in $\mathrm{Y}$ type ganglion cells in the cat or alpha-type ganglion cells in the rabbit and mouse, 
inhibition is responsible for the nonlinear response to a contrast reverse grating (J. B. Demb, L. Haarsma, M. A. Freed, \& P. Sterling, 1999).

Based on whole-cell recordings from goldfish retinal ganglion cells, Johnston and Lagnado (2015) proposed that a feedforward inhibitory circuit was responsible for phase advancing in this species. This was based on experiments where phase advancing was eliminated after the chloride concentration in the intracellular solution of individual cells was increased, thus disabling inhibition local to the recorded cell. Ganglion cell inhibition is driven by chloride ions entering the cell after receptors are activated by inhibitory neurotransmitters GABA and glycine. The pharmacological blockers ( $1 \mu \mathrm{M}$ strychnine, $10 \mu \mathrm{M}$ gabazine, $50 \mu \mathrm{M}$ TPMPA) I used were selective antagonists to inhibitory receptors in the retina. Pharmacological blocker application procedure was the same for all three drugs. Each drug was bath applied with oxygenated Ames solution for three minutes before presentation of the stimulus and electrophysiological recording.

$\mathrm{GABA}_{\mathrm{A}}$ receptors are localized to the dendrites of ganglion cells (Yang, 2004). Using a loss-of-function approach, selectively blocking $\mathrm{GABA}_{\mathrm{A}}$ receptors with gabazine will identify the role of $\mathrm{GABA}_{\mathrm{A}}$ receptor-mediated inhibition in phase advancing. The current traces in Figure 19 shows the excitatory (A, top) and inhibitory (A, bottom) current responses recorded from an OFF-alpha ganglion cell before (black traces) and during $10 \mu \mathrm{M}$ gabazine treatment (magenta traces). Drug application significantly decreased the excitatory response amplitude to moving spots but did not significantly change the response amplitude to the flashed spot. When recording inhibitory synaptic input during gabazine application, I observed a decrease in response amplitude after removal of the dark spot. This demonstrates that GABAergic inhibition mediates suppression of the OFF-alpha ganglion cell when stimulated with light increment (Farajian, Pan, Akopian, Völgyi, \& Bloomfield, 2011; Marco, Protti, \& Solomon, 2013). 
A OFF ganglion cells - Strychnine application

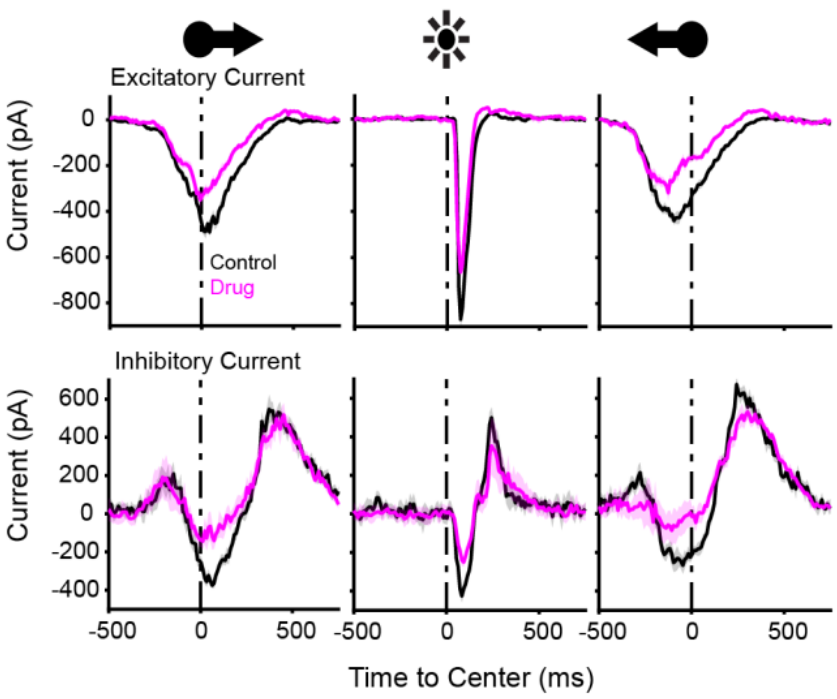

B Onset Phase Advancing
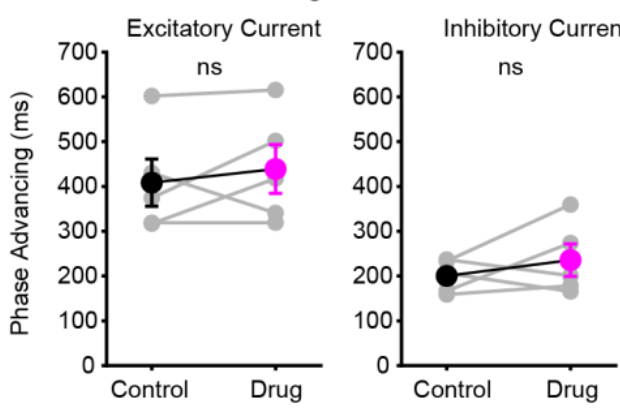

C Time-to-Peak Phase Advancing
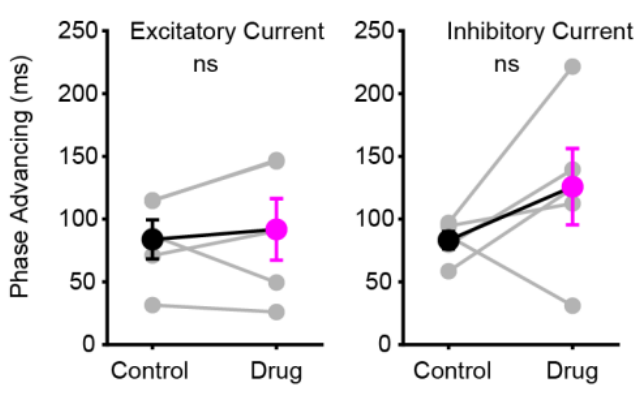

Figure 21. Glycine receptor blockage in OFF-alpha ganglion cells. A, Top, Changes in excitatory synaptic inputs under control conditions (black) and during strychnine $(1 \quad \mu \mathrm{M})$ application (magenta). Bottom, Same as the top but for light-evoked inhibitory current recordings. Shaded area represents \pm SEM. B, left, onset phase advancing values in control and drug conditions during OFF ganglion cell excitatory current recordings $(n=5)$. Middle, osPA values for visually evoked inhibitory recordings in control and drug conditions $(n=5)$. Right, osPA values from recording changes in membrane voltages $(n=5)$. C, Same as B but for time-to-peak phase advancing values (excitatory current, $n=4$; inhibitory current, $\mathrm{n}=4$; membrane voltages, $n=5)$. Gray lines show individual cells, black and magenta points/error bars

$$
\begin{array}{cl}
{ }^{700}{ }_{1}^{\text {Membrane Voltage }} & \text { show summary mean } \pm \text { SEM, ns, not } \\
\text { ns } & \text { significant. }
\end{array}
$$

\section{Gabazine did not have}

a significant effect on the

phase advancing of excitatory

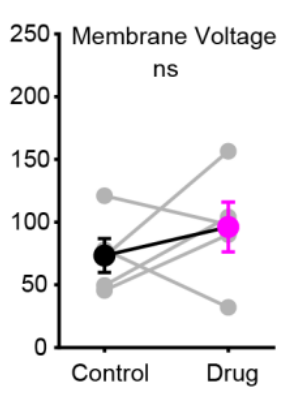

or inhibitory synaptic inputs to

OFF-alpha ganglion cells.

When recording excitatory

synaptic currents, I did not see

a significant change in the

osPA or ttpPA values during application of gabazine (excitatory osPA: $n=6$, mean

difference $26 \pm 13.8 \mathrm{~ms}, \mathrm{t}=1.88, \mathrm{p}=0.12$; excitatory ttpPA: mean difference $32 \pm 24.5 \mathrm{~ms}$, $t=1.29, p=0.26$; Figure 19B and $C$, left). While recording inhibitory currents, I observed no statistical difference in osPA or ttpPA values (inhibitory osPA: $n=6$, mean difference $18 \pm 19.8 \mathrm{~ms}, \mathrm{t}=0.90, \mathrm{p}=0.41$; inhibitory ttpPA: $\mathrm{n}=6$, mean difference $-25 \pm 11.06 \mathrm{~ms}$, $t=2.26, p=0.073$; Figure 19B and $C$, middle). Membrane voltage recordings in current 
clamp mode $(\mathrm{I}=0)$ showed no significant effect of gabazine $(10 \mu \mathrm{M})$ on phase advancing values compared with control values $(\mathrm{l}=0$ osPA: $\mathrm{n}=6$, mean difference $8.0 \pm 28.5 \mathrm{~ms}$, $\mathrm{t}=0.28, \mathrm{p}=0.79 ; \mathrm{l}=0 \mathrm{ttpPA}: \mathrm{n}=6$, mean difference $6 \pm 3.37 \mathrm{~ms}$, paired $\mathrm{t}$-test, $\mathrm{t}=1.78$, $\mathrm{p}=.135$; Figure $19 \mathrm{~B}$ and $\mathrm{C}$, right). These results demonstrate that $\mathrm{GABA}_{\mathrm{A}}$ receptormediated inhibition does not play a specific role in phase advancing in mouse retinal ganglion cells.

$G A B A_{C}$ receptors are the other predominant GABAergic receptor type located in the mammalian retina. GABAc receptors are mainly localized to the bipolar cell terminals, but little expression has also been shown on ganglion cell dendrites (Popova, 2014). Application of $50 \mu \mathrm{M}$ TPMPA in the bath selectively blocks $\mathrm{GABA}_{C}$ receptors without off-target effects on $\mathrm{GABA}_{\mathrm{A}}$ receptor signaling. Figure 20A shows stimulusevoked responses of an example OFF-alpha cell before and during treatment with TPMPA.

Application of TPMPA had no significant effect on the phase advancing values of the recorded OFF-alpha ganglion cell excitatory synaptic inputs (excitatory osPA: $n=5$, mean difference $6.0 \pm 13.0 \mathrm{~ms}, \mathrm{t}=0.43, \mathrm{p}=0.69$; excitatory ttpPA: mean difference $-11 \pm$ $10.5 \mathrm{~ms}, \mathrm{t}=1.04, \mathrm{p}=0.36$; Figure 20B and $\mathrm{C}$, left). While OFF-alpha ganglion cell inhibitory synaptic inputs trend towards a decrease during TPMPA (50 $\mu \mathrm{M})$ application, this decrease was not statistically significant (inhibitory osPA: $n=5$, mean difference -24 $\pm 17 \mathrm{~ms}, \mathrm{t}=1.43, \mathrm{p}=0.23$; inhibitory ttpPA: $\mathrm{n}=5$, mean difference $-12 \pm 10.3 \mathrm{~ms}$, paired $\mathrm{t}-$ test, $\mathrm{t}=1.17, \mathrm{p}=0.31$; Figure $20 \mathrm{~B}$ and $\mathrm{C}$, middle). Membrane voltage recordings also showed no significant change duringTPMPA application $(\mathrm{l}=0$ osPA: $\mathrm{n}=5$, mean difference $-7.0 \pm 27.3 \mathrm{~ms}, \mathrm{t}=.269, \mathrm{p}=0.80 ; \mathrm{l}=0 \mathrm{ttpPA}: \mathrm{n}=5$, mean difference $-9.0 \pm 7.1 \mathrm{~ms}$, paired t-test, $\mathrm{t}=1.33, \mathrm{p}=0.26$; Figure $20 \mathrm{~B}$ and $\mathrm{C}$, right). Thus, it appears that $\mathrm{GABA} C$ receptor-mediated inhibition is not required for phase advancing OFF-alpha ganglion cell responses. 
Glycinergic receptor expression is spread among bipolar cell terminals, ganglion cell dendrites, and amacrine cell dendrites (Eggers \& Lukasiewicz, 2011). The example traces in Figure 21 A show decreased amplitudes of excitatory and inhibitory synaptic inputs (magenta) in an OFF-alpha ganglion cell following application of the glycine receptor selective antagonist strychnine $(1 \mu \mathrm{M})$ due to the expression of glycinergice receptors (Zhang, Nobles, \& McCall, 2015).

A ON ganglion cells - Gabazine application
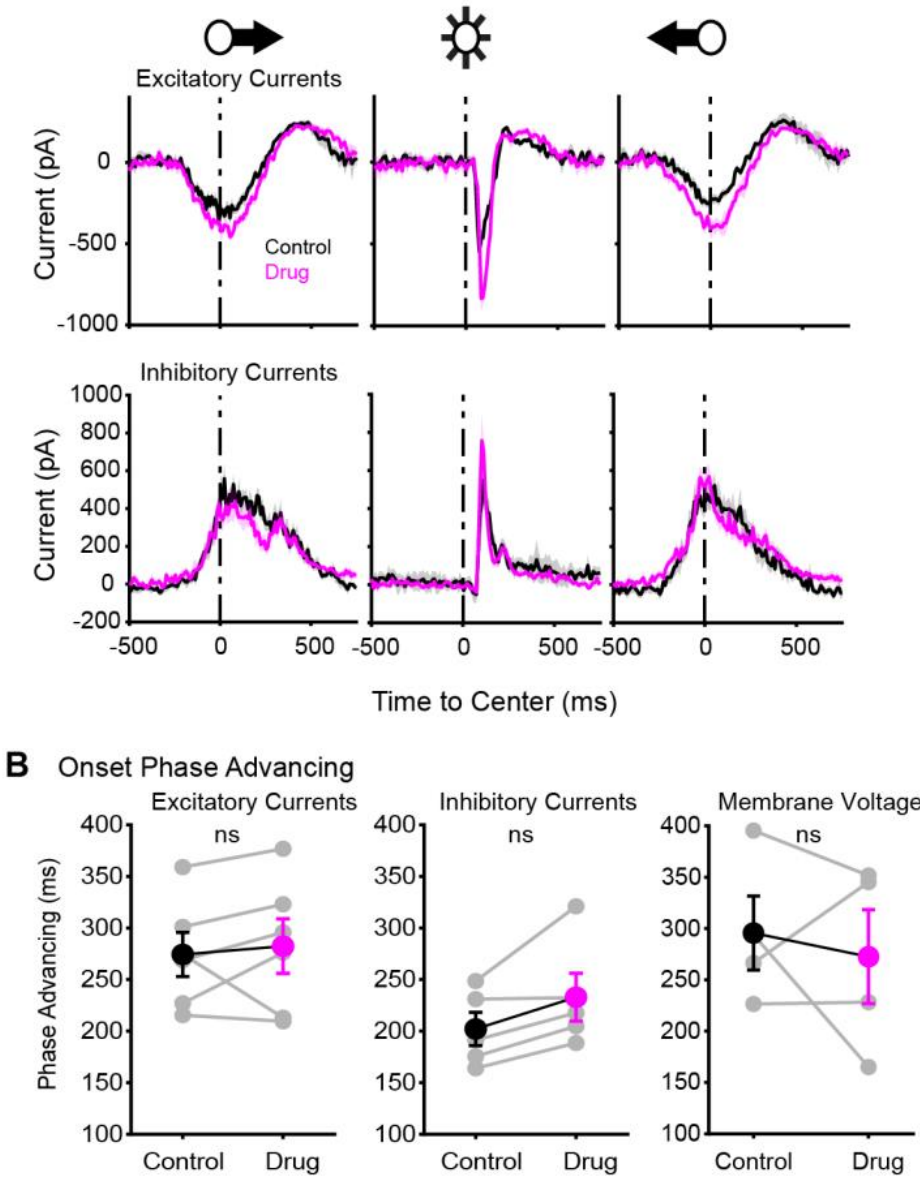

C Time-to-Peak Phase Advancing
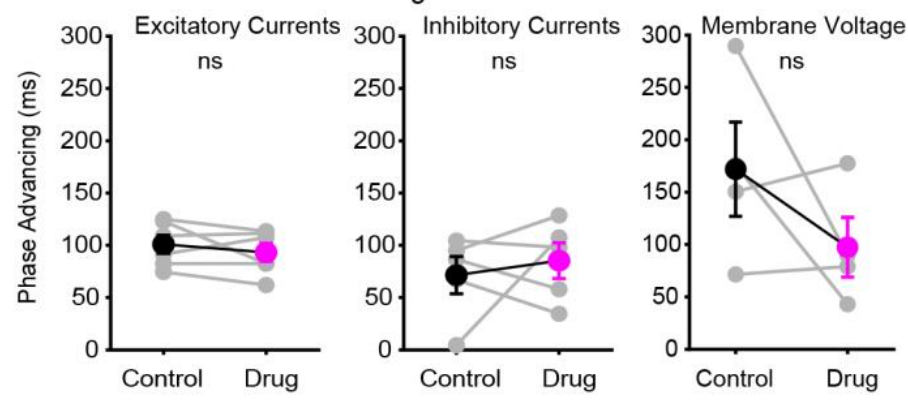

Figure 22. $\mathrm{GABA}_{\mathrm{A}}$ receptor blockage in $\mathrm{ON}$-alpha ganglion cells. A, Top, Changes in excitatory synaptic inputs under control conditions (black) and during Gabazine $(10 \mu M)$ application (magenta). Bottom, Same as the top but for light-evoked inhibitory current recordings. Shaded area represents \pm SEM. B, left, Onset phase advancing values in control and drug conditions during $\mathrm{ON}$ ganglion cell excitatory current recordings $(n=6)$. Middle, OsPA values for visually evoked inhibitory recordings in control and drug conditions $(n=5)$. Right, osPA values from recording changes in membrane voltages $(n=4)$. C, Same as B but for time-topeak phase advancing values (excitatory current, $\mathrm{n}=6$; inhibitory current, $n=5$; membrane voltages, $n=4$ ). Gray lines show individual cells, black and magenta points/error bars show summary mean \pm SEM, ns, not significant.

Figure $21 \mathrm{~B}$ and $\mathrm{C}$

shows the osPA and ttpPA

values before and during

pharmacological block of

glycine receptors. There 
was no significant change in either phase advancing metric in the excitatory inputs to OFF alpha-ganglion cells excitatory osPA: $n=5$, mean difference $31 \pm 38.7 \mathrm{~ms}, \mathrm{t}=.788$, $\mathrm{p}=0.48$; excitatory ttpPA: mean difference $8.0 \pm 13.3 \mathrm{~ms}, \mathrm{t}=.604, \mathrm{p}=.579$; Figure $21 \mathrm{~B}$ and C, left). Similarly, there was no significant difference during application of strychnine compared to control for the inhibitory current phase advancing metrics (inhibitory osPA: $n=5$, mean difference $35 \pm 35 \mathrm{~ms}, \mathrm{t}=1.01, \mathrm{p}=0.37$; inhibitory ttpPA: $n=5$, mean difference $43 \pm 29.8 \mathrm{~ms}, \mathrm{t}=1.43, \mathrm{p}=0.23 ;$ Figure $21 \mathrm{~B}$ and $\mathrm{C}$, middle). Strychnine application also did not significantly change phase advancing values during membrane voltage recordings ( $l=0$ osPA: $n=5$, mean difference $23 \pm 12.6 \mathrm{~ms}, \mathrm{t}=1.80, \mathrm{p}=0.15 ; \mathrm{l}=0 \mathrm{ttpPA}: \mathrm{n}=5$, mean difference $23 \pm 24.6 \mathrm{~ms}, \mathrm{t}=0.93, \mathrm{p}=0.41$; Figure $21 \mathrm{~B}$ and $\mathrm{C}$, right). I conclude that none of the three inhibitory synaptic mechanisms probed here are necessary for phase advancing.

\section{Blocking inhibitory circuits in ON-alpha ganglion cells}

Similarly, to OFF-alpha ganglion cells I applied inhibitory blockers while recording from ON-alpha ganglion cells (Figure 22A). $10 \mu \mathrm{M}$ of bath applied gabazine did not show a significant increase in phase advancing while recording excitatory inputs (excitatory osPA: $n=6$, mean difference $8.0 \pm 15.7 \mathrm{~ms}, \mathrm{t}=0.51, \mathrm{p}=0.63$; excitatory ttpPA: mean difference $-8.0 \pm 7.8 \mathrm{~ms}, \mathrm{t}=0.979, \mathrm{p}=0.372$; Figure 22B and $\mathrm{C}$, left). Inhibitory current phase advancing values measured during application gabazine $(10 \mu \mathrm{m})$ were not significantly different compared to control values (inhibitory osPA: $n=5$, mean difference $31 \pm 11.5 \mathrm{~ms}, \mathrm{t}=2.68, \mathrm{p}=0.06$; inhibitory ttpPA: $n=5$, mean difference $14 \pm 25.2 \mathrm{~ms}$, $t=0.55, p=0.61$; Figure 22B and $C$, middle). Neither osPA or ttpPA values were significantly different from control during gabazine application when recording changes in $\mathrm{ON}$-alpha ganglion cell membrane voltages $(\mathrm{I}=0$ osPA: $n=4$, mean difference $-23 \pm$ $43.4 \mathrm{~ms}, \mathrm{t}=0.53, \mathrm{p}=0.63 ; \mathrm{l}=0 \mathrm{ttpPA}: \mathrm{n}=4$, mean difference $-75 \pm 54.8 \mathrm{~ms}, \mathrm{t}=1.36, \mathrm{p}=0.27$; 
Figure $22 \mathrm{~B}$ and $\mathrm{C}$, right). $\mathrm{GABA}_{\mathrm{A}}$ receptor mediated inhibition is not required for phase advancing responses in $\mathrm{ON}$-alpha ganglion cells.

A ON ganglion cells - TPMPA application

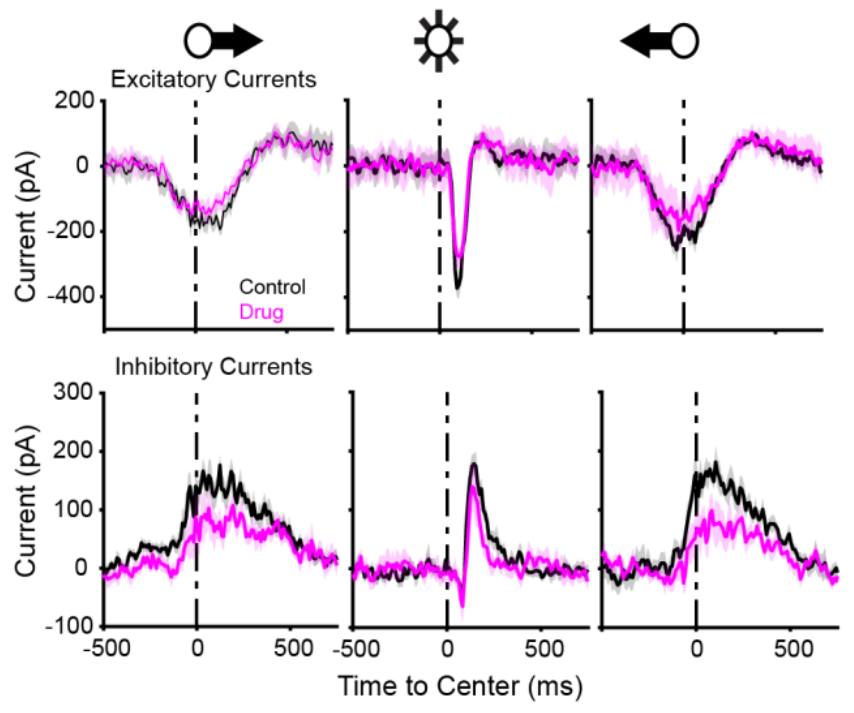

B Onset Phase Advancing
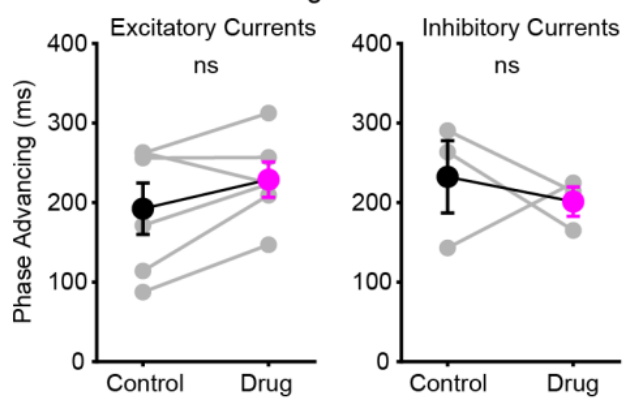

C Time-to-Peak Phase Advancing
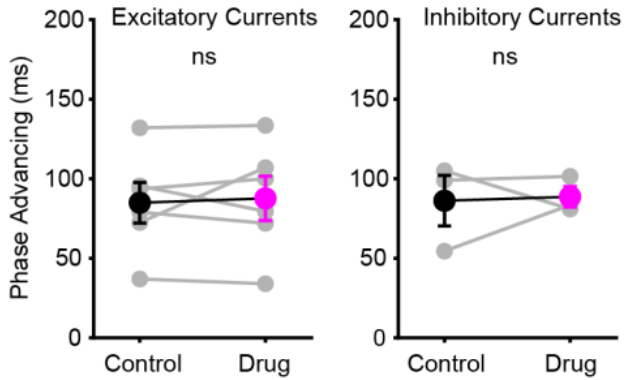

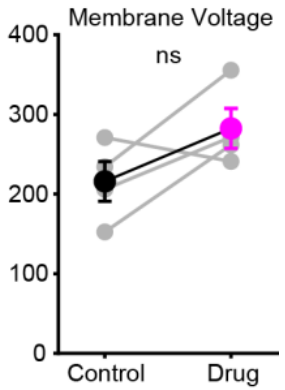

Figure 23. GABAc receptor blockage in ON-alpha ganglion cells. A, Top, Changes in excitatory synaptic inputs under control conditions (black) and during TPMPA $(50 \quad \mu \mathrm{M})$ application (magenta). Bottom, Same as the top but for light-evoked inhibitory current recordings. Shaded area represents \pm SEM. B, left, Onset phase advancing values in control and drug conditions during $\mathrm{ON}$ ganglion cell excitatory current recordings $(n=6)$. Middle, osPA values for visually evoked inhibitory recordings in control and drug conditions $(n=3)$. Right, osPA values from recording changes in membrane voltages $(n=4)$. C, Same as B but for time-topeak phase advancing values (excitatory current, $n=6$; inhibitory current, $\mathrm{n}=3$; membrane voltages, $n=4)$. Gray lines show individual cells, black and magenta points/error bars show summary mean \pm SEM, ns, not significant.

TPMPA $(50 \mu \mathrm{M})$

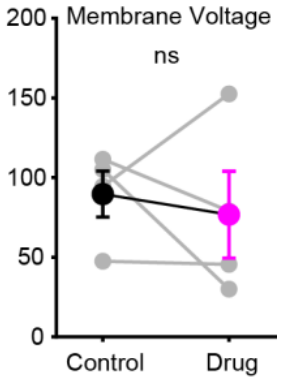

application during $\mathrm{ON}$-alpha ganglion cell recordings did not cause statistically significant changes to the phase advancing values for excitatory synaptic inputs (excitatory osPA: $n=6$, mean difference $37 \pm 19.4 \mathrm{~ms}, \mathrm{t}=1.89, \mathrm{p}=0.12$; excitatory ttpPA: mean difference $3.0 \pm 7.1 \mathrm{~ms}$, $t=0.39, p=0.71$; Figure 23B and $C$, left). Blockage of $G A B A_{C}$ receptors did not significantly change phase advancing values of recorded inhibitory synaptic inputs to 
ON-alpha ganglion cells (inhibitory osPA: $n=3$, mean difference $-31 \pm 56.8 \mathrm{~ms}, \mathrm{t}=0.55$, $p=0.64$; inhibitory ttpPA: $n=3$, mean difference $3.0 \pm 15.3 \mathrm{~ms}, \mathrm{t}=0.16, p=0.89$; Figure 23B and $\mathrm{C}$, middle). Recording light-evoked changes in membrane voltage showed no significant difference in phase advancing during application of TPMPA ( $=0$ osPA: $n=4$,

A ON ganglion cells - Strychnine application

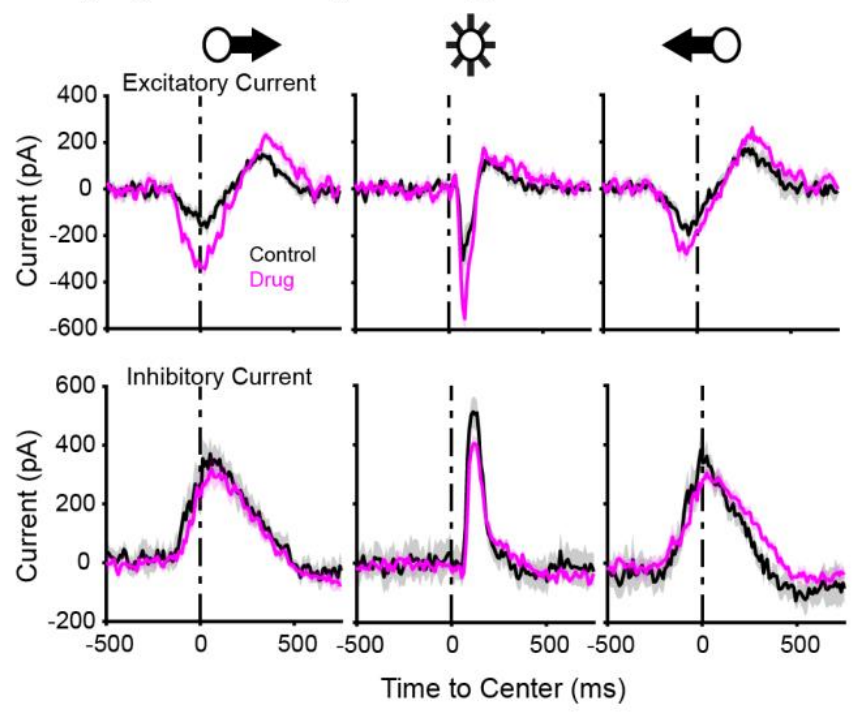

B Onset Phase Advancing
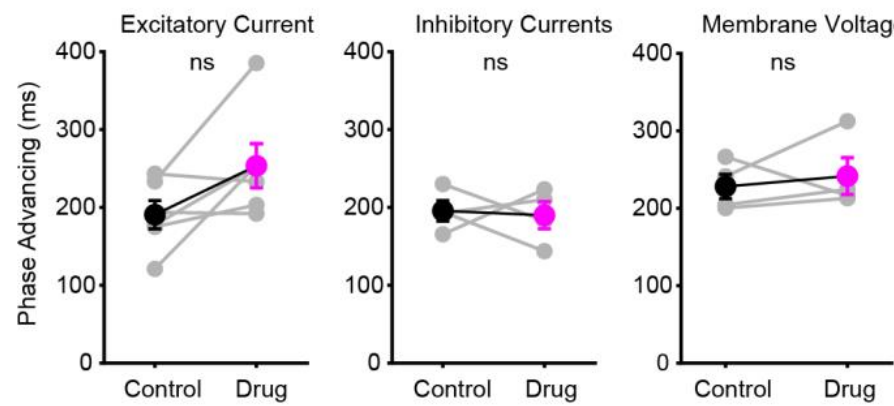

C Time-to-Peak Phase Advancing
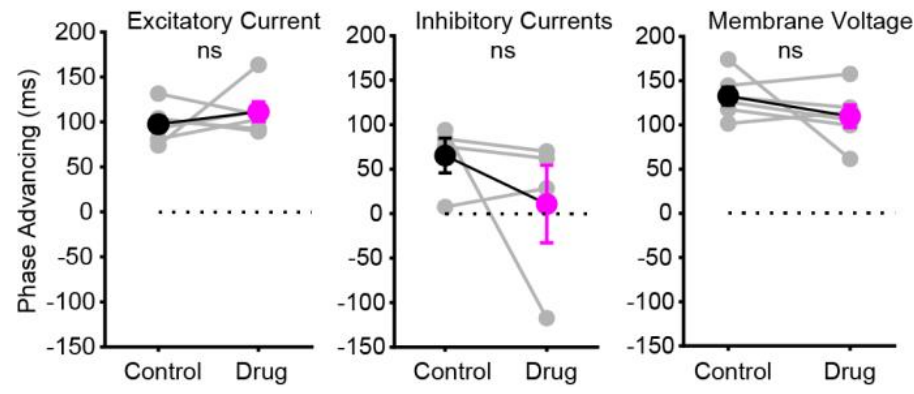

Figure 24. Glycine receptor blockage in ON-alpha ganglion cells. A, Top, Changes in excitatory synaptic inputs under control conditions (black) and during strychnine (1 $\mu \mathrm{M})$ application (magenta). Bottom, Same as the top but for light-evoked inhibitory current recordings. Shaded area represents \pm SEM. B, left, Onset phase advancing values in control and drug conditions during $\mathrm{ON}$ ganglion cell excitatory current recordings $(n=6)$. Middle, osPA values for visually evoked inhibitory recordings in control and drug conditions $(n=4)$. Right, osPA values from recording changes in membrane voltages $(n=4)$. C, Same as B but for time-topeak phase advancing values (excitatory current, $n=6$; inhibitory current, $n=4$; membrane voltages, $n=6)$. Gray lines show individual cells, black and magenta points/error bars show summary mean \pm SEM, ns, not significant.

mean difference $67 \pm 34.3$

$m s, t=1.94, p=0.15 ; l=0$ ttpPA:

$\mathrm{n}=5$, mean difference $-13.0 \pm$

$28.0 \mathrm{~ms}, \mathrm{t}=0.46, \mathrm{p}=0.68$;

Figure 23B and $\mathrm{C}$, right).

Next, I blocked glycine

receptors with strychnine (1

$\mu \mathrm{M})$ while recording synaptic inputs to $\mathrm{ON}$-alpha ganglion cells. Neither excitatory osPA

or ttpPA values were significantly different compared to control conditions when 
glycinergic receptors were blocked (excitatory osPA: $n=6$, mean difference $63 \pm 28.1 \mathrm{~ms}$, $t=2.23, p=0.08$; excitatory ttpPA: mean difference $14 \pm 16.9 \mathrm{~ms}, t=0.83, p=0.45$; Figure 24B and C, left). There was no significant difference compared to control in phase advancing values during blocker application when recording inhibitory synaptic inputs (inhibitory osPA: $n=4$, mean difference $-6.0 \pm 26.3 \mathrm{~ms}, \mathrm{t}=0.21, \mathrm{p}=0.84$; inhibitory ttpPA: $\mathrm{n}=4$, mean difference $-55 \pm 53 \mathrm{~ms}, \mathrm{t}=1.03, \mathrm{p}=0.34$; Figure $24 \mathrm{~B}$ and $\mathrm{C}$, middle). Recording light-evoked changes in membrane voltage did not have an significant effect on phase advancing values when strychnine was added to the bath ( $I=0$ osPA: $n=4$, mean difference $13 \pm 24.9 \mathrm{~ms}, \mathrm{t}=0.54, \mathrm{p}=0.62 ; \mathrm{l}=0$ ttpPA: $n=6$, mean difference $-23 \pm$ $19.0 \mathrm{~ms}, \mathrm{t}=1.21, \mathrm{p}=0.28$; Figure 24B and $\mathrm{C}$, right).

The absence of inhibitory contributions to phase advancing in both OFF and ONalpha ganglion cells raises the next question: Is phase advancing an inherent property of the ganglion cell receptive field or the result of active processing mechanisms? Next, I explored whether a linear model is sufficient at generating phase advanced responses in alpha ganglion cells.

\section{A LN model of phase advancing in alpha ganglion cells}

In complex neuronal systems not all circuits are experimentally accessible, so computational strategies have been developed to elucidate these systems. For example, in 1952, Hodgkin and Huxley presented in a series of papers a mathematical model for the propagation of action potentials in the giant squid axon (Hodgkin \& Huxley, 1952a, 1952b). The published set of differential equations described ion flow across cell membrane and the driving force of action potential generation. The work by Hodgkin and Huxely (1952) not only spawned massive interest in electrophysiology but also brought about use of quantitative modeling as a tool for advancing the understanding of neuroscience systems (Schwiening, 2012). 
A powerful model for assessing and predicting the visual responses of retinal ganglion cells has been the Linear-nonlinear (LN) model (Chichilnisky, 2001). LN models combine linear spatio-temporal summation of inputs to the ganglion cell with a static nonlinear transfer function. Previous work in salamander show that simple LN models do not accurately capture phase advancing, but require a gain-control feedback loop (LfN) to show a phase advancing response (Berry et al., 1999; Leonardo \& Meister, 2013).

These previous models were based on action potential firing rates. Here I tested LN model performance for predicting phase advanced responses of ganglion cells based on voltage clamp and current clamp recordings. These experiments enabled me to determine whether phase advancing involves a nonlinear mechanism that extend beyond the static nonlinearity. One such mechanism would be contrast gain control.
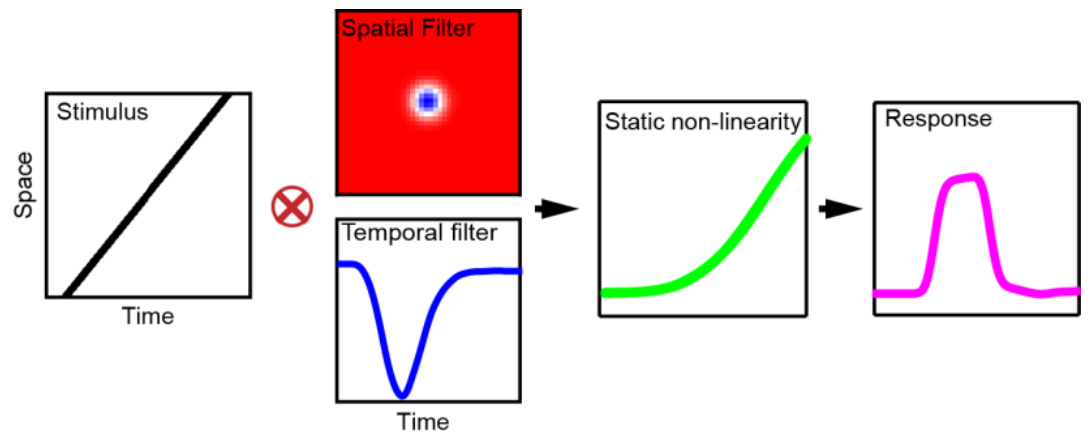

Figure 25. Linear-nonlinear cascade model. To model changes in ganglion cell synaptic input and membrane voltage, first the stimulus (left) was cross-multiplied with the measured ganglion cell's spatiotemporal receptive field fitted to a Gaussian. That product was then passed through the static nonlinearity (green) which functions to nonlinearly scale and normalize the filter output. The output (magenta) is the modeled response of that cell to the sweep stimulus.

Figure 25 illustrates the LN model used in the model simulations. First, the sweep stimulus was convolved with the measured spatiotemporal filter from the ganglion cell responses to the white-noise stimulus. That product was then passed through a static nonlinearity, which functions to normalize the filter output (Schwartz \& Rieke, 2011; Zaghloul, Boahen, \& Demb, 2005). The output is the modeled response of that cell to the sweep stimulus in either current or membrane voltage, depending on the units of 
the initial spatiotemporal filter. Examples of the spatiotemporal filters generated from OFF and $\mathrm{ON}$-alpha ganglion cells through reverse correlation analysis are shown in Figures 26 and 28, respectively. For each spatial kernel collected, the data was fitted with a 2D Gaussian function to measure the spatial receptive field. The measured peak response to the white noise stimulus gave us the temporal filter (Figure 26B and 28B).
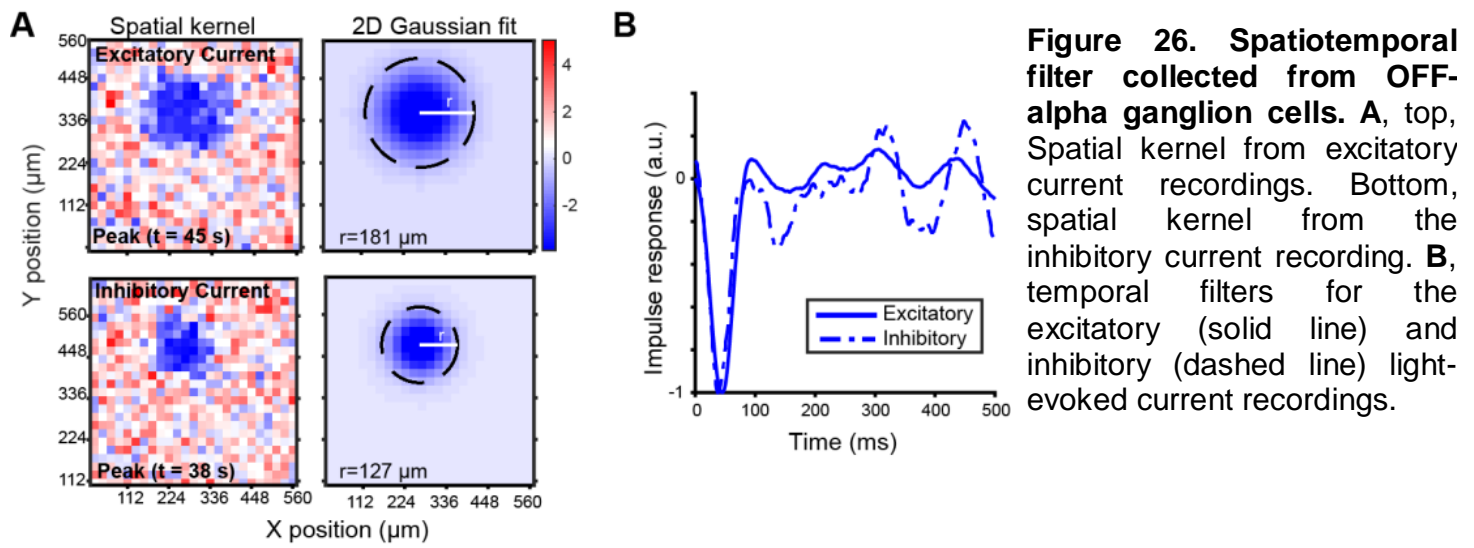

In Figure 27A I show an example of the modeled excitatory synaptic inputs overlaid on the measured excitatory responses from an OFF-alpha ganglion cell (Figure 27B and $\mathrm{C}$, orange dot). Table 3 shows the results of the paired t-tests from the OFFalpha ganglion cell modeling data and electrophysiological recordings. I found statistically significant differences in the between the model osPA and the recorded osPAs for the slower moving spot $\left(670 \mu \mathrm{m}^{*} \mathrm{~s}^{-1}\right)\left(\right.$ Table $3 ; \mathrm{E}_{\mathrm{Cl}}:-63.3 \mathrm{~ms} \pm 12.7 \mathrm{~ms}, \mathrm{n}=37$ pairs, $t=4.97, p<0.0001 ; E_{c a t}:-47.8 \pm 9.4 \mathrm{~ms}, \mathrm{n}=23$ pairs, $t=5.08, \mathrm{p}<0.0001 ; \mathrm{l}=0: 75.4 \pm$ 14.1, $\mathrm{t}=5.37, \mathrm{p}<0.0001)$. I did not see statistically significant differences for the excitatory responses to that faster moving spots in OFF-alpha ganglion cells. 
A OFF-alpha GC

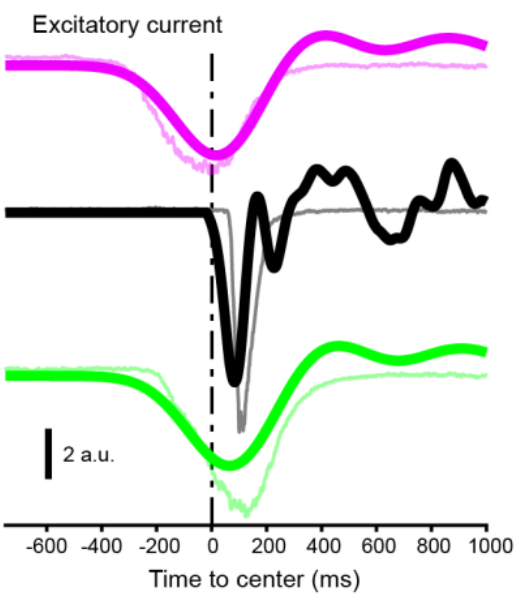

F Membrane voltage response

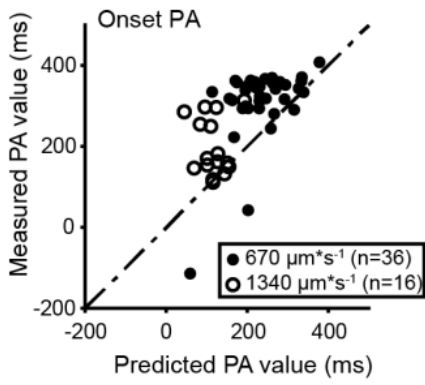

G

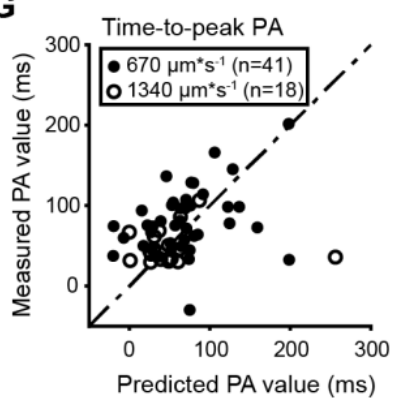

B Excitatory currents

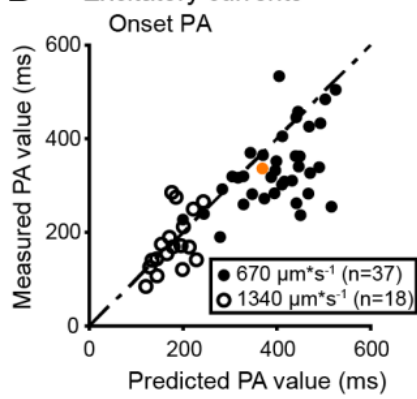

C

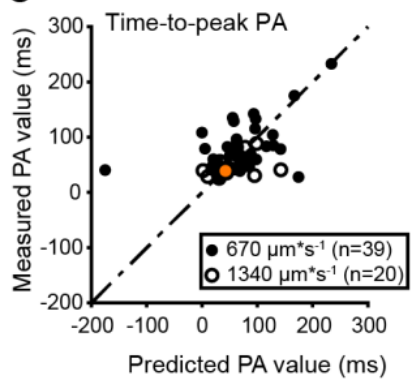

D Inhibitory currents

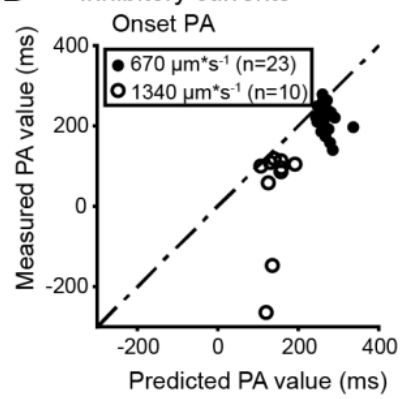

E

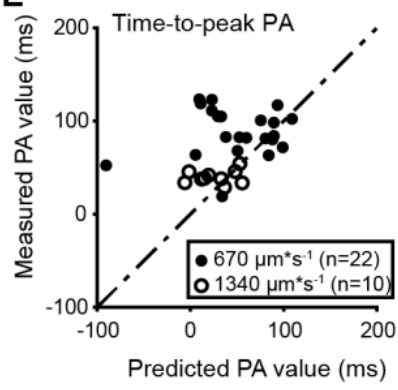

Figure 27. Modeled responses of OFF-alpha GCs to the sweep stimulus. A, Example of modeled excitatory current responses (thick lines) overlain the light-evoked responses (faded lines) from an OFF-alpha ganglion cell. Magenta is from the rightward moving, green from the leftward moving and black represents the response to the flashed spot. B, Scatterplot of the measured osPA values vs the modeled values collected from excitatory current recordings. Orange point are the values from the example cell shown in A. C, Same as in $B$ but for ttpPA values. D and E, Same as in B and $C$ but for inhibitory current recordings. F and $\mathbf{G}$, Same as in B and C but for changes in membrane voltage recordings. Dashed line shows unity. 
Table 3. Statistics from the modeled response of OFF-alpha ganglion cells. Paired t-test; mean difference (measured-model) \pm SEM.,$+ 670 \mu \mathrm{m}^{*} \mathrm{~s}^{-1} ;++, 1340 \mu \mathrm{m}^{*} \mathrm{~s}^{-1}$

\begin{tabular}{|c|c|c|c|c|c|c|c|}
\hline \multicolumn{8}{|c|}{ OFF Ganglion cells } \\
\hline $\begin{array}{c}\text { Recording } \\
\text { Type }\end{array}$ & $\begin{array}{c}\text { PA/ } \\
\text { Speed }\end{array}$ & $\begin{array}{l}\text { \# of } \\
\text { Pairs }\end{array}$ & $\begin{array}{c}\text { Mean Difference } \\
(\mathrm{ms})\end{array}$ & \pm SEM & $\mathrm{T}$ value & $P$ value & \\
\hline \multirow{5}{*}{$\begin{array}{c}\text { Excitatory } \\
\text { Currents }\end{array}$} & osPA+ & 37 & -63.3 & 12.7 & 4.97 & $<0.0001$ & 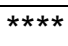 \\
\hline & ttpPA+ & 38 & 10.9 & 9.2 & 1.18 & 0.244 & \\
\hline & osPA++ & 18 & -1.4 & 11.6 & 0.12 & 0.908 & \\
\hline & ttpPA++ & 20 & -1.1 & 6.9 & 0.16 & 0.872 & \\
\hline & osPA+ & 23 & -47.8 & 9.4 & 5.08 & $<0.0001$ & $* * * *$ \\
\hline \multirow{4}{*}{$\begin{array}{l}\text { Inhibitory } \\
\text { Currents }\end{array}$} & ttpPA+ & 23 & 62.4 & 25.9 & 2.41 & 0.025 & * \\
\hline & osPA++ & 10 & -104.8 & 39.7 & 2.64 & 0.027 & * \\
\hline & ttpPA++ & 10 & 13.3 & 6.9 & 1.92 & 0.088 & \\
\hline & osPA+ & 36 & 75.4 & 14.1 & 5.37 & $<0.0001$ & $\star * * *$ \\
\hline \multirow{3}{*}{$\begin{array}{c}\text { Membrane } \\
\text { Voltage }\end{array}$} & $\operatorname{ttpPA+}$ & 41 & 11.5 & 8.1 & 1.42 & 0.165 & \\
\hline & osPA++ & 16 & 82.8 & 20.4 & 4.06 & 0.001 & $\star \star$ \\
\hline & ttpPA++ & 18 & 142.4 & 16.8 & 8.49 & $<0.0001$ & $\star \star \star *$ \\
\hline
\end{tabular}

Figure 29A shows example modeled excitatory synaptic inputs overlaid on the measured responses from an $\mathrm{ON}$-alpha ganglion cell. Table 4 shows the results of the paired t-tests from the OFF-alpha ganglion cell modeling data. The only statistically significant differences between the modeled data and the recorded data were the osPA values of the modeled excitatory currents overestimated the amount of phase advancing (Table 4; osPA+: $-193.6 \mathrm{~ms} \pm 30.3 \mathrm{~ms}, \mathrm{n}=33$ pairs, $\mathrm{t}=6.38, \mathrm{p}<0.0001$; osPA++: $-183.4 \pm$ $55.2 \mathrm{~ms}, \mathrm{n}=13$ pairs, $\mathrm{t}=3.33, \mathrm{p}=0.0061)$.

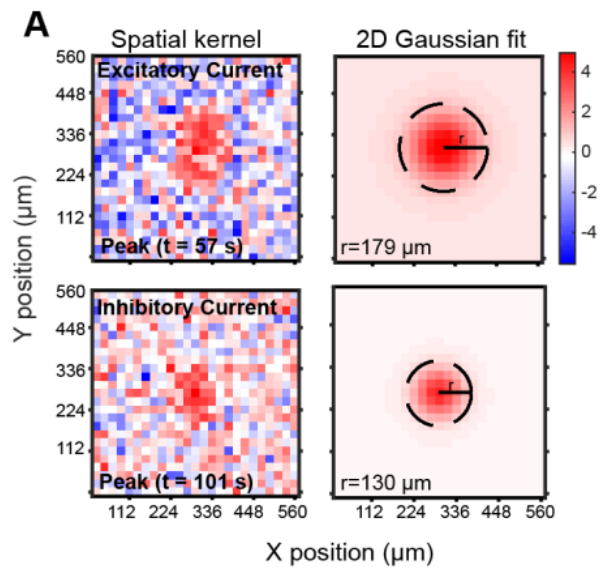

B

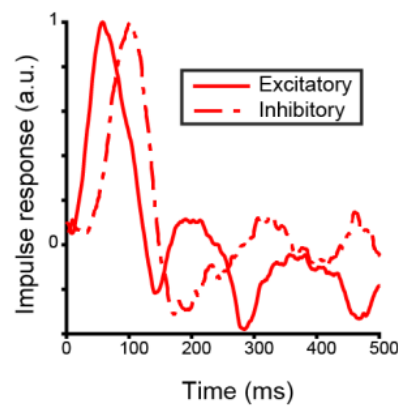

Figure 28. Spatiotemporal filter collected from ONalpha ganglion cells. A, top, Spatial kernel from excitatory current recordings. Bottom, spatial kernel from the inhibitory current recording. B, temporal filters for the excitatory (solid line) and inhibitory (dashed line) lightevoked current recordings. 
A ON-alpha GC

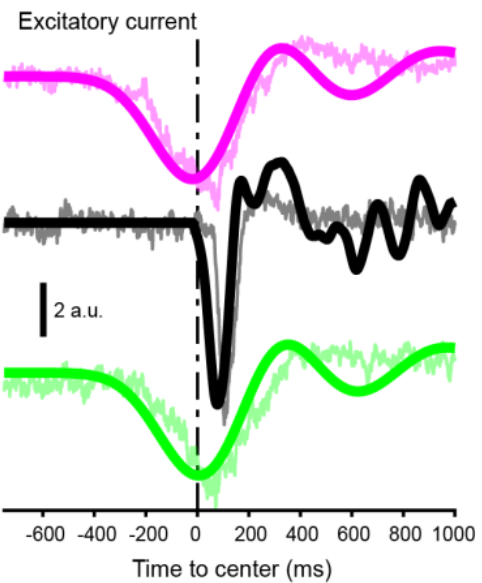

F Membrane voltage response

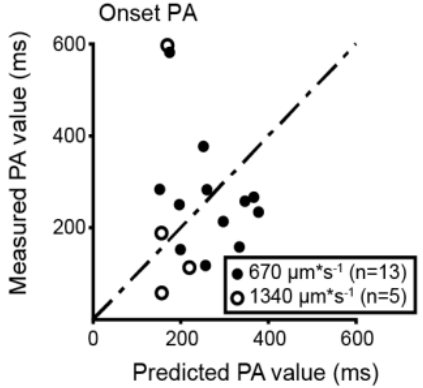

G

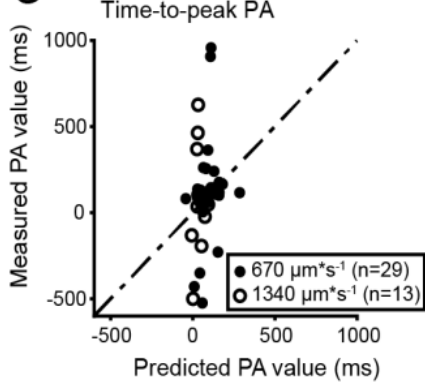

B Excitatory currents Onset PA

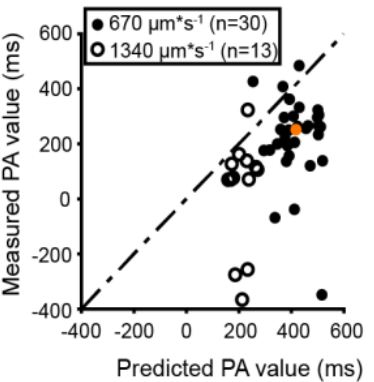

C

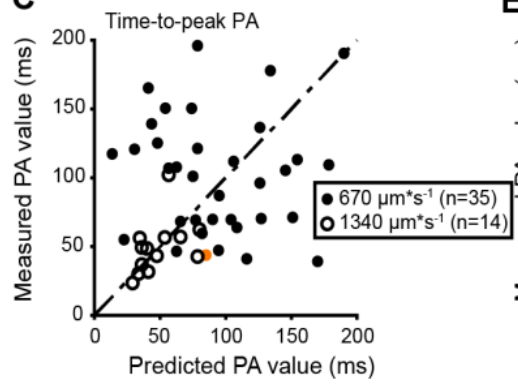

D Inhibitory currents

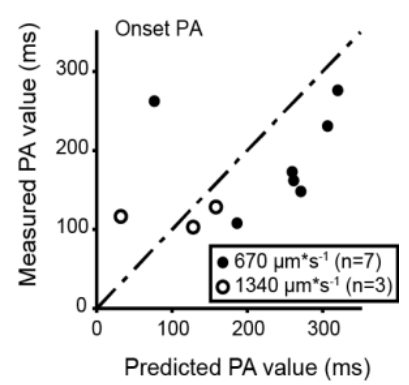

E

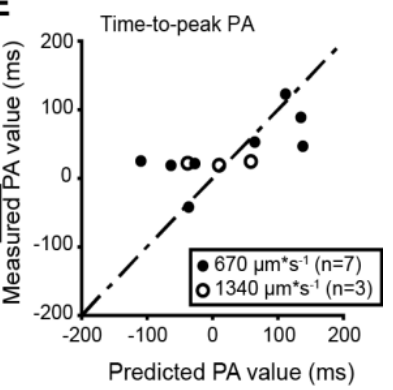

Figure 29. Modeled responses of ON-alpha GCs to the sweep stimulus. A, Example of modeled excitatory current responses (thick lines) overlain the light-evoked responses (faded lines) from an OFF-alpha ganglion cell. Magenta is from the rightward moving, green from the leftward moving and black represent the response to the flashed spot. B, Scatterplot of the measured osPA values vs the modeled values collected from excitatory current recordings. Orange point are the values from the example cell shown in A. C, Same as in B but for ttpPA values. D and E, Same as in B and C but for inhibitory current recordings. F and $\mathbf{G}$, Same as in B and $C$ but for changes in membrane voltage recordings. Dashed line shows unity.

Here, I have reported on a LN model for phase advancing in ON and OFF-alpha ganglion cells. Thus, it appears that a static nonlinearity is not sufficient in modeling phase advancing in OFF-alpha ganglion cells. ON-alpha ganglion cells appear more likely follow the LN model (Table 4). 
Table 4. Statistics from the modeled response of $\mathrm{ON}$-alpha ganglion cells. Paired ttest; mean difference (measured-model) \pm SEM.,$+ 670 \mu \mathrm{m}^{*} \mathrm{~s}^{-1} ;++, 1340 \mu \mathrm{m}^{*} \mathrm{~s}^{-1}$

\begin{tabular}{|c|c|c|c|c|c|c|c|}
\hline \multicolumn{8}{|c|}{ ON Ganglion cells } \\
\hline $\begin{array}{l}\text { Recording } \\
\text { Type }\end{array}$ & $\begin{array}{c}\mathrm{PA} / \\
\text { Speed }\end{array}$ & $\begin{array}{l}\text { \# of } \\
\text { Pairs }\end{array}$ & $\begin{array}{c}\text { Mean Difference } \\
\text { (ms) }\end{array}$ & \pm SEM & T value & $P$ value & \\
\hline \multirow{4}{*}{$\begin{array}{l}\text { Excitatory } \\
\text { Currents }\end{array}$} & osPA+ & 33 & -193.6 & 30.3 & 6.38 & $<0.0001$ & 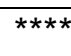 \\
\hline & ttpPA+ & 35 & 7.9 & 10.7 & 0.74 & 0.463 & \\
\hline & osPA++ & 13 & -183.4 & 55.2 & 3.33 & 0.0061 & ** \\
\hline & ttpPA++ & 14 & 3.3 & 5.6 & 0.58 & 0.572 & \\
\hline \multirow{4}{*}{$\begin{array}{l}\text { Inhibitory } \\
\text { Currents }\end{array}$} & osPA+ & 7 & -45.8 & 39.7 & 1.15 & 0.293 & \\
\hline & ttpPA+ & 8 & 15.3 & 25.4 & 0.6 & 0.567 & \\
\hline & osPA++ & 3 & 9.9 & 37.3 & 0.27 & 0.815 & \\
\hline & ttpPA++ & 3 & 11.7 & 27.2 & 0.43 & 0.709 & \\
\hline \multirow{4}{*}{$\begin{array}{l}\text { Membrane } \\
\text { Voltage }\end{array}$} & osPA+ & 12 & -34.2 & 54.1 & 0.63 & 0.539 & \\
\hline & $\operatorname{ttpPA+}$ & 29 & -9.3 & 61.8 & 0.15 & 0.881 & \\
\hline & osPA++ & 5 & -19.1 & 127.6 & 0.15 & 0.889 & \\
\hline & ttpPA++ & 13 & 40.3 & 79.4 & 0.51 & 0.621 & \\
\hline
\end{tabular}

\section{Discussion}

Excitatory currents in ON and OFF alpha ganglion cells show phase advancing when presenting moving stimuli (Figure 13 and Figure 15). My data differs from the results obtained in goldfish ganglion cells, where excitatory currents lag behind the moving stimulus (Johnston \& Lagnado, 2015).In addition, I found that inhibitory currents, too, showed phase advancing in both ON and OFF alpha ganglion cells (Figure 13 and 15). The four types of alpha ganglion cells have remarkably similar light response kinetics and morphology within the mouse retina (Krieger et al., 2017). I classified the ganglion cells as either OFF-alpha or ON-alpha because the stationary flashed spot in the sweep stimulus is too brief ( $80 \mathrm{~ms})$ to evoke a sustained response from the recorded ganglion cells. Although deemed unnecessary in these experiments I could have used a $1000 \mathrm{~ms}$ alternating spot stimulus (light increment/light decrement) with to sort the alpha ganglion cells into the four identified types. 
When I presented a moving spot at different velocities the amount of phase advancing generally decreased at higher sport velocities. At higher speeds, phase advancing was nearly eliminated (Figure 17 and 18). The theory of Berry et al. (1999) proposed that faster moving bars should fail to initiate the contrast-gain control mechanism at bar velocities greater than $\sim 2 \mathrm{~mm}^{*} \mathrm{~s}^{-1}$. My findings are consistent with this, I found a similar dependence of phase advancing on stimulus speed in OFF-alpha cells and I extended their observations to show that the same effect in ON-alpha ganglion cells.

Selective elimination of inhibitory inputs through retina-wide pharmacologic block of $\mathrm{GABA}_{A}, \mathrm{GABA}_{C}$, or glycine receptors had no significant effect on phase advancing in these alpha ganglion cells. There was no significant difference in the osPA or ttpPA of synaptic inputs compared to control conditions for both ON and OFF-alpha ganglion cells. This differs from the results of Johnston and Lagnado (2015) in goldfish ganglion cells, where disabling inhibitory current through manipulation of intracellular calcium eliminated the phase advancing response. While the bath application method I used to block inhibition differed from that used by Johnston and Lagnado (2015) to establish circuit mechanism for phase advancing the fact that the more gross manipulation used here did not impact phase advancing, whereas the more subtle one of Johnston and Lagnado did, suggests that this difference reflects not a methodological difference but something else, and one explanation would be a species difference (mouse vs. goldfish).

The LN model did not fully capture phase advancing of recorded excitatory and inhibitory currents. I found that LN model overestimated the timing of onset response for the recorded excitatory and inhibitory currents. The modeled changes in membrane voltage underestimated the amount of onset phase advancing compared to the recorded data (Table 3). The LN model of phase advancing for ON-alpha ganglion cells showed an overestimation for onset phase advancing in excitatory currents (Table 4). This result 
is consistent with the idea that additional dynamic nonlinearities act to generate phase advancing, and one such mechanism could be the contrast gain-control feedback loop (Berry et al., 1999; Leonardo \& Meister, 2013).

Additional modeling experiments have been developed to elucidate other interesting retinal responses (motion reversal response). Built upon the $\mathrm{LN}$ model first proposed by Berry et al. (1999), an adaptive cascade model (ACM) uses additional gain control subunits to represent the input from bipolar cells (Chen, Chou, Park, Schwartz, \& Berry, 2014; E. Y. Chen et al., 2013). The increased complexity of the ACM can accurately account for nonlinear responses including the motion reversal response in salamander and mouse ganglion cells (Chen et al., 2014; E. Y. Chen et al., 2013). The important takeaway is that models can be built to solve the complex neuronal functions I see. My goal for the LN model was to observe how static nonlinear functions integrated motion compared to the phase advancing responses from the recorded currents. There is room to develop upon the LN model I have used here to expand its utility in explain phase advancing.

A motion specific circuit has been shown in salamander retina, the object motion sensitive (OMS) ganglion cell, is a selective detector of local motion that shows suppressed responses to motion in the surround, such as during global motion stimulation. The underlying compact motion detection circuit relies on polyaxonal amacrine cells to selectively inhibit bipolar cell terminals (Baccus, Olveczky, Manu, \& Meister, 2008; Kühn \& Gollisch, 2016; Olveczky, Baccus, \& Meister, 2003). The circuit proposed by Baccus et al. (2008) hypothesized that polyaxonal amacrine cells integrated information from beyond the ganglion cell's receptive field using bipolar cells (Baccus et al., 2008), which due to its spatial offset could mediate a phase advanced response. In the mouse, the W3 and excitatory VGluT3 amacrine cell have shown similar preference for local object motion (Kim, Soto, \& Kerschensteiner, 2015). 
Several ganglion cell subtypes have been shown to be gap junction-coupled to nearby ganglion cells of the same type (homotypic coupling) and also to amacrine cells within the dendritic field (heterotypic coupling) (Völgyi, Chheda, \& Bloomfield, 2009). A potential model for phase advancing of excitatory input would comprise a network of gap-junction coupled bipolar cells. Gap junctions laterally spread the signal from neuron to neuron through movement of cations through ion-conducting channels comprising connexin proteins (Völgyi, Kovács-Öller, Atlasz, Wilhelm, \& Gábriel, 2013). Cells outside of the ganglion cell receptive field would laterally activate bipolar cells ahead of the moving. That activation traveling ahead of the moving spot would be sufficient to compensate for a lag in phototransduction. Indeed, a predictive mechanism based on electrical coupling has been demonstrated in directionally selective ganglion cells tuned to upward motion (Trenholm, Schwab, et al., 2013). Thus, there is evidence of a connected system tracking motion across the visual space in addition to the theory that phase advancing is autonomous to each individual ganglion cell (Johnston \& Lagnado, 2015).

To test this hypothesis, a future experiment could block gap junctions to explore whether those broadly contribute to phase advancing in ganglion cell types (Trenholm, McLaughlin, et al., 2013). One can potentially test this using the bath-applied pharmacologic gap junction blocker, meclofenamic acid (MFA) to block gap junctions in the retina. However, MFA is known to have severe off-target effects and greatly diminishes the health of the retina, but a strong alternative approach is lacking (Pan, Mills, \& Massey, 2007). A more targeted approach would be to use a conditional knockout to selectively remove gap junctions in a specific cell type or multiple related subtypes e.g. alpha ganglion cells. 


\section{CHAPTER IV \\ PHASE ADVANCING IN THE INNER PLEXIFORM LAYER, PRIOR TO GANGLION CELL INTEGRATION}

\section{Introduction}

In the previous two chapters I demonstrated using calcium imaging and whole-cell electrophysiology that phase advancing is a common property of many ganglion cell types. This raises the question if it is generated de novo within each type, or whether it may be received as a feedforward feature of the excitatory input from presynaptic bipolar cells. Indeed, some key response properties of ganglion cells are known to originate presynaptically. For example, studies from salamander and guinea pig retina showed gain control mechanisms in ganglion cells originate from presynaptic bipolar cells (Beaudoin, Borghuis, \& Demb, 2007; Rieke, 2001). In this chapter, I show that some phase advancing, too, occurs prior to the ganglion cells, at the level of synaptic release from bipolar cell axon terminals.

In 2017, a study used two-photon fluorescence imaging of the glutamate biosensor, iGluSnFR (Marvin et al., 2013), to functionally classify all bipolar cell types in the mouse retina (Franke et al., 2017). iGluSnFR, when virally transduced into the ganglion cell layer, increases fluorescence when bipolar cells are activated and release glutamate. Franke and colleagues collected visually-evoked fluorescent responses from $\sim 13,000$ regions of interest in the inner plexiform layer (IPL) and clustered them into the previously identified 14 bipolar cell types (Euler, Haverkamp, Schubert, \& Baden, 2014). 
Franke et al. (2017) took an additional step to further to explore how glycinergic inhibitory inputs to the surround receptive field increases the functional diversity of bipolar cells by decorrelating bipolar cell output during activation of the local receptive field vs activation of the surround receptive field.

The glutamatergic inputs from cone photoreceptors onto a bipolar cell make up the bipolar cell's excitatory receptive field. Electrophysiological recordings showed an ON bipolar cell receptive field diameter is $\sim 44 \mu \mathrm{m}$ (Schwartz et al., 2012). A separate study using iGluSnFR reported for ON bipolar cells a receptive field center width was 81 $\mu \mathrm{m}$ and OFF bipolar cell receptive field center width was $66 \mu \mathrm{m}$ (Borghuis et al., 2013). Numerical discrepancy aside, these separate studies do agree on the fact that the excitatory receptive field is significantly larger than the bipolar cell dendritic field $(\sim 15-$ $20 \mu \mathrm{m})$. This is hypothesized to be due to electrical coupling between cone photoreceptors, as well as amacrine cell circuits that carry the spread of the signal beyond the bipolar cell dendritic field, thus expanding the receptive field (Schwartz et al., 2012; Simmons et al., 2017).

In Chapter III, I asked whether phase advancing is a product of inputs to the ganglion cell receptive field or a property intrinsic to ganglion cells. Electrophysiological whole-cell recordings from ganglion cells showed that phase advancing occurs at the level of excitatory and inhibitory synaptic inputs. Also, I know from previous studies that nonlinearities in ganglion cell receptive fields are present already at the level of glutamate release at bipolar cell terminals (Borghuis et al., 2013; Schwartz et al., 2012). These lines of evidence together lead to the hypothesis that phase advancing begins prior to ganglion cell input, at the level of glutamate release from the bipolar cell axon terminals. 


\section{Methods}

\section{Viral Injections}

All animal procedures were approved by the Institutional Animal Care and Use Committee at the University of Louisville and were in compliance with National Institutes of Health guidelines. I performed intravitreal injections in the left and right eyes of adult wild-type (C57BL/6, 3 - 4 weeks old) mice with $1.4-1.6 \mu$ of AAV2/1-hSynapsiniGluSnFR (Marvin et al., 2013). The mouse was anesthetized using a mixture of isoflurane and oxygen in an induction chamber. When the animal was stable it was then moved to the injection station in a fume hood. There it was placed under a light microscope with a nose cone where it received constant isoflurane/oxygen. Then I applied an ophthalmic solution (Proparacaine hydrochloride ophthalmic solution, USP $5 \%$; Henry Schein) to each eye and wiped away any excess.

Using curved forceps to rotate outward and stabilize the eye, I first used a 30gauge sharp needle to make puncture the corneal limbus (i.e. where the cornea meets the sclera). Then using a modified Hamilton syringe (Borghuis Instruments) with a 33gauge tip, curved to avoid damaging the lens, I injected the virus over the ventral portion of the retina. After $18-21$ days of incubation the retinas were harvested and mounted as described in the General Methods.

\section{Imaging and visual stimuli}

Two-photon fluorescence imaging was performed with a modified Olympus microscope controlled by Scanlmage 3.8 software using an Olympus 60x, 1.0NA, LUMPlanFL/IR objective. The scan laser (Chameleon Ultra II; Coherent) was tuned to $910 \mathrm{~nm}$ for iGluSnFR fluorescence excitation in retinal areas up to $100 \times 100 \mu \mathrm{m}$ and recorded at 16 frames per second. Evoked fluorescence responses using the sweep 
stimulus were collected at approximately $16 \mu \mathrm{m}$ and $31 \mu \mathrm{m}$ from the ganglion cell layer to record from the ON and OFF-layers of the IPL, respectively.

A OFF layer

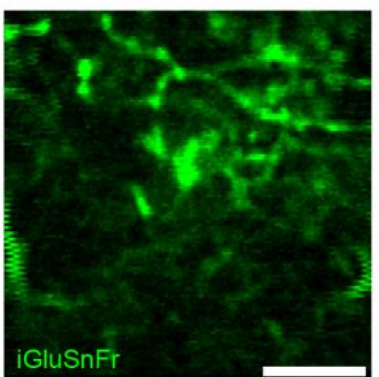

B Onset Phase Advancing

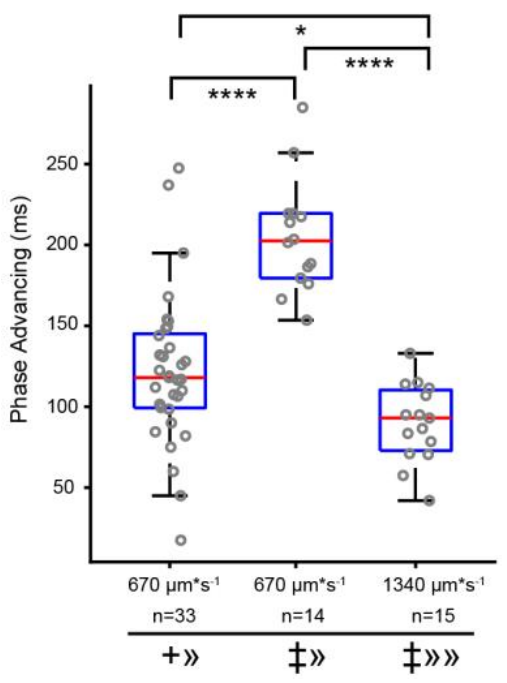

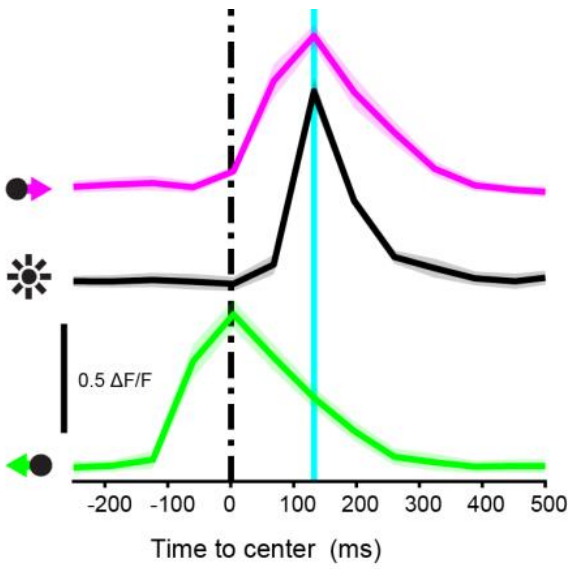

C Time-to-Peak Phase Advancing

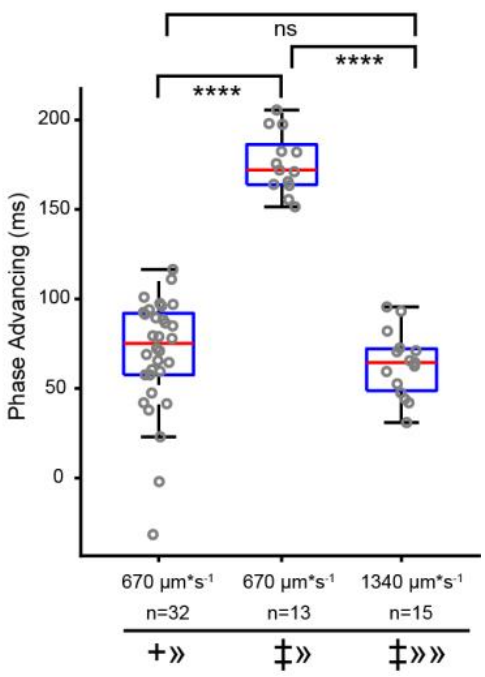

Figure 30. iGluSnFR phase advancing responses in the OFF layer of the IPL. A, left, twophoton micrograph of the imaged region in the IPL, scale bar $10 \mu \mathrm{m}$. Right, example iGluSnFR responses to rightward (magenta line) and leftward (green line) moving spots and stationary flashed spots (black line). Vertical black line shows when the spot is in the center of the imaging window $(\mathrm{t}=0)$. Vertical cyan line shows the time at the peak response to the flashed spot. Shaded area represents \pm SEM across trials. B, Box plot for the calculated osPA values from recorded areas. C, Same as B but for the calculated ttpPA values. Central line (red) is the median, the top and bottom edges of the box (blue) represent the 25th and 75th percentiles, respectively. Gray circles are the individual datapoints. Symbols representing size and speed of the moving spots: +, $160 \mu \mathrm{m}$ spot; $\neq, 220 \mu \mathrm{m}$; $\gg, 670 \mu \mathrm{m}^{*} \mathrm{~s}^{-1} ; \gg \gg, 1340 \mu \mathrm{m}^{*} \mathrm{~s}^{-1}$. ns, not significant. ns, not significant; ${ }^{*} p<0.05 ;{ }^{* *} p<0.01 ;{ }^{* * *}$ $p<0.001 ;{ }^{* * \star} p<0.0001$.

The video projector emits light in the UV range $(395 \mathrm{~nm})$ to optimally stimulate S-

cones (General Methods), and the background light intensity $\left(1.2^{*} 10^{5} R^{*} / \mathrm{rods} / \mathrm{s}\right)$ is in the mid-to-high photopic range. At this light intensity, the rod $\rightarrow$ rod bipolar cell synapse has been shown to be saturated (Bloomfield \& Dacheux, 2001). Therefore, a light increment spot would not elicit an iGluSnFR response through the rod pathway: Rod $\rightarrow$ Rod bipolar cell $\left(\mathrm{C}_{\mathrm{R}}\right) \rightarrow$ All amacrine cell $\rightarrow \mathrm{ON}$ cone bipolar cell $\rightarrow \mathrm{ON}$-alpha ganglion cell (Ke et al., 2014). Studies have recently found rod bipolar cell light responses while stimulating in the photopic range of light intensity (Franke et al., 2017; Tikidji-Hamburyan et al., 2015). 
These results leave unanswered questions about rod bipolar cell contributions to the visual signal under brighter light conditions.

A ON layer

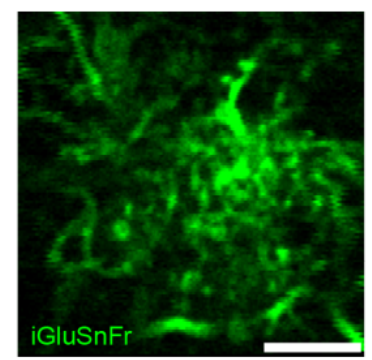

B

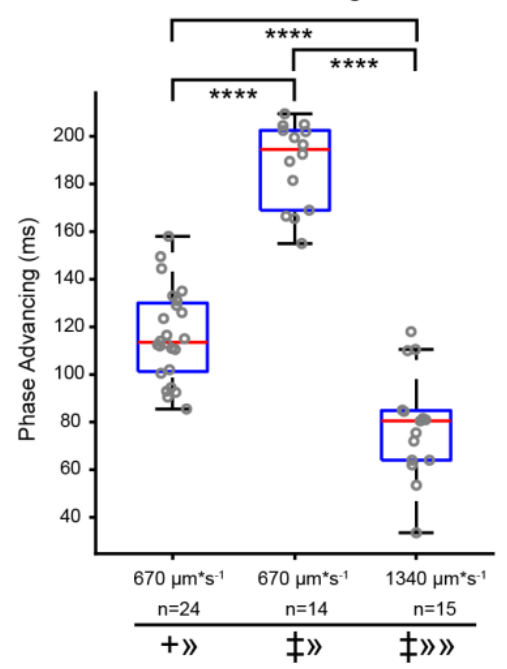

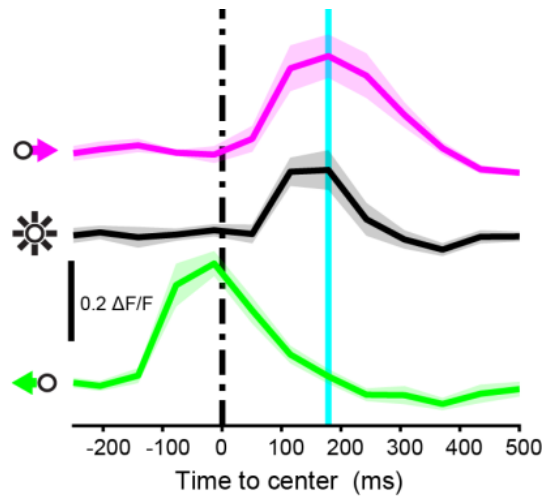

C Time-to-Peak Phase Advancing

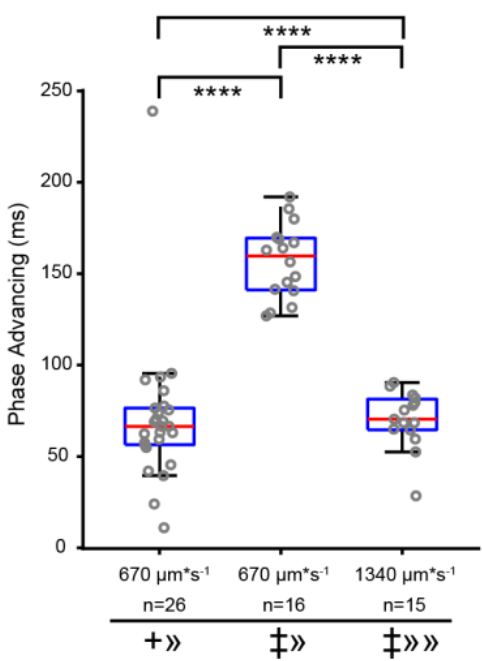

Figure 31. iGluSnFR phase advancing responses recorded in the ON layer of the IPL. A, left, two-photon micrograph of the imaged region in the IPL, scale bar $10 \mu \mathrm{m}$. Right, example iGluSnFR responses to rightward (magenta line) and leftward (green line) moving spots and stationary flashed spots (black line). Vertical black line shows when the spot is in the center of the imaging window $(t=0)$. Vertical cyan line shows the time at the peak response to the flashed spot. Shaded area represents \pm SEM across trials. B, Box plot for the calculated osPA values from recorded areas. C, Same as B but for the calculated ttpPA values. Central line (red) is the median, the top and bottom edges of the box (blue) represent the 25th and 75th percentiles, respectively. Gray circles are the individual datapoints. Symbols representing size and speed of the moving spots: +, $160 \mu \mathrm{m}$ spot; $\neq, 220 \mu \mathrm{m}$;

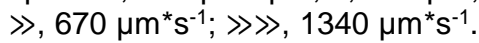
ns, not significant; * $\mathrm{p}<0.05$; ** $p<0.01 ; \quad * * * \quad p<0.001$; $p<0.0001$.

\section{Results}

Glutamate release from bipolar cells shows phase advancing

The excised retinas from virus-injected animals typically showed a hot spot of

fluorescence expression near the injection site. Labeling in the ganglion cell layer was restricted to the membranes of the ganglion cell somata. Focusing deeper into the tissue, a web-like structures of densely overlapping, fluorescently labeled ganglion cell dendrites comes into view. Viral transduction with the glutamate biosensor allows direct 
measurements of light evoked excitatory inputs with high spatial $(<1 \mu \mathrm{m})$ and temporal (up to $15 \mathrm{~Hz}$ resolution from ON and OFF layers of the IPL (Borghuis et al., 2013).

The goal of the following experiments was to measure the light evoked iGluSnFR responses in the ON and OFF layers of the IPL during visual stimulation of photoreceptors with the sweep stimulus. These measurements should enable calculating osPA and ttpPA values of the bipolar cell output to determine whether phase advancing is present at the bipolar cell axon terminals. The receptive field of bipolar cells has been shown to be most responsive to spots with a diameter of $\sim 150 \mu \mathrm{m}$ (Borghuis et al., 2013). Here I presented a spot with a diameter of $168 \mu \mathrm{m}$ to be near-optimal for evoking an optimal response from the bipolar cell excitatory receptive field, and a $280 \mu \mathrm{m}$ diameter spot for comparison with the ganglion cell recordings of experiments in the previous chapters.

Figure 30A shows an example fluorescence image obtained at a focal plane within the OFF layer of the IPL at, approximately $32 \mu \mathrm{m}$ from the ganglion cell layer. From this example I recorded an onset phase advancing of $126 \mathrm{~ms}$ and a time-to-peak phase advancing value of $72 \mathrm{~ms}$. Across all imaged areas I measured an average osPA of $122 \pm 8.1 \mathrm{~ms}$ ( $n=33$ ROls). The average ttpPA value was $69 \pm 5.6 \mathrm{~ms}$ ( $n=32$ ROls; one area excluded based on poor response).

Using larger light decrement spots $(280 \mu \mathrm{m})$ moving at $670 \mu \mathrm{m}^{*} \mathrm{~s}^{-1} \mathrm{I}$ recorded a mean osPA of $205 \pm 9.3 \mathrm{~ms}$ ( $\mathrm{n}=14$ ROIs) and a mean ttpPA of $176 \pm 4.6 \mathrm{~ms}(\mathrm{n}=13$ ROIs). For the faster moving spot $\left(1340 \mu \mathrm{m}^{*} \mathrm{~s}^{-1}\right)$, I imaged iGluSnFR labeled regions from seven injected retinas. The average osPA value was $90 \pm 6.2 \mathrm{~ms}$ ( $\mathrm{n}=15 \mathrm{ROIs}$ ) and the average ttpPA value was $64 \pm 4.7 \mathrm{~ms}$ ( $\mathrm{n}=15$ ROIs) (Figure $30 \mathrm{~B}$ and $\mathrm{C}$ ).

The example shown in Figure 31A was obtained at $16 \mu \mathrm{m}$ below the ganglion cell layer, in an ON layer of the IPL. Here, the osPA value was $117 \mathrm{~ms}$ and the ttpPA value was 75 ms. A slower moving visual stimulus with smaller spot size (168 $\mu \mathrm{m}$ diameter; 
$\left.670 \mu \mathrm{m}^{*} \mathrm{~s}^{-1}\right)$ in the IPL ON layer gave an average osPA value of $116 \pm 3.9 \mathrm{~ms}(\mathrm{n}=24$

ROls, $n=14$ retinas). The mean ttpPA value was $70 \pm 7.8 \mathrm{~ms}$ ( $\mathrm{n}=26$ ROls, $\mathrm{n}=16$ retinas).
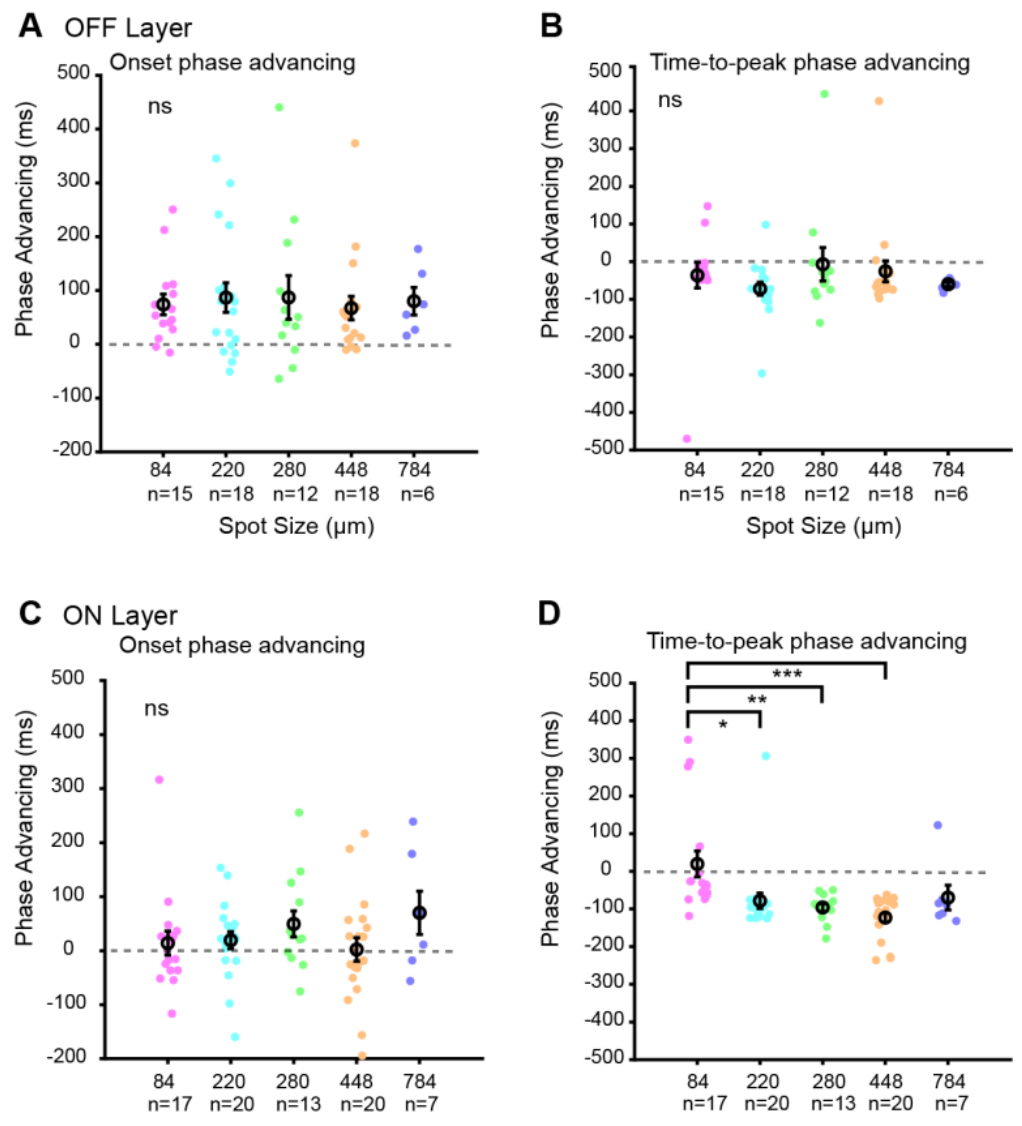

Spot Size $(\mu \mathrm{m})$

Spot Size $(\mu \mathrm{m})$

Figure 32. Phase advancing values from iGluSnFR recordings during stimulation with different sized moving and flashed spots. A, osPA, left, and ttpPA, right, values measured from the OFF layer of the IPL. B, osPA, left, and ttpPA, right, values measured from the ON layer of the IPL. Open circles represent mean \pm SEM, ns, not significant; ${ }^{*} \mathrm{p}<0.05 ;{ }^{* *} \mathrm{p}<0.01$; ${ }^{* * *}$ $\mathrm{p}<0.001 ;{ }^{* * *} \mathrm{p}<0.0001$.

Using larger light decrement spots $(280 \mu \mathrm{m})$ moving at $670 \mu \mathrm{m}^{*} \mathrm{~s}^{-1}$ I recorded a mean osPA of $189 \pm 4.8 \mathrm{~ms}(\mathrm{n}=14$ ROls $)$ and a mean ttpPA of $157 \pm 5.1 \mathrm{~ms}(\mathrm{n}=16$ ROls). I recorded an average osPA value of $78 \pm 5.8 \mathrm{~ms}(\mathrm{n}=15 \mathrm{ROls}, 8$ retinas, Figure (Figure 31B) and an average ttpPA of $70 \pm 4.1 \mathrm{~ms}$ ( $\mathrm{n}=15 \mathrm{RO} \mathrm{s}, 8$ retinas) when larger spots moved at $1340 \mu \mathrm{m}^{*} \mathrm{~s}^{-1}$ (Figure $31 \mathrm{C}$ ). I see a difference in how spot size affects phase advancing in the iGluSnFR recordings (Figure 30 and 31), so the next step was to measure phase advancing with a range of spot sizes.

Phase advancing in the inner plexiform layer does not depend on spot size 
Compared to alpha-type ganglion cells, bipolar cells have a significantly smaller excitatory receptive field ( 5-fold difference, around 35-45 $\mu \mathrm{m}$ in diameter). This raises the question whether phase advancing responses of bipolar cells depends on the size of the visual stimulus. In Figures 30 and 31, I showed the differences in phase advancing values for two spot sizes (168 $\mu \mathrm{m}$ vs $280 \mu \mathrm{m})$. To determine the relationship between spot size and the magnitude of phase advancing, I presented the sweep stimulus with a range of spot diameters $(84,220,280,448,784 \mu \mathrm{m})$ and imaged the time course of glutamate release from iGluSnFR-labeled regions of the ON and OFF IPL (Figure 32).

I initially measured an increase in both osPA and ttpPA as spot size increased for both OFF and ON layers of the IPL. My measurements use the time to center $(t=0)$ as the timepoint when center of the moving spots is in the center of the imaging window (General Methods; Eq. 1). However, the increased diameter of the moving spot necessarily stimulates the photoreceptors underlying the imaged area earlier in time as compared with the smaller spots. Indeed, there is a problem when using the center of the spot as the reference point, because the leading edge of the larger spots already stimulated the photoreceptors for a greater amount of time compared with the smaller spots.

To further clarify, at $t=0$ when the center of the largest spot $(d=784 \mu \mathrm{m})$ was at the center of the imaged area, the leading edge had passed the center of the imaged area $\sim 584$ ms earlier. For the smallest spots $(d=84 \mu \mathrm{m})$, the leading edge was at $t=0$ about 83 ms before the spot's center was at $t=0$. This presents a discrepancy when calculating the phase advancing values, but because the spatial and temporal aspects are precisely known, it could be perfectly corrected for by adding the edge time offset for each individual spot size to the fluorescence response. osPA and ttpPA values were then calculated from these values, which now represented the time at center of the leading edge (Figure 32). 
A one-way ANOVA was used to compare the effect of spot size on phase advancing. Fluorescence imaging data from the OFF layer of the IPL showed no statistically significant effect on osPA values for the five spot sizes (Figure 32A, F $(4,64)$ $=0.11, p=0.98)$. There was no significant effect on the ttpPA in the OFF layer for the five spot sizes when using an ANOVA (Figure 32B, $F(4,64)=0.73, p=0.57)$. Interestingly, the OFF time-to-peak values lagged behind the response to the flashed spot for all five spot sizes (Figure 32B; ttpPA<0; $84 \mu \mathrm{m},-36 \pm 34.2 \mathrm{~ms} ; 220 \mu \mathrm{m},-72 \pm 17.4 \mathrm{~ms} ; 280 \mu \mathrm{m}$, $-7 \pm 44.3 \mathrm{~ms} ; 448 \mu \mathrm{m},-25 \pm 27.7 \mathrm{~ms} ; 784 \mu \mathrm{m},-60 \pm 5.9 \mathrm{~ms})$.

Fluorescence responses from regions in the ON layer of the IPL were not significantly affected by size of the stimulus spot (Figure $32 \mathrm{C}, \mathrm{F}(4,72)=1.11, \mathrm{p}<=0.36$ ). The ttpPA values from ON layer fluorescence imaging experiments were statistically significant for the range in spot sizes presented (Figure 32D, $F(4,72)=6.0, p=0.0003$ ). A Tukey's post-hoc test showed the statistically significant difference between the smallest spot $(84 \mu \mathrm{m})$ and $220 \mu \mathrm{m}, 280 \mu \mathrm{m}$, and $448 \mu \mathrm{m}$ diameter spots $(\mathrm{p}<0.05)$. The remaining groups showed no statistical difference in means.

\section{Glycine receptor blockage and phase advancing}

Narrow field GABAergic amacrine cells directly inhibit bipolar cell terminals. Widefield glycinergic amacrine cells were shown to primarily modulate bipolar cell output by inhibiting the GABAergic amacrine cells. In published work, blocking the glycinergic input with strychnine decorrelated the center and surround receptive fields and revealed a mechanism that decreased signaling redundancy among bipolar cell types (Franke et al., 2017). To determine whether glycinergic inhibitory circuit interactions impact bipolar cell 
response timing, I next tested how blocking inhibitory inputs to the surround affected phase advancing at the bipolar cell terminal.

A OFF Layer - Strychnine Application
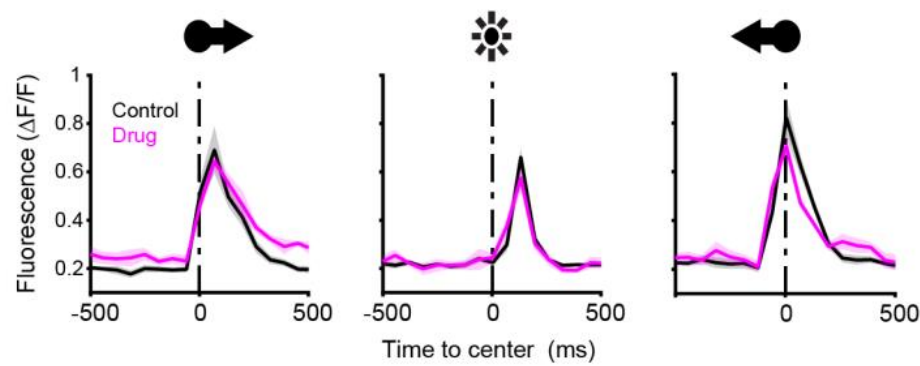

B
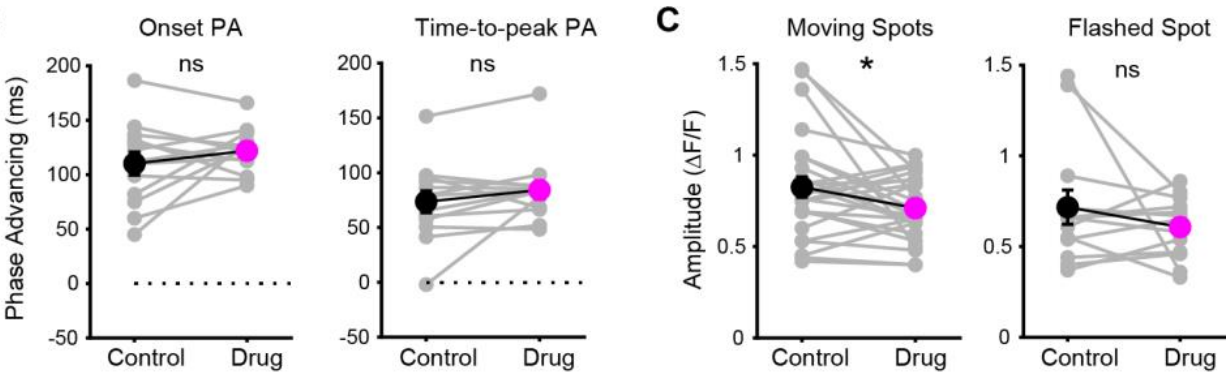

Figure 33. Phase advancing responses to sweep stimulus during strychnine application in the OFF layer of the IPL. A, Example of light-evoked iGluSnFR responses under control conditions (black) and during strychnine $(1 \mu \mathrm{M})$ application (magenta). Shaded area represents \pm SEM across trials. B. Phase advancing values for recorded responses in control compared with drug conditions (osPA, $n=13$ areas; ttpPA, $n=13$ areas). C, Response amplitudes in control compared with drug conditions (moving spots, $n=26$; flashed spots, $n=13$ ). Gray lines show individual cells, black and magenta points/error bars show summary mean \pm SEM, ns, not significant; ${ }^{*} p<0.05 ;{ }^{* *} p<0.01 ;{ }^{* * *} p<0.001 ;{ }^{* * \star *}$ $\mathrm{p}<0.0001$.

In Figure 33 I selectively inhibited glycinergic receptors with strychnine $(1 \mu \mathrm{M})$ in the whole-mount retina while recording visually-evoked fluorescence glutamate responses from the ON and OFF layers of the IPL. I did not observe a significant difference from control in the phase advancing values from the ON layer of the IPL during application of strychnine (osPA: $n=15$, mean difference $-5 \pm 9.7 \mathrm{~ms}, \mathrm{t}=0.47$, $p=0.65 ;$ ttpPA: $n=15$, mean difference $-2.9 \pm 9.6 \mathrm{~ms}, t=0.30, p=0.77$; Figure $33 \mathrm{~A}, \mathrm{~B})$. The iGluSnFR fluorescence response amplitudes in the ON layer during strychnine application were not significantly different compared to control (flash: $n=15$, mean difference $0.02 \pm 0.05 \Delta F / F, t=0.49, p=0.63$; moving: $n=30$, mean difference $0.05 \pm 0.04$ $\Delta F / F, t=1.23, p=0.23$; Figure 33C). 
Imaging iGluSnFR fluorescence responses in the OFF layer during strychnine application yielded no significant changes in phase advancing values compared to control conditions (osPA: $n=13$, mean difference $12 \pm 9.8 \mathrm{~ms}, \mathrm{t}=1.2, \mathrm{p}=0.25$; ttpPA: $\mathrm{n}=15$, mean difference $10.7 \pm 7.0 \mathrm{~ms}, \mathrm{t}=1.52, \mathrm{p}=0.15$; Figure $34 \mathrm{~A}, \mathrm{~B})$. The presence of strychnine significantly decreased in the amplitude of iGluSnFR response to the moving spots in the OFF layer of the IPL, although no change in response amplitude to the flashed spots was found (flash: $n=13$, mean difference $-0.11 \pm 0.09 \Delta F / F, t=1.09, p=0.29$; moving: $\mathrm{n}=26$, mean difference $-0.11 \pm 0.05 \Delta F / F, t=2.19, p=0.038$; Figure $34 C$ ).

A ON Layer - Strychnine Application
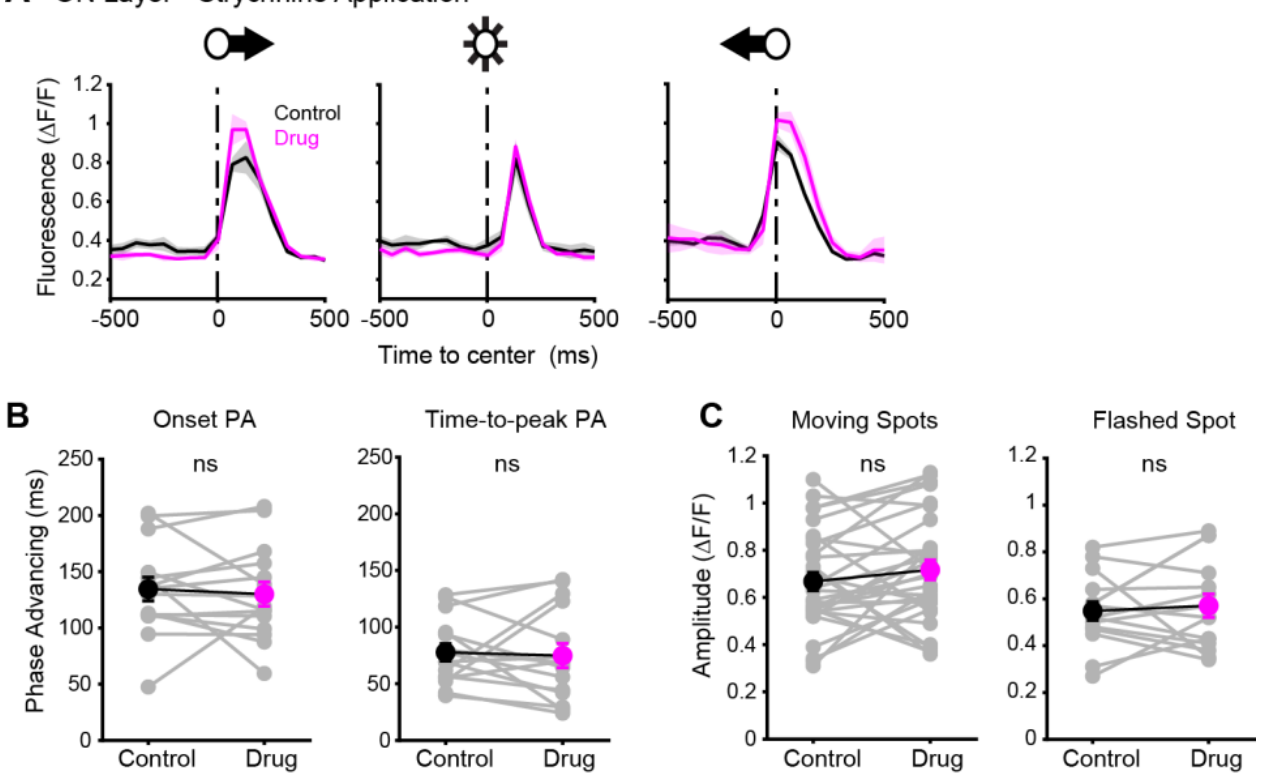

Figure 34. Phase advancing responses to sweep stimulus during strychnine application in the ON layer of the IPL. A, Example of light-evoked iGluSnFR responses under control conditions (black) and during strychnine $(1 \mu \mathrm{M})$ application (magenta). Shaded area represents \pm SEM across trials. B, Phase advancing values for recorded responses in control compared with drug conditions (osPA, $n=13$ areas; ttpPA, $n=13$ areas). C, Response amplitudes in control compared with drug conditions (moving spots, $\mathrm{n}=15$ areas; flashed spots, $\mathrm{n}=15$ areas). Gray lines show individual cells, black and magenta points/error bars show summary mean \pm SEM.

\section{Discussion}

The experiments of Chapter IV demonstrated that phase advancing occurs at the level of bipolar cell terminals in both the ON and OFF layer of the IPL (Figure 30 and 31). When 
correcting for the leading edge I observed that onset phase advancing responses persist in both layers of the IPL.

Multiple bipolar cell types synapse onto a single ganglion cell (Dunn \& Wong, 2014). Due to the lack of selectivity of the AAV serotype (2/1) and gene promoter (human synapsin-1), most ganglion cells and amacrine cells within the transduce area will be labeled with iGluSnFR expression (Borghuis et al., 2011). Based on the known stratification depths of bipolar cells in the IPL my recordings likely collected responses from 13 of the 14 identified bipolar cell types (Franke et al., 2017). This means that when I imaged the OFF layer approximately $\sim 31 \mu \mathrm{m}$ down from the ganglion cell layer, I sampled the five OFF bipolar cells types $\left(\mathrm{C}_{1}, \mathrm{C}_{2}, \mathrm{C}_{3 \mathrm{a}}, \mathrm{C}_{3 \mathrm{~b}}, \mathrm{C}_{4}\right)$. Likewise, in the ON layer I likely sampled responses from the eight identified $\mathrm{ON}$ cone bipolar cell types $\left(\mathrm{C}_{5 t}, \mathrm{C}_{50}\right.$, $\left.\mathrm{C}_{5 i}, \mathrm{C}_{x}, \mathrm{C}_{6}, \mathrm{C}_{7}, \mathrm{C}_{8}, \mathrm{C}_{9}\right)$

Franke et al. (2017) showed that activation of the surround receptive field with a larger spot during strychnine application decorrelated responses of bipolar cells of different types during stimulation with a full-field 'chirp stimulus', that consisted of a sinusoidal light increment steps that increase in frequency over time (Baden et al., 2016). I hypothesized that the moving spot would activate the inhibitory surround as it moved across the retina, and that disrupted inhibition would alter the response. I found that application of strychnine to block glycinergic receptors - the inhibitory receptor that dominates bipolar cell output when activating the bipolar cell surround receptive field (Franke et al., 2017) - had no significant effect on phase advancing measured either at the onset or time-to-peak of the glutamatergic response within the IPL (Figure 33 and 34).

When testing the dependence of phase advancing on stimulus spot size it would be most accurate to measure the time of response onset with respect to the center of the moving spots. As demonstrated in previous publications (Berry et al., 1999; Johnston \& 
Lagnado, 2015; Leonardo \& Meister, 2013), the leading-edge measurement gives an unbiased account of when the stimulus is entering the receptive field that is not affected by spot size. This is especially important when measuring the smaller receptive fields of bipolar cells with larger spots $(>200 \mu \mathrm{m})$. By shifting the measured response in time by the temporal difference between the edge and center location, this correction ensured that I measured onset response times with respect to the center of the spot and the leading edge.

The elimination of the time-to-peak phase advancing in the OFF and ON layers of the IPL when estimating the response to the leading edge was an interesting result. The leading edge remains a useful reference point for calculating the onset response because it relates exactly when the cell is first getting stimulated by the moving spot. 


\section{CHAPTER V \\ SUMMARY AND FUTURE DIRECTIONS}

The research presented in this dissertation supports the results of Berry et al. (1999) in rabbit that there is a motion compensating mechanism called phase advancing within the mammalian retina. To restate, phase advancing acts to shift the response to moving objects ahead in time, which helps to compensate for delays in neural transduction.

In Chapter II, using two-photon fluorescence calcium imaging, I showed that phase advancing was common to the ON, OFF, ON-OFF, and the direction-selective ganglion cell pathways within the mammalian retina. I showed that the Thy1-GCaMP6f mouse line stochastically labels a sub-population of ganglion cell types with stable response kinetics for extended two-photon fluorescence imaging experiments $(4-6 \mathrm{hrs}$;

Figures 7-12). The improvement and expansion of available Cre-LoxP transgenic mouse lines with cell-type specific expression patterns, brighter and faster fluorescent indicators, and advanced microscopy techniques continue to improve large scale neuronal population imaging. These developments culminated in recently reported recordings from up to 10,000 neurons in the mouse CNS (Stringer, Pachitariu, Steinmetz, Carandini, \& Harris, 2019; Stringer, Pachitariu, Steinmetz, Reddy, et al., 2019).

Bringing some of these large-scale imaging and analysis techniques to the retina, will help move the field forward. Replacing the 60x objective with perhaps a 20x objective will give a wider field of view, so that more ganglion cells can be imaged at a given time increasing analysis at the population-level, similar to spiking responses 
measured with an MEA (Leonardo \& Meister, 2013). Improved viral transduction with GCaMP6f could give useful biosensor expression across a larger retinal area, although compared with viral transduction bulk loading of the small molecule calcium indicator OGB-1 is currently still more effective for labeling large regions (Briggman \& Euler, 2011).

In the retina, high density MEA recordings can collect electrophysiological (action potential) responses from hundreds of cells simultaneously. The downside of MEA recording is that in typical applications it does not give information about cell morphology, and doesn't allow specific cell targeting and assessment of stimulus-evoked synaptic currents (Li et al., 2015). While fluorescence imaging currently cannot resolve the time course of electrical responses with high fidelity due to a biosensor temporal limit around $15 \mathrm{~Hz}$, it does expand researchers' ability to assess light evoked responses by enabling following imaging with targeted whole-cell current recording and morphological analyses.

In Chapter III I used targeted whole-cell electrophysiology to demonstrate phase advancing in excitatory and inhibitory synaptic inputs to alpha-type ganglion cells. I observed phase advancing in synaptic inputs to both ON and OFF-alpha ganglion cells (Figures 13 -16). In both cell types phase advancing depended on the speed of the moving stimulus (Figures 17 and 18).

My experiments showed that a pharmacological block of inhibitory circuits had no significant effect on phase advancing in ON or OFF-alpha ganglion cells (Figures 19 24). This result was surprising given the broadly demonstrated role of inhibition in retinal circuit function (Franke et al., 2017), and previous work from Johnston and Lagnado (2015) that showed a significant delay in ganglion cell responses to moving stimuli compared to flashed spots following disruption of inhibitory synaptic inputs in single ganglion cells. 
Modeling of neuronal systems is a powerful tool for testing hypotheses about neuronal function. In Chapter III, I presented data that utilized a linear nonlinear (LN) model of the ganglion cell receptive field to compute the expected response to the sweep stimulus (Figures 25 - 30). If the cell's response, including response timing, were well-characterized by a spatio-temporally linear filter with static nonlinearity (the two components of the LN model) then the recorded response would closely match the computed expected response. Instead, I found substantial differences in the response timing. My interpretation is that dynamic nonlinear aspects contribute to the response., and one such aspect may be dynamic gain control, which has previously demonstrated in contrast response (Beaudoin et al., 2007) and motion evoked response context (Berry et al., 1999; Leonardo \& Meister, 2013). In terms of the complexity of the pathways in the retina, the $L N$ model is a simplistic view. Several groups have reviewed the real-life nonlinear behavior with respect to the $\mathrm{LN}$ model in both reptilian and mammalian ganglion cell receptive fields (Demb, 2008; Gollisch \& Meister, 2010; Schwartz \& Rieke, 2011). My results are consistent with limitations of this model, in that it does not accurately capture some of the essential response timing of the ganglion cell response.

A limitation of using the $\mathrm{LN}$ model ganglion cell responses is the lack of nonlinear integration prior to the ganglion cell (Kim \& Rieke, 2001). In terms of phase advancing, the addition of a contrast gain-control feedback process to the LN model shifted the response forward to match what is observed experimentally (Berry et al., 1999; Leonardo \& Meister, 2013). In the LN model I do see a statistically significant difference in the LN model phase advancing values compared to the measured values in OFFalpha ganglion cells (Table 3).

Modifying the visual stimulus paradigm could offer insights into the ganglion cell linear integration over time. For example, Kuo et al. (2016) collected responses using an apparent motion stimulus that consisted of a bar moving across a local area within a 
ganglion cell's receptive field. Time of the evoked response was compared with the response to stationary bars, flashed randomly at different locations in the cell's receptive field. Averaged light-evoked responses showed an increased sensitivity to the moving bars over the stationary bars, evident as an increase in response amplitude. This paradigm could be used in future experiments to study the timing of the responses to these two stimuli. This experiment may also prove invaluable when measuring whether spot size has an effect on phase advancing during iGluSnFR recordings. Flashed spots of different sizes along the receptive field of a bipolar cell would eliminate the discrepancy with the distance from the leading edge to the center of the moving spots.

All model simulations in my work were performed with custom algorithms in MATLAB. As an alternative, the NEURON simulation environment is a free software package that focuses on building computational models of neurons and neuronal networks (Hines \& Carnevale, 1997). This robust simulation environment can be used to develop a compartmental model of the ganglion cell including ion channel kinetics, and could potential be used to make an improved model of phase advancing at the ganglion cell level, because it would be based in the known biological/molecular neural 'parts'. Additionally, the ability to create a network of ganglion cells may offer more insight into the mechanisms responsible for phase advancing.

Future directions bridging imaging and electrophysiology could include paired recordings from the Thy1-GCaMP6f mouse line. Based on imaging a group of cells (610) and online analysis I would select two that have phase advancing fluorescence responses. It would be interesting to compare the spike rates and timing between two cells of the same type (ex. ON $\rightarrow$ ON) or different types (ex. OFF $\rightarrow$ DSGC). Filling the cells with a fluorescent tracer and imaging post hoc to visualize dendritic size of the two cells and then quantify the dendritic overlap to test model-predicted vs measured response timing during object motion stimulation. 
Chapter IV measured phase advancing at the bipolar cell terminal using twophoton fluorescence imaging of glutamate release. These are was the first data demonstrating that presented phase advancing prior to ganglion cell integration (Figure 30 and 31). Recently, an improved version of iGluSnFR, SF-iGluSnFR, has shown brighter baseline fluorescence and improved resistance to bleaching in the mammalian brain (Marvin et al., 2018). Improved stability of iGluSnFR in the retina could reduce variance between trials and extend the overall health of the retina during long experiments, allowing studies of the timing of synaptic release in greater detail, for example, focusing on potential timing difference across bipolar cell types, following type identification using the methods of Franke et al. (2017).

My final thoughts on phase advancing in the mammalian retina are that the 'shift' forward in time is not an active process. Instead, phase advancing at the level of individual ganglion cells is a passive feature of the spatio-temporal receptive field that helps negate the temporal delay introduced by phototransduction delay within the photoreceptors. 


\section{REFERENCES}

Arshavsky, Lamb, \& Edward N. Pugh. (2002). G Proteins and Phototransduction. Annual $\begin{array}{llll}\text { Review of } & \text { Physiology, }\end{array}$ doi:10.1146/annurev.physiol.64.082701.102229

Baccus, Olveczky, Manu, \& Meister. (2008). A retinal circuit that computes object motion. J Neurosci, 28(27), 6807-6817. doi:10.1523/jneurosci.4206-07.2008

Baden, Berens, Franke, Roman Roson, Bethge, \& Euler. (2016). The functional diversity of retinal ganglion cells in the mouse. Nature, 529(7586), 345-350. doi:10.1038/nature16468

Badura, Sun, Giovannucci, Lynch, \& Wang. (2014). Fast calcium sensor proteins for monitoring neural activity. Neurophotonics, 1(2), $025008-025008$. doi:10.1117/1.NPh.1.2.025008

Bae, Mu, Kim, Turner, Tartavull, Kemnitz, ... Seung. (2018). Digital Museum of Retinal Ganglion Cells with Dense Anatomy and Physiology. Cell, 173(5), 12931306.e1219. doi:https://doi.org/10.1016/j.cell.2018.04.040

Barlow, \& Levick. (1965). The mechanism of directionally selective units in rabbit's retina. J Physiol, 178(3), 477-504.

Baylor, Nunn, \& Schnapf. (1984). The photocurrent, noise and spectral sensitivity of rods of the monkey Macaca fascicularis. The Journal of Physiology, 357, 575-607. doi:10.1113/jphysiol.1984.sp015518

Baylor, Nunn, \& Schnapf. (1987). Spectral sensitivity of cones of the monkey Macaca fascicularis. J Physiol, 390, 145-160.

Beaudoin, Borghuis, \& Demb. (2007). Cellular Basis for Contrast Gain Control over the Receptive Field Center of Mammalian Retinal Ganglion Cells. The Journal of Neuroscience, 27(10), 2636-2645. doi:10.1523/jneurosci.4610-06.2007

Benardete, \& Kaplan. (1997). The receptive field of the primate P retinal ganglion cell, II: Nonlinear dynamics. Visual neuroscience, 14(1), 187-205. doi:10.1017/S0952523800008865 
Berry, Brivanlou, Jordan, \& Meister. (1999). Anticipation of moving stimuli by the retina. Nature, 398(6725), 334-338. doi:10.1038/18678

Bloomfield, \& Dacheux. (2001). Rod vision: pathways and processing in the mammalian retina. Prog Retin Eye Res, 20(3), 351-384.

Borghuis, \& Leonardo. (2015). The Role of Motion Extrapolation in Amphibian Prey Capture. J Neurosci, 35(46), 15430-15441. doi:10.1523/JNEUROSCI.318915.2015

Borghuis, Marvin, Looger, \& Demb. (2013). Two-photon imaging of nonlinear glutamate release dynamics at bipolar cell synapses in the mouse retina. J Neurosci, 33(27), 10972-10985. doi:10.1523/jneurosci.1241-13.2013

Borghuis, Tian, Xu, Nikonov, Vardi, Zemelman, \& Looger. (2011). Imaging Light Responses of Targeted Neuron Populations in the Rodent Retina. The Journal of Neuroscience, 31(8), 2855-2867. doi:10.1523/jneurosci.6064-10.2011

Brainard. (1997). The Psychophysics Toolbox. Spat Vis, 10(4), 433-436. doi:doi:https://doi.org/10.1163/156856897X00357

Briggman, \& Euler. (2011). Bulk electroporation and population calcium imaging in the adult mammalian retina. J Neurophysiol, 105(5), 2601-2609. doi:10.1152/jn.00722.2010

Buldyrev, \& Taylor. (2013). Inhibitory mechanisms that generate centre and surround properties in ON and OFF brisk-sustained ganglion cells in the rabbit retina. The Journal of Physiology, 591(Pt 1), 303-325. doi:10.1113/jphysiol.2012.243113

Cafaro, Zylberberg, \& Field. (2019). Global motion processing by populations of directionselective retinal ganglion cells. bioRxiv, 572438. doi:10.1101/572438

Carter-Dawson, \& LaVail. (1979). Rods and cones in the mouse retina. I. Structural analysis using light and electron microscopy. J Comp Neurol, 188(2), 245-262. doi:10.1002/cne.901880204

Chen, Chou, Park, Schwartz, \& Berry. (2014). The Neural Circuit Mechanisms Underlying the Retinal Response to Motion Reversal. 34(47), 15557-15575. doi:10.1523/JNEUROSCI.1460-13.2014 \%J The Journal of Neuroscience

Chen, Cichon, Wang, Quu, Lee, Campbell, ... Feng. (2012). Imaging Neural Activity Using Thy1-GCaMP Transgenic mice. Neuron, 76(2), 297-308. doi:10.1016/j.neuron.2012.07.011 
Chen, Marre, Fisher, Schwartz, Levy, da Silveira, \& Berry. (2013). Alert Response to Motion Onset in the Retina. The Journal of Neuroscience, 33(1), 120-132. doi:10.1523/JNEUROSCI.3749-12.2013

Chen, Wardill, Sun, Pulver, Renninger, Baohan, ... Kim. (2013). Ultrasensitive fluorescent proteins for imaging neuronal activity. Nature, 499(7458), 295-300. doi:10.1038/nature12354

http://www.nature.com/nature/journal/v499/n7458/abs/nature12354.html\#supplementaryinformation

Chichilnisky. (2001). A simple white noise analysis of neuronal light responses. Network, 12(2), 199-213.

Conway, Kitaoka, Yazdanbakhsh, Pack, \& Livingstone. (2005). Neural Basis for a Powerful Static Motion Illusion. The Journal of Neuroscience, 25(23), 5651-5656. doi:10.1523/jneurosci.1084-05.2005

Cook, \& McReynolds. (1998). Lateral inhibition in the inner retina is important for spatial tuning of ganglion cells. Nat Neurosci, 1(8), 714-719. Retrieved from http://dx.doi.org/10.1038/3714

Dana, Chen, Hu, Shields, Guo, Looger, ... Svoboda. (2014). Thy1-GCaMP6 Transgenic Mice for Neuronal Population Imaging In Vivo. PLOS ONE, 9(9), e108697. doi:10.1371/journal.pone.0108697

Dana, Sun, Mohar, Hulse, Hasseman, Tsegaye, .. . Kim. (2018). High-performance GFPbased calcium indicators for imaging activity in neuronal populations and microcompartments. 434589. doi:10.1101/434589\%J bioRxiv

Daniele, Lillo, Lyubarsky, Nikonov, Philp, Mears, . . . Pugh. (2005). Cone-like morphological, molecular, and electrophysiological features of the photoreceptors of the Nrl knockout mouse. Invest Ophthalmol Vis Sci, 46(6), 2156-2167. doi:10.1167/iovs.04-1427

Deban, O'Reilly, Dicke, \& van Leeuwen. (2007). Extremely high-power tongue projection in plethodontid salamanders. Journal of Experimental Biology, 210(4), 655-667. doi:10.1242/jeb.02664

Demb. (2007). Cellular mechanisms for direction selectivity in the retina. Neuron, 55(2), 179-186. doi:10.1016/j.neuron.2007.07.001

Demb. (2008). Functional circuitry of visual adaptation in the retina. The Journal of Physiology, 586(18), 4377-4384. doi:10.1113/jphysiol.2008.156638 
Demb, Haarsma, Freed, \& Sterling. (1999). Functional Circuitry of the Retinal Ganglion Cell's Nonlinear Receptive Field. The Journal of Neuroscience, 19(22), 9756-9767. doi:10.1523/jneurosci.19-22-09756.1999

Demb, Haarsma, Freed, \& Sterling. (1999). Functional circuitry of the retinal ganglion cell's nonlinear receptive field. J Neurosci, 19(22), 9756-9767.

Demb, \& Singer. (2015). Functional Circuitry of the Retina. Annual review of vision science, 1, 263-289. doi:10.1146/annurev-vision-082114-035334

Demb, \& Singer. (2016). Mind the Gap Junctions: The Importance of Electrical Synapses to Visual Processing. Neuron, 90(2), 207-209. doi:10.1016/j.neuron.2016.04.007

Demb, Zaghloul, Haarsma, \& Sterling. (2001). Bipolar Cells Contribute to Nonlinear Spatial Summation in the Brisk-Transient (Y) Ganglion Cell in Mammalian Retina. The Journal of Neuroscience, 21(19), 7447-7454.

Denk, Strickler, \& Webb. (1990). Two-photon laser scanning fluorescence microscopy. 248(4951), 73-76. doi:10.1126/science.2321027 \%J Science

Ding, Smith, Poleg-Polsky, Diamond, \& Briggman. (2016). Species-specific wiring for direction selectivity in the mammalian retina. Nature, 535(7610), 105-110. doi:10.1038/nature18609

Drinnenberg, Franke, Morikawa, Juttner, Hillier, Hantz, . . Roska. (2018). How Diverse Retinal Functions Arise from Feedback at the First Visual Synapse. Neuron, 99(1), 117-134.e111. doi:10.1016/j.neuron.2018.06.001

Dunn, \& Wong. (2014). Wiring patterns in the mouse retina: collecting evidence across the connectome, physiology and light microscopy. The Journal of Physiology, 592(22), 4809-4823. doi:10.1113/jphysiol.2014.277228

Eagleman. (2001). Visual illusions and neurobiology. Nature Reviews Neuroscience, 2, 920. doi: $10.1038 / 35104092$

Eagleman, \& Sejnowski. (2000). Motion Integration and Postdiction in Visual Awareness. Science, 287(5460), 2036-2038. doi:10.1126/science.287.5460.2036

Eggers, \& Lukasiewicz. (2006). GABA(A), GABA(C) and glycine receptor-mediated inhibition differentially affects light-evoked signalling from mouse retinal rod bipolar cells. J Physiol, 572(Pt 1), 215-225. doi:10.1113/jphysiol.2005.103648

Eggers, \& Lukasiewicz. (2011). Multiple pathways of inhibition shape bipolar cell responses in the retina. Visual neuroscience, 28(1), 95-108. doi:10.1017/S0952523810000209 
Ellis, Gauvain, Sivyer, \& Murphy. (2016). Shared and distinct retinal input to the mouse superior colliculus and dorsal lateral geniculate nucleus. Journal of Neurophysiology, 116(2), 602-610. doi:10.1152/jn.00227.2016

Enroth-Cugell, \& Robson. (1966a). The contrast sensitivity of retinal ganglion cells of the cat. J Physiol, 187(3), 517-552.

Enroth-Cugell, \& Robson. (1966b). The contrast sensitivity of retinal ganglion cells of the cat. The Journal of Physiology, 187(3), 517-552. Retrieved from https://www.ncbi.nlm.nih.gov/pubmed/16783910

https://www.ncbi.nlm.nih.gov/pmc/PMC1395960/

Euler, Detwiler, \& Denk. (2002). Directionally selective calcium signals in dendrites of starburst amacrine cells. Nature, 418(6900), 845-852. Retrieved from http://dx.doi.org/10.1038/nature00931

Euler, Haverkamp, Schubert, \& Baden. (2014). Retinal bipolar cells: elementary building blocks of vision. Nature Reviews Neuroscience, 15, 507. doi:10.1038/nrn3783

https://www.nature.com/articles/nrn3783\#supplementary-information

Famiglietti. (2004). Class I and class II ganglion cells of rabbit retina: A structural basis for $X$ and $Y$ (brisk) cells. Journal of Comparative Neurology, 478(4), 323-346. doi:doi:10.1002/cne.20268

Farajian, Pan, Akopian, Völgyi, \& Bloomfield. (2011). Masked excitatory crosstalk between the ON and OFF visual pathways in the mammalian retina. The Journal of Physiology, 589(Pt 18), 4473-4489. doi:10.1113/jphysiol.2011.213371

Franke, Berens, Schubert, Bethge, Euler, \& Baden. (2017). Inhibition decorrelates visual feature representations in the inner retina. Nature, 542(7642), 439-444. doi:10.1038/nature21394

http://www.nature.com/nature/journal/v542/n7642/abs/nature21394.html\#supple mentary-information

Fransen, \& Borghuis. (2017). Temporally Diverse Excitation Generates DirectionSelective Responses in ON- and OFF-Type Retinal Starburst Amacrine Cells. Cell Rep, 18(6), 1356-1365. doi:10.1016/j.celrep.2017.01.026

Fried, Münch, \& Werblin. (2002). Mechanisms and circuitry underlying directional selectivity in the retina. Nature, 420, 411. doi:10.1038/nature01179

Gollisch. (2013). Features and functions of nonlinear spatial integration by retinal ganglion cells. Journal of Physiology-Paris, 107(5), 338-348. doi:https://doi.org/10.1016/i.jphysparis.2012.12.001 
Gollisch, \& Meister. (2010). Eye smarter than scientists believed: neural computations in circuits of the retina. Neuron, 65(2), 150-164. doi:10.1016/j.neuron.2009.12.009

Hartline. (1938). THE RESPONSE OF SINGLE OPTIC NERVE FIBERS OF THE VERTEBRATE EYE TO ILLUMINATION OF THE RETINA. 121(2), 400-415. doi:10.1152/ajplegacy.1938.121.2.400

Hartline. (1940). THE RECEPTIVE FIELDS OF OPTIC NERVE FIBERS. 130(4), 690-699. doi:10.1152/ajplegacy.1940.130.4.690

Hausselt, Euler, Detwiler, \& Denk. (2007). A Dendrite-Autonomous Mechanism for Direction Selectivity in Retinal Starburst Amacrine Cells. PLoS Biology, 5(7), e185. doi:10.1371/journal.pbio.0050185

Hestrin, \& Korenbrot. (1990). Activation kinetics of retinal cones and rods: response to intense flashes of light. 10(6), 1967-1973. doi:10.1523/JNEUROSCI.10-06$01967.1990 \% \mathrm{~J}$ The Journal of Neuroscience

Hines, \& Carnevale. (1997). The NEURON simulation environment. Neural Comput, 9(6), 1179-1209.

Hodgkin, \& Huxley. (1952a). Propagation of electrical signals along giant nerve fibers. Proc R Soc Lond B Biol Sci, 140(899), 177-183.

Hodgkin, \& Huxley. (1952b). A quantitative description of membrane current and its application to conduction and excitation in nerve. J Physiol, 117(4), 500-544.

Ito, \& Feldheim. (2018). The Mouse Superior Colliculus: An Emerging Model for Studying Circuit Formation and Function. Frontiers in neural circuits, 12, 10-10. doi:10.3389/fncir.2018.00010

Jancke, Erlhagen, Schöner, \& Dinse. (2004). Shorter latencies for motion trajectories than for flashes in population responses of cat primary visual cortex. The Journal of Physiology, 556(3), 971-982. doi:10.1113/jphysiol.2003.058941

Johnston, \& Lagnado. (2015). General features of the retinal connectome determine the computation of motion anticipation. Elife, 4. doi:10.7554/eLife.06250

Ke, Wang, Borghuis, Cembrowski, Riecke, Kath, . . . Singer. (2014). Adaptation to Background Light Enables Contrast Coding at Rod Bipolar Cell Synapses. Neuron, 81(2), 388-401. doi:https://doi.org/10.1016/j.neuron.2013.10.054

Kim, \& Rieke. (2001). Temporal Contrast Adaptation in the Input and Output Signals of Salamander Retinal Ganglion Cells. The Journal of Neuroscience, 21(1), 287-299. doi:10.1523/jneurosci.21-01-00287.2001 
Kim, Soto, \& Kerschensteiner. (2015). An excitatory amacrine cell detects object motion and provides feature-selective input to ganglion cells in the mouse retina. Elife, 4, e08025. doi:10.7554/eLife.08025

Krieger, Qiao, Rousso, Sanes, \& Meister. (2017). Four alpha ganglion cell types in mouse retina: Function, structure, and molecular signatures. PLOS ONE, 12(7), e0180091. doi:10.1371/journal.pone.0180091

Kuffler. (1953). Discharge patterns and functional organization of mammalian retina. $J$ Neurophysiol, 16(1), 37-68. doi:10.1152/jn.1953.16.1.37

Kühn, \& Gollisch. (2016). Joint Encoding of Object Motion and Motion Direction in the Salamander Retina. The Journal of Neuroscience, 36(48), 12203-12216. doi:10.1523/jneurosci.1971-16.2016

Kuo, Schwartz, \& Rieke. (2016). Nonlinear spatiotemporal integration by electrical and chemical synapses in the retina. Neuron, 90(2), 320-332. doi:10.1016/j.neuron.2016.03.012

Lamb. (1996). Gain and kinetics of activation in the G-protein cascade of phototransduction. Proceedings of the National Academy of Sciences of the United States of America, 93(2), 566-570. Retrieved from https://www.ncbi.nlm.nih.gov/pubmed/8570596

https://www.ncbi.nlm.nih.gov/pmc/PMC40092/

Lamb, Heck, \& Kraft. (2018). Implications of dimeric activation of PDE6 for rod phototransduction. 8(8), 180076. doi:doi:10.1098/rsob.180076

Leonardo, \& Meister. (2013). Nonlinear dynamics support a linear population code in a retinal target-tracking circuit. J Neurosci, 33(43), 16971-16982. doi:10.1523/jneurosci.2257-13.2013

Lettvin, Maturana, McCulloch, \& Pitts. (1959). What the Frog's Eye Tells the Frog's Brain. Proceedings of the IRE, 47(11), 1940-1951. doi:10.1109/JRPROC.1959.287207

Li, Gauthier, Schiff, Sher, Ahn, Field, . . Chichilnisky. (2015). Anatomical Identification of Extracellularly Recorded Cells in Large-Scale Multielectrode Recordings. 35(11), 4663-4675. doi:10.1523/JNEUROSCI.3675-14.2015 \%J The Journal of Neuroscience

Mackay. (1958). Perceptual Stability of a Stroboscopically Lit Visual Field containing SelfLuminous Objects. Nature, 181, 507. doi:10.1038/181507a0

Mandell, Czernik, De Camilli, Greengard, \& Townes-Anderson. (1992). Differential expression of synapsins I and II among rat retinal synapses. The Journal of Neuroscience, 12(5), 1736-1749. doi:10.1523/jneurosci.12-05-01736.1992 
Mangel. (1991). Analysis of the horizontal cell contribution to the receptive field surround of ganglion cells in the rabbit retina. $J$ Physiol, 442, 211-234. doi:10.1113/jphysiol.1991.sp018790

Manookin, Beaudoin, Ernst, Flagel, \& Demb. (2008). Disinhibition combines with excitation to extend the operating range of the OFF visual pathway in daylight. $J$ Neurosci, 28(16), 4136-4150. doi:10.1523/jneurosci.4274-07.2008

Marco, Protti, \& Solomon. (2013). Excitatory and inhibitory contributions to receptive fields of alpha-like retinal ganglion cells in mouse. 110(6), 1426-1440. doi:10.1152/jn.01097.2012

Martersteck, Hirokawa, Evarts, Bernard, Duan, Li, ... Harris. (2017). Diverse Central Projection Patterns of Retinal Ganglion Cells. Cell Rep, 18(8), 2058-2072. doi:10.1016/j.celrep.2017.01.075

Marvin, Borghuis, Tian, Cichon, Harnett, Akerboom, . . L Looger. (2013). An optimized fluorescent probe for visualizing glutamate neurotransmission. Nat Methods, 10(2), 162-170. doi:10.1038/nmeth.2333

Marvin, Scholl, Wilson, Podgorski, Kazemipour, Müller, . . L Looger. (2018). Stability, affinity, and chromatic variants of the glutamate sensor iGluSnFR. Nat Methods, 15(11), 936-939. doi:10.1038/s41592-018-0171-3

Maunsell, \& Gibson. (1992). Visual response latencies in striate cortex of the macaque monkey. 68(4), 1332-1344. doi:10.1152/jn.1992.68.4.1332

Meister, Pine, \& Baylor. (1994). Multi-neuronal signals from the retina: acquisition and analysis. J Neurosci Methods, 51(1), 95-106.

Morin, \& Studholme. (2014). Retinofugal projections in the mouse. J Comp Neurol, 522(16), 3733-3753. doi:10.1002/cne.23635

Munch, da Silveira, Siegert, Viney, Awatramani, \& Roska. (2009). Approach sensitivity in the retina processed by a multifunctional neural circuit. Nat Neurosci, 12(10), 13081316.

doi:http://www.nature.com/neuro/journal/v12/n10/suppinfo/nn.2389 s1.html

Nath, \& Schwartz. (2016). Cardinal Orientation Selectivity Is Represented by Two Distinct Ganglion Cell Types in Mouse Retina. The Journal of Neuroscience, 36(11), 32083221. doi:10.1523/jneurosci.4554-15.2016

Nijhawan. (1994). Motion extrapolation in catching. Nature, 370(6487), 256-257. doi:10.1038/370256b0 
Nijhawan. (1997). Visual decomposition of colour through motion extrapolation. Nature, 386(6620), 66-69. doi:10.1038/386066a0

Nijhawan. (2002). Neural delays, visual motion and the flash-lag effect. Trends Cogn Sci, 6(9), 387-393. doi:https://doi.org/10.1016/S1364-6613(02)01963-0

Nobles, Zhang, Müller, Betz, \& McCall. (2012). Selective glycine receptor a2 subunit control of crossover inhibition between the on and off retinal pathways. J Neurosci, 32(10), 3321-3332. doi:10.1523/JNEUROSCI.5341-11.2012

Olveczky, Baccus, \& Meister. (2003). Segregation of object and background motion in the retina. Nature, 423(6938), 401-408. doi:10.1038/nature01652

Pan, Mills, \& Massey. (2007). Screening of gap junction antagonists on dye coupling in the rabbit retina. Visual neuroscience, 24(4), 609-618. doi:10.1017/S0952523807070472

Pang, Gao, \& Wu. (2003). Light-evoked excitatory and inhibitory synaptic inputs to ON and OFF alpha ganglion cells in the mouse retina. $J$ Neurosci, 23(14), 6063-6073.

Pérez-Schuster, Kulkarni, Nouvian, Romano, Lygdas, Jouary, . . . Sumbre. (2016). Sustained Rhythmic Brain Activity Underlies Visual Motion Perception in Zebrafish. Cell Rep, 17(4), 1098-1112. doi:10.1016/j.celrep.2016.09.065

Peterka, Takahashi, \& Yuste. (2011). Imaging voltage in neurons. Neuron, 69(1), 9-21. doi:10.1016/j.neuron.2010.12.010

Popova. (2014). lonotropic GABA Receptors and Distal Retinal ON and OFF Responses. Scientifica, 2014, 149187-149187. doi:10.1155/2014/149187

Rieke. (2001). Temporal Contrast Adaptation in Salamander Bipolar Cells. The Journal of Neuroscience, 21(23), 9445-9454. doi:10.1523/jneurosci.21-23-09445.2001

Roska, \& Werblin. (2001). Vertical interactions across ten parallel, stacked representations in the mammalian retina. Nature, 410(6828), 583-587. doi:10.1038/35069068

Rotov, Astakhova, Firsov, \& Govardovskii. (2017). Origins of the phototransduction delay as inferred from stochastic and deterministic simulation of the amplification cascade. Mol Vis, 23, 416-430.

Sabbah, Gemmer, Bhatia-Lin, Manoff, Castro, Siegel, . . Berson. (2017). A retinal code for motion along the gravitational and body axes. Nature, 546(7659), 492-497. doi:10.1038/nature22818 
Sakai. (1992). White-noise analysis in neurophysiology. 72(2), 491-505. doi:10.1152/physrev.1992.72.2.491

Sanes, \& Masland. (2015). The types of retinal ganglion cells: current status and implications for neuronal classification. Annu Rev Neurosci, 38, 221-246. doi:10.1146/annurev-neuro-071714-034120

Schnapf, Kraft, \& Baylor. (1987). Spectral sensitivity of human cone photoreceptors. Nature, 325, 439. doi:10.1038/325439a0

Schwartz, Okawa, Dunn, Morgan, Kerschensteiner, Wong, \& Rieke. (2012). The spatial structure of a nonlinear receptive field. Nat Neurosci, 15(11), 1572-1580. doi:10.1038/nn.3225

Schwartz, \& Rieke. (2011). Perspectives on: information and coding in mammalian sensory physiology: nonlinear spatial encoding by retinal ganglion cells: when $1+$ $1 \neq 2$. J Gen Physiol, 138(3), 283-290. doi:10.1085/jgp.201110629

Schwiening. (2012). A brief historical perspective: Hodgkin and Huxley. J Physiol, 590(11), 2571-2575. doi:10.1113/jphysiol.2012.230458

Shapley, \& Victor. (1978). The effect of contrast on the transfer properties of cat retinal ganglion cells. The Journal of Physiology, 285, 275-298. Retrieved from http://www.ncbi.nlm.nih.gov/pmc/articles/PMC1281756/

Simmons, Bloomsburg, Sukeena, Miller, Ortega-Burgos, Borghuis, \& Fuerst. (2017). DSCAM-mediated control of dendritic and axonal arbor outgrowth enforces tiling and inhibits synaptic plasticity. 114(47), E10224-E10233. doi:10.1073/pnas.1713548114 \%J Proceedings of the National Academy of Sciences

Smirnakis, Berry, Warland, Bialek, \& Meister. (1997). Adaptation of retinal processing to image contrast and spatial scale. Nature, 386, 69. doi:10.1038/386069a0

Stabio, Sondereker, Haghgou, Day, Chidsey, Sabbah, \& Renna. (2018). A novel map of the mouse eye for orienting retinal topography in anatomical space. J Comp Neurol, 526(11), 1749-1759. doi:10.1002/cne.24446

Stone, \& Pinto. (1993). Response properties of ganglion cells in the isolated mouse retina. Visual neuroscience, 10(1), 31-39. doi:10.1017/S0952523800003205

Stringer, Pachitariu, Steinmetz, Carandini, \& Harris. (2019). High-dimensional geometry of population responses in visual cortex. Nature. doi:10.1038/s41586-019-1346-5 
Stringer, Pachitariu, Steinmetz, Reddy, Carandini, \& Harris. (2019). Spontaneous behaviors drive multidimensional, brainwide activity. 364(6437), eaav7893. doi:10.1126/science.aav7893 \%J Science

Subramaniyan, Ecker, Berens, \& Tolias. (2013). Macaque monkeys perceive the flash lag illusion. PLOS ONE, 8(3), e58788. doi:10.1371/journal.pone.0058788

Subramaniyan, Ecker, Patel, Cotton, Bethge, Pitkow, ... Tolias. (2018). Faster processing of moving compared to flashed bars in awake macaque V1 provides a neural correlate of the flash lag illusion. Journal of Neurophysiology, $O(0)$, null. doi:10.1152/jn.00792.2017

Svoboda, \& Yasuda. (2006). Principles of Two-Photon Excitation Microscopy and Its Applications to Neuroscience. Neuron, 50(6), 823-839. doi:https://doi.org/10.1016/j.neuron.2006.05.019

Theis, Berens, Froudarakis, Reimer, Román Rosón, Baden, . . . Bethge. (2016). Benchmarking Spike Rate Inference in Population Calcium Imaging. Neuron, 90(3), 471-482. doi:https://doi.org/10.1016/j.neuron.2016.04.014

Tian, Hires, Mao, Huber, Chiappe, Chalasani, . . Looger. (2009). Imaging neural activity in worms, flies and mice with improved GCaMP calcium indicators. Nat Methods, 6(12), 875-881. doi:10.1038/nmeth.1398

Tien, Pearson, Heller, Demas, \& Kerschensteiner. (2015). Genetically Identified Suppressed-by-Contrast Retinal Ganglion Cells Reliably Signal Self-Generated Visual Stimuli. The Journal of Neuroscience, 35(30), 10815-10820. doi:10.1523/JNEUROSCI.1521-15.2015

Tikidji-Hamburyan, Reinhard, Seitter, Hovhannisyan, Procyk, Allen, ... Münch. (2015). Retinal output changes qualitatively with every change in ambient illuminance. Nature neuroscience, 18(1), 66-74. doi:10.1038/nn.3891

Trenholm, McLaughlin, Schwab, \& Awatramani. (2013). Dynamic tuning of electrical and chemical synaptic transmission in a network of motion coding retinal neurons. $J$ Neurosci, 33(37), 14927-14938. doi:10.1523/jneurosci.0808-13.2013

Trenholm, Schwab, Balasubramanian, \& Awatramani. (2013). Lag normalization in an electrically coupled neural network. Nat Neurosci, 16(2), 154-156. doi:10.1038/nn.3308

Turner, Schwartz, \& Rieke. (2018). Receptive field center-surround interactions mediate context-dependent spatial contrast encoding in the retina. Elife, 7, e38841. doi:10.7554/eLife.38841 
Van Wyk, Wässle, \& Taylor. (2009). Receptive field properties of ON- and OFF-ganglion cells in the mouse retina. Visual neuroscience, 26(3), 297-308. doi:10.1017/s0952523809990137

Vaney, Sivyer, \& Taylor. (2012). Direction selectivity in the retina: symmetry and asymmetry in structure and function. Nature Reviews Neuroscience, 13, 194. doi:10.1038/nrn3165

Völgyi, Chheda, \& Bloomfield. (2009). Tracer coupling patterns of the ganglion cell subtypes in the mouse retina. J Comp Neurol, 512(5), 664-687. doi:10.1002/cne.21912

Völgyi, Kovács-Öller, Atlasz, Wilhelm, \& Gábriel. (2013). Gap junctional coupling in the vertebrate retina: Variations on one theme? Progress in Retinal and Eye Research, 34, 1-18. doi:https://doi.org/10.1016/i.preteyeres.2012.12.002

Wang, Weick, \& Demb. (2011). Spectral and temporal sensitivity of cone-mediated responses in mouse retinal ganglion cells. J Neurosci, 31(21), 7670-7681. doi:10.1523/jneurosci.0629-11.2011

Watanabe, Kitaoka, Sakamoto, Yasugi, \& Tanaka. (2018). Illusory Motion Reproduced by Deep Neural Networks Trained for Prediction. Frontiers in Psychology, 9(345). doi:10.3389/fpsyg.2018.00345

Wei, Hamby, Zhou, \& Feller. (2011). Development of asymmetric inhibition underlying direction selectivity in the retina. Nature, 469(7330), 402-406. doi:10.1038/nature09600

Werblin. (2010). Six different roles for crossover inhibition in the retina: Correcting the nonlinearities of synaptic transmission. Visual neuroscience, 27(1-2), 1-8. doi:10.1017/s0952523810000076

Whitney, \& Murakami. (1998). Latency difference, not spatial extrapolation. Nat Neurosci, 1(8), 656-657. doi:10.1038/3659

Yang. (2004). Characterization of receptors for glutamate and GABA in retinal neurons. $\begin{array}{llll}\text { Progress in } & \text { 127-150. }\end{array}$ doi:https://doi.org/10.1016/i.pneurobio.2004.04.002

Zaghloul, Boahen, \& Demb. (2005). Contrast Adaptation in Subthreshold and Spiking Responses of Mammalian Y-Type Retinal Ganglion Cells. The Journal of Neuroscience, 25(4), 860-868. doi:10.1523/jneurosci.2782-04.2005

Zhang, Kim, Sanes, \& Meister. (2012). The most numerous ganglion cell type of the mouse retina is a selective feature detector. Proceedings of the National Academy of 
Sciences of the United States of America, 109(36), E2391-E2398. doi:10.1073/pnas.1211547109

Zhang, Nobles, \& McCall. (2015). GlyRalpha2, not GlyRalpha3, modulates the receptive field surround of OFF retinal ganglion cells. Vis Neurosci, 32, E026. doi: $10.1017 / \mathrm{s} 0952523815000280$ 


\title{
CURRICULUM VITAE
}

\author{
Victor Julian DePiero
}

9921 Wyncliff Court

Louisville, KY 40241

(502) 299-9604

vjdepi01@cardmail.louisville.edu

\section{Education}

$2014-2019$

Ph.D. program, Department of Anatomical Sciences and

Neurobiology,

$2009-2013$

University of Louisville School of Medicine, Louisville, KY, USA

SC, USA

Spring 2012

B.S., cum laude, Bioengineering, Clemson University, Clemson,

International Student (5 months), Nanyang Technological

University, Singapore, Singapore

\section{Professional Experience}

2014 - present Graduate student. Laboratory of Dr. Bart G. Borghuis, Department

of Anatomical Sciences and Neurobiology, Louisville, KY, USA.

Research focus and approach:

i. The role of temporal phase advancing in object motion encoding in identified retinal ganglion cell circuits. Two-photon fluorescence calcium and glutamate imaging with genetically encoded biosensors in the mouse retina. Targeted whole-cell electrophysiology. Responsibilities include the development of visual stimuli, collection and processing of imaging and electrophysiological data with custom algorithms in MATLAB and computational modeling of cellular responses to moving stimuli.

ii. Excitatory and inhibitory synaptic organization of morphologically identified ganglion cells in the mouse retina. Biolistic labeling, confocal imaging, anatomical reconstruction, and quantification of synaptic distribution density across ganglion cell types.

2014 - 2015 Panel Engineer. Northwood Machine, Louisville, KY, USA.

Responsible for the assembly of electrical components in automatic numerical control cutting machines.

2011-2013 Team leader. Applied research, Clemson University, Clemson, SC, USA.

Led a senior design project focused on the development of a therapeutic device for stretching spastic limbs after traumatic brain injury or stroke.2012 Biomedical Department Internship, University of Louisville Hospital, Louisville, KY, USA. 
Hands on experience working on medical equipment in a hospital Assisted in electronic archiving of patient records.

\section{Publications}

Jonathan S. Marvin, Benjamin Scholl, Daniel E. Wilson, Kaspar Podgorski, Abbas Kazemipour, Johannes Alexander Müller, Susanne Schoch, Francisco José Urra Quiroz, Nelson Rebola, Huan Bao, Justin P. Little, Ariana N. Tkachuk, Edward Cai, Adam W. Hantman, Samuel S.-H. Wang, Victor J. DePiero, Bart G. Borghuis, Edwin R. Chapman, Dirk Dietrich, David A. DiGregorio, David Fitzpatrick, and Loren L. Looger. Stability, affinity and chromatic variants of the glutamate sensor iGluSnFR. Nature Methods (2018) Nov;15(11):936-939

\section{Meetings and Abstracts}

July 2018 FENS Forum of Neuroscience. Berlin, Germany

DePiero VJ, Borghuis, BG. Understanding object motion encoding in the mammalian retina.

June 2018 Data Blitz Presenter, FASEB: Retinal Neurobiology and Visual

Processing. Olean, NY, USA.

DePiero VJ, Hasan F, Lovett A, Borghuis, BG. Biolistic gene transfer reveals diverse synaptic organization of retinal ganglion cells.

August 2017 Research! Louisville. Louisville, KY, USA

DePiero VJ, Borghuis, BG. Phase advancing is a common property of mammalian ON and OFF-type retinal ganglion cells

June 2017 Cold Spring Harbor Summer Course Vision: A Platform for Linking Circuits, Behavior \& Perception. Cold Spring Harbor, NY, USA.

April 2017 Data Blitz Presenter, Neuroscience Day, The Society for Neuroscience. Louisville, KY, USA

DePiero VJ, Borghuis, BG. Phase advancing is a common property of mammalian ON and OFF-type retinal ganglion cells

Sept. 2016 Research! Louisville. Louisville, KY, USA.

DePiero VJ, Borghuis, BG. Temporal phase advancing is a common response property of ON and OFF ganglion cells in the mouse retina.

July 2016 Data Blitz Presenter, FASEB: Retinal Neurobiology and Visual Processing. Keystone, CO, USA.

DePiero VJ, Borghuis, BG. Temporal phase advancing is a common response property of ON and OFF ganglion cells in the mouse retina.

\section{Teaching and Outreach}

2017-2019 Outreach and Social Media Coordinator, The Society for Neuroscience, Louisville Chapter, Louisville, KY, USA

Fall $2015 \quad$ Neuroanatomy Teaching Assistant, ASNB 602 - Fundamentals of Neuroscience, University of Louisville, Louisville, KY, USA. 